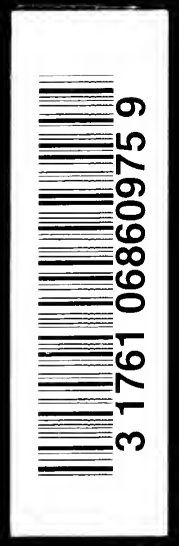







\section{THOMAS DAVIDSON}

$$
\text { I 840-I } 900
$$






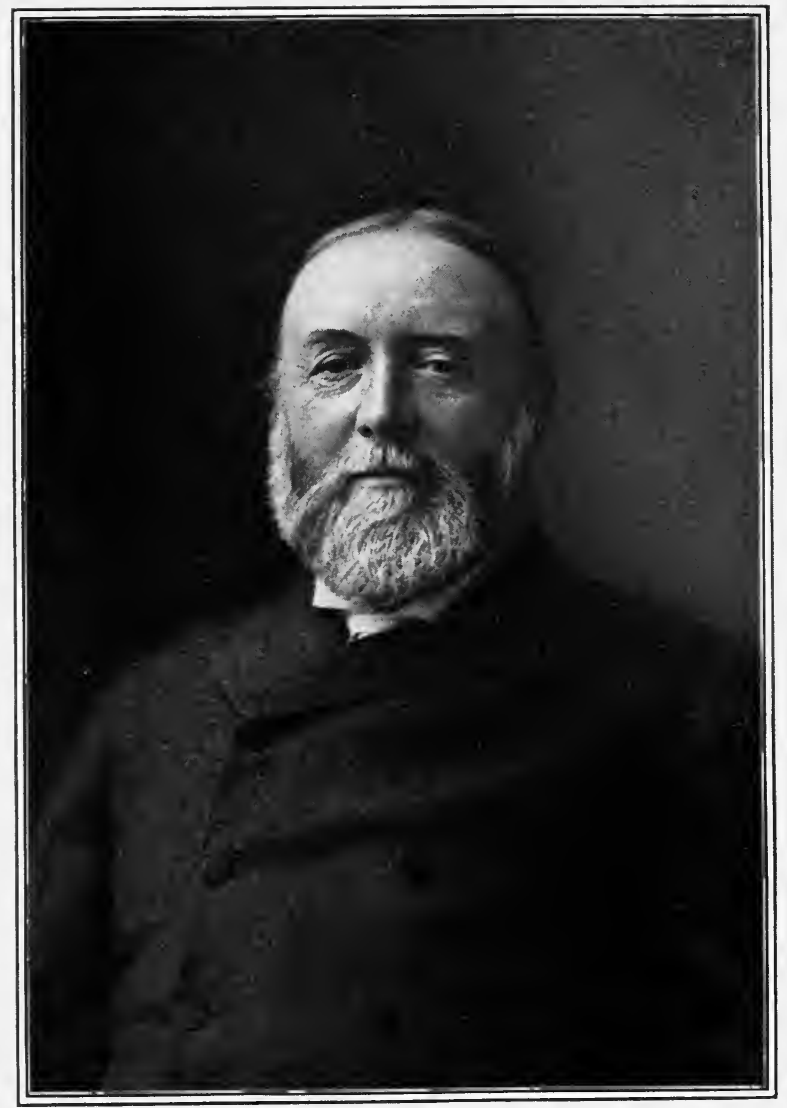

Thomas Davidson 


\title{
MEMORIALS OF
}

\section{THOMAS DAVIDSON}

\author{
THE WANDERING SCHOLAR
}

\author{
COLLECTED AND EDITED \\ BY
}

WILLIAM KNIGHT

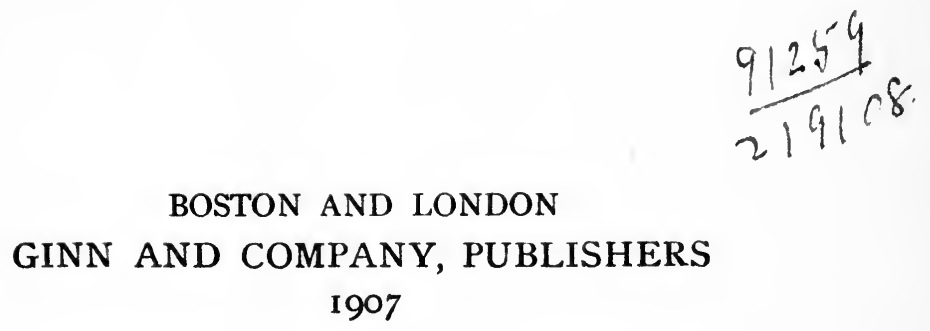


Entered at Stationers' Hall

COPYRIGHT, 1907

By WILLIAM KNIGHT

ALL RIGHTS RESERVED

$$
\begin{array}{r}
1900+1 \\
00
\end{array}
$$


TO

THE MANY FRIENDS OF THOMAS DAVIDSON

WHOM HE INFLUENCED FOR GOOD

THESE PAGES ARE

INSCRIBED 


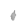




\section{PREFACE}

Since the following pages were written a book entitled The Education of the Wage-Earners, a Contribution toward the Solution of the Educational Problem of Democracy, by Thomas Davidson, has been edited by his student-friend, Professor Charles M. Bakewell of Yale University, and published by Messrs. Ginn \& Company. It is a distinctive memorial of Davidson's work, especially in the closing years of his life ; but it does not render the present volume inopportune, nor does it in any way supersede it. Both have the same end in view, namely, the memorialization of the life and work of a very remarkable man, - rare at any time, and more especially rare as the years advance, - a unique teacher of the nineteenth century, who sowed seed which is even now yielding a rich harvest.

It may be well to state in a paragraph what $\mathrm{Mr}$. Bakewell has done in his little book for the memory of our common friend. $\mathrm{He}$ first gives a comprehensive introductory sketch of Davidson and his philosophy. He then inserts an address on "The Task of the Nineteenth Century," given by Mr. Davidson before the Educational Alliance of New York in 1898, and first published in the International Journal of Ethics in October, I90I. His third chapter contains a very interesting statement, also by Mr. Davidson, on "The Educational Problem which the Nineteenth Century hands over to the Twentieth "; while the fourth contains "The History of the Experiment." His fifth chapter is, however, by far the most valuable in the volume. It is entitled "The Underlying Spirit (of the experiment) as shown by the Weekly Letters to the Class." From 
May, I899, to August, I900, the teacher wrote to this class, from his temporary home at Hurricane in Essex County, some thirty letters, in which he discussed many a problem in the philosophy of Ethics, Sociology, and kindred subjects with almost conversational ease, full of genuine insight and instructiveness. They are remarkable letters, many of them composed when the writer was a great sufferer.

I have prepared this volume on lines somewhat parallel to the biographies or memoirs of others with whose lives it has fallen to me in past years to deal ; namely, Wordsworth, Principal Shairp of St. Andrews, Professor Nichol of Glasgow, and Minto of Aberdeen, as well as other nineteenth-century Scotsmen. The method adopted in the volumes devoted to these men is even more necessary in the case of this wandering scholar and peripatetic teacher. I think it is impossible for any one man to deal adequately with a character so complex, an individuality made up of many various elements, if he merely collects estimates, and mingles them together into an olla-podrida of his own. I have, therefore, given a number of estimates, or characterizations, by friends from opposite points of view - a series of mental photographs or appraisals of the man - and have allowed these, in their separateness, to tell the story of his life and work.

As I have had occasion to remark elsewhere, critical biographies - in which the biographer obtrudes - are objectionable, while those in which he dominates are unnecessary; and so in this volume the letters of the author, his essays and papers, with the estimates of those who knew him in various relationships - in many cases curtailed, and their superfluities removed - are left to speak for themselves. It is my belief that this plan will be more useful than a formal biography would be, and quite as interesting to those who read it. The reminiscences of various friends, and estimates taken from 
different points of view, often give a much more vivid idea of a man and his life work than a continuous narrative of events could do; and, although there may be a few repetitions in these sketches as they refer to different periods and occasions, a substantial unity will be discernible underneath the variety that is inevitable.

Many have wondered why Thomas Davidson remained so long a wanderer, the travelling teacher-friend, instead of settling down within university precincts as the honored instructor of an existing school. I believe that in this he followed the guidance of an inward instinct, which directed him from his earliest years. There was a curiously independent element in him, which found its symbol in the national Scottish thistle, Nemo me impune lacessit. He could not work in the prescribed rule or routine of other minds; and so, perhaps, he could never have submitted to academic fetters which were not of his own creation. With superabundant energy ever welling up within him, he preferred to be not exactly a free lance, but a ubiquitous inspirer of the lives of other people in many various directions ; and so he became a puzzle alike to his liberal and to his conservative friends. $\mathrm{He}$ was not more of a mystery to those he occasionally met in his travels than he was to his coadjutors in public social work, whom he could not bring into complete sympathy with his own ideals. A curious story is told of his once being at Domodossola in the company of three men, a Frenchman, a German, and an Italian, and of his speaking all three languages so fluently and easily that each man mistook him for a fellow-countryman. If this was a sign of wide culture, it did not imply any lack of concentration in thought. Davidson saw the best things in all the systems that had been evolved, but indiscriminate mental wandering was distasteful to him. 
In a brief preface I can say little more of the man whom I had long ago to address in the old pathetic words, Frater ave, atque vale; it is enough to leave this memorial volume as it now stands to tell its own tale as best it may. ${ }^{1}$

W. K.

1 As originally written this book contained chapters giving a full analytic synopsis of Thomas Davidson's books on The Parthenon Frieze and Prolegomena to Tennyson's "In Memoriam," his letters to the Breadwinners' College in New York, a detailed account of his teaching at Glenmore, and extracts from some of his forgotten contributions to newspapers and magazines. In deference to the opinion of my publishers that it was inexpedient " to include abstracts of works which were in print and might be consulted by those interested," I have agreed to suppress the greater part of these chapters, although my judgment was in favor of their appearance. They have been preserved, however, in their original form, and I shall be glad to send them to any readers who may wish to know more of the life and work of the "Wandering Scholar." -W. K. 


\section{CONTIENTS}

Chapter

PAGE

I. INTRODUCTORY . . . . . . . . . . . . . . I

II. The Man : a Sketch and an Estimate . . . 9

III. Formation of the Fellowship of the New Life 16

IV. The Occasion, Principles, Rules, Creed, and Organization OF THE NEW Fellowship as DRAWN UP BY ThOMAS DAVIDSON . . . . . . . . $2 \mathrm{I}$

V. Development of the Society . . . . . . . 26

VI. Estimates of Davidson by Percival ChubB and

FELIX AdLER . . . . . . . . . . . . . 29

VII. Letters to Havelock Ellis . . . . . . . . 37

VIII. Reminiscences by Havelock Ellis . . . . . . 44

IX. The New York Branch of the New Fellowship 48

X. The Summer Schools of the Culture Sciences

at Farmington and Glenmore . . . . . 55

XI. Recollections of Glenmore by Mary Foster . 63

XII. Charlotte Daley's Retrospects of Davidson's

TEACHING . . . . . . . . . . . . 74

XIII. Lectures to the Breadwinners . . . . . . . 80

XIV. LetTers From Davidson IN REFERENCE TO HIS

WORK ON MEDIEVAlism . . . . . . . . . 98

XV. Professor William James's Reminiscences and

Estimate . . . . . . . . . . . . • . 107

XVI. Recollections by Wyndham R. Dunstan . . . I 20

XVII. The Moral Aspects of the Economic Question 130

XVIII. LetTers to Morris R. COHEN . . . . . . . . I37

XIX. Rousseau, and Education according to Nature . I 52

XX. Intellectual Piety . . . . . . . . . . . . I73

XXI. Faith as a Faculty of the Human Mind . . 197

APPENDIX . . . . . . . . . . . . . . . 215 


\section{MEMORIALS OF \\ THOMAS DAVIDSON}

\section{CHAPTER I}

\section{INTRODUCTORY}

The issue of this memorial volume on Thomas Davidson, the "wandering scholar," teacher, philanthropist, and friend, has been unfortunately delayed from causes beyond my power to control. When I undertook, in response to several requests, to collect material for it, I had already written a short notice of him for a volume entitled Some Nineteenth-Century Scots$m^{2} n^{1}$; and I have had no materials, then or since, voluntarily offered to me from any quarter, and placed at my disposal for biographic use. Everything included in the book as it now appears had to be collected by me from various sources. Some of Davidson's friends and pupils have been most kind in writing down their reminiscences, when asked to assist. Others who promised to send contributions have not been able to do so; although, in the hope of receiving them, I have delayed the issue of the volume as long as possible.

In the nature of the case, as well as from the circumstance just mentioned, it is not in any sense a biography. There are no data for an extended memoir. It is a miscellany of facts, reminiscences, letters, estimates, and memoranda of various kinds, all casting light on the man and his work; with appendices containing some of his lectures, essays, and addresses. These, however, may be found as useful to posterity, if not

1 Oliphant, Anderson, \& Ferrier, 1903. 
so interesting, as a more elaborate memoir would be. The incidents in Davidson's career were few, but their significance was great; and the influence of what he did survives, and is more powerful even than the teaching of his books.

He was one of those men whose magnetic personality had a charm which it is difficult to define. It is almost a commonplace to say that our greatest, as well as our most strenuous and subtle, characters are those whose influence it is hard to describe, and imssible to reproduce in words. Memory may supply the look, the tone, the non so che of personality to the spirit that remembers it; but that is often as dull and colorless to others as a faded photograph which has been preserved from distant years.

The story of Davidson's life is the record of a very remarkable influence. He educated others by a personality in which lay the slumbering fire of genius, a volcanic energy which was sometimes for long periods latent, and when active was sometimes slightly erratic in its mode of working. Continuity, or even consistency, was not possible to him in practical affairs. He chafed under constraint $a b$ extra, while his whole being was alive and working out ideals $a b$ intra.

Testimony is borne from every quarter to the range of his learning, his marvellous memory, his knowledge of the ultimate problems of human thought, his mastery of many languages, his large humanity and affability, his loyalty as a friend, his unceasing toil in behalf of every pupil who came within the circle of his friendship, his hatred of superficiality and still more of all pretence, with his wonderful gift of appraising merit, or goodness of character, behind the ordinary shows of life. These things are well known to those who came in contact with him.

And yet, as the great always are, he was a very humble man. He had no vanity, and was not ambitious of fame or recognition. For himself he "coveted earnestly the best gifts" of culture, but he understood "the more excellent 
way" of "spending and being spent" for others. No one knew better than he did the truth embodied in the motto, "What I spent I had; what I saved I lost; what I gave I have." And yet it was not because he coveted possession that he thus spent himself in efforts for those whom he taught and helped. Some men have founded schools of disciples who have afterwards adored them, and the wish to be surrounded by such groups has been the mainspring of their endeavor. It was not so with Davidson; and perhaps it was because he had no system to bequeath, no dogmas which he wished to see introduced into a school, and all-dominant there, that he was so altruistic in his endeavors. It is not as a doctrinaire philosopher that he will be remembered in Europe and America, but as the helpful comrade, who led many pupils out of the shallows of tradition and the back-water eddies of conventional belief, who made them think for themselves, reverently sifting the inheritances they had received from others, and carefully cross-examining every theory set before them for adoption. He was the friend who helped them day by day to get quit of illusions, not one who vicariously aided them by removing rubbish heaps out of their path, but a guide who taught them how to clear their own way; and, having swept aside the sand of mere opinion, to build upon the universal reason of the race a new fabric that would last with them and for them securely.

As to his own convictions, - so far as I can speak from personal knowledge, - he was, as wise men are, both gnostic and agnostic; gnostic as to the root ideas of the true, the beautiful, and the good; agnostic as to the terra incognita which lies behind them, and the ultimate principle of things. In this he was essentially Hebraic and profoundly Christian. I think that he believed the real and the ideal to be one, and that they are known together in perpetual synthesis, - " the real apprehended through its ideality, and the ideal grasped in its reality," as I once put it to him. We had been talking 
of the correlation, and the coöperation, of analysis and synthesis ; but he would not follow me in the further proposition that the true, the beautiful, and the good - as the several subsections of knowledge - may be also known together or synthetically in their germ, while a subsequent analysis brings out their distinction and difference.

My own correspondence with him was chiefly on the subject of the book I asked him to write for a series of projected works on Philosophy in its National Developments. ${ }^{1}$ His letters to me are printed in this volume; and I have purposely placed them together in a series because they form a unity, and in combination illustrate his character. The development of his mind on the subject he undertook to deal with will be apparent in these letters. At first he thought he could condense the whole story of mediævalism into a volume of the size of those in the Philosophical Classics for English Readers, - some two hundred or three hundred pages. But, as he pursued the study of it in detail, the subject grew in magnitude before him; and even after I gave him - alone amongst the contributors - two volumes instead of one for his work, he found it, as so many others have done, too vast for compression.

The Aberdeen school at which he was first trained in classics, and his subsequent course of tuition in our University of the North, did much for him, and he loved the intellectual discipline he had gone through in Scotland. Even in his later years he said that if he were young again and were offered his choice, he would elect to go through it all once more rather than experience a different upbringing. But after his undergraduate work was over, subsequent life in the old country did not satisfy him; and the instinct of the wandering scholar led him to travel from country to country in Europe (as will be seen in the following pages), and then to migrate to America. When across the Atlantic he went from New York to Boston, thence to Canada, next to St. Louis, and afterwards

1 See Some Nineteenth-Century Scotsmen, page 354. 
back to New York. The fetters of university life in America were not relished by him any more than those in England. $\mathrm{He}$ preferred the freedom of the peripatetic, who, calling no man master, could gather round him disciples as he went ; and, having sown some seed of influence, pass on to continue the sowing elsewhere. The raw material for tuition provided at our universities - young men and women who were preparing to enter the various professions, and were therefore to a large extent tied to ancient methods, some of them with already definitely formed opinions, and who sought at college merely an outfit for professional success - was not the material on which he could hope to work successfully. I think it was the quest for a wider and more genuine sphere of influence and a field for more profitable work (i.e. one in which he could do more good) that led him to wander as he did; and the three stages of learning, of travel, and of mastership, - Lehrjahre, Wanderjahre, and Meisterjahre, - which have been consecutive in the experiences of so many, from Plato to Descartes and onwards, were combined in him all along. He was, at one and the same time, scholar, wanderer, and teacher; and this continued almost from first to last.

As learner and instructor, and as a high-souled missionary of education, he carried out four notable experiments, and achieved success in all of them. They were the founding (I) of the New Fellowship in London, (2) of the New Fellowship in New York, (3) of the Glenmore School of the Culture-Sciences, and (4) of the New York settlement for Russian Jews, the "Breadwinners' College." He was not completely satisfied with any of them; and, having started one, felt it his duty to pass on and organize another. But in carrying out this mission he had, as already said, no finished system to unfold. He abjured finality, and rejected dogmas imposed on him, both $a b$ ante and $a b$ extra, until they were reconstructed anew within his own inner consciousness. He felt that he was "conscript and consecrated" to be a reformer of abuses of the intellect and the heart. An 
intense philanthropic passion urged him onward in this work; and intellectual culture pursued selfishly, or in isolation, was abhorrent to him. He desired to enrich his fellow-creatures by all he thought and felt and did. To a certain extent a socialist, he was a Fabian of a very cautious type. Exceedingly conservative in his socialism, he held that the end of human existence was the freedom, the education, and the perfection of the individual, when his fetters were broken and all trammels withdrawn.

The London Fabian Society, an offshoot from the one he founded, did not continue to satisfy him, because it seemed to tend toward an external, rather than an inward, ideal. He preferred his "Fellowship of the New Life," because its explicit aim was the development of the individual spirit, the evolution of a new and higher, although a much simpler life. But neither of these socialistic experiments fully corresponded to his ideal; and the progress of his mind and character through them to a farther step in the western world is one of the most interesting episodes in the history of an inquiring spirit, and an ever-expanding and maturing character.

I have said that he had no elaborated system to offer and to teach; but he had many resting-places in his forward journey. One of them, and perhaps the most important, was the philosophy of Rosmini, in which pantheistic monism is met by an individualism proclaiming the inherent and intrinsic value of every unit in the race. According to this teaching each one of us is an impenetrable unit, cut off from every other by the boundaries which limit, form, and determine his individuality. But each of the units resembles every other one: all have points of contact, and can disclose their individualities to others. Each is the heir of all the ages, not only by unconscious inheritance, but because the gains of the past, all ancestral possessions, can be entered into a fresh, reappropriated by culture, and lived over again in new experience ; while that experience, after receiving its own enrichment from 
the past, is destined to give place to a larger and fuller one. Every individual yearns for new development and fresh environments, but what it is possible for each to realize is met by the discernment of what it is good for others to experience. The worth of particular states, however, cannot be known, a priori, in the abstract. It can only be known through the experiences themselves. Thus Davidson's philosophy was both individualistic and pluralistic. When experience is analyzed we find a unity within the plurality ; and in that unity is found, and out of it may be deduced, a theism of which the evidence is clear and the outcome stable.

The psychological, metaphysical, and ethical teaching of Thomas Davidson is well known to those who heard him teach. It is with its results that I have chiefly to do in this volume; especially with the outcome of his ethical teaching. Very early in life he saw that "man's chief end" (as his Scottish catechism put it) was the attainment of knowledge, insight, and freedom, - the realization of what is true, and beautiful, and good; but he also saw that this had to be conjoined with the realization of an equally supreme good or "chief end" by others, that is to say, by the community. It was this double or twin conviction, more than anything else, that dominated his whole life. The chief good for each, and the summum bonum for all, were not theoretically antagonistic; and they did not practically conflict. But, how were they to be realized and harmonized? It was his prolonged pondering and revolving of this problem that led him to his "Fellowship of the New Life." The very name "fellowship," rather than "society" or "organization," meant a great deal. It carried its small band of devotees back to the Pythagorean, the Socratic or Platonic, and the Epicurean brotherhoods. Even the manual labor called for from each member was significant. But Davidson soon saw that he could not realize his ideal in England. It was Utopian to his British contemporaries. Hence he sought for it in the New World, "the unexhausted West." 
As, however, his aim has been a good deal misunderstood, it is desirable again to state that the "New Fellowship," the realization of which he sought for, was based not upon uniformity of opinion or belief, not on mere camaraderie, or sympathy in pursuing ends which are not ideals; but on the realization of the highest possible life, the broadest and most varied culture, altruistic in every sense from first to last. To Thomas Davidson culture was not a selfish pursuit that could be followed out in solitude. It was only attainable in a community established and knit together by disinterested social bonds, the varied knowledge sought being obtained with a view to the elevation and betterment of society around. His aim was to present to the world a new example of "plain living and high thinking" by the courageous pursuit and advocacy of truth when freed from the trammels of convention, and by the realization of the beautiful in Art and of the good in Life. If a parallel to this may be found in earlier efforts, it is to be sought, not in the phalanstery schemes of the eighteenthcentury economists, but in the pantisocracy of Samuel Taylor Coleridge and his friends, and their projected settlement on the banks of the Susquehanna. The "Fellowship of the New Life," however, was wider in its original programme, much fuller and richer in its ideals, although not more realizable in the world of the actual. 


\section{CHAPTER II ${ }^{1}$}

\section{THE MAN : A SKETCH AND AN ESTIMATE}

Thomas Davidson was born in I840 in the parish of Old Deer, at Drinies, a croft situated a little to the north of the coach stables of Pitfour, now attached to the farm of Toux. After the death of his grandfather the family removed to the village of Fetterangus, about a mile distant, where the widowed mother with her two daughters occupied a house. His mother, Mary Warrender, and her sister Margaret toiled industriously to support their aged mother and themselves, with a laudable pride, now less common, in order to be independent of public charity or parochial aid. In fine weather Mary wrought at outdoor labor, chiefly on the home farm of Pitfour, assisting in spring by gathering weeds, hoeing turnips, shearing sheep, at the latter of which she was an adept, being able to shear forty to fifty a day. In harvest she gathered the corn cut by a reaper with his scythe, and in winter was often employed lifting turnips for the cattle, or other homely agricultural work. On bad days she plied her needle or knitting pins in untiring assiduity, and always managed to keep the household clean and tidy.

When a boy Thomas Davidson was of a blonde complexion, with hair inclining to yellow, hazel eyes, and an open smiling face. He was a great reader, and being of a lively and happy disposition, as well as docile, he was a general favorite with young and old. His mother was desirous that her two boys, - Thomas, and another younger by two years, who afterwards became a well-known man, John Morrison Davidson,

1 Part of this chapter was contributed by me to the volume entitled Some Nineteenth-Century Scotsmen. 
barrister at law, political and social journalist, - should receive a good education, and be brought up to be pious and reverent.

The first school that Thomas attended was the girls' school in the village of Fetterangus, taught by Elizabeth Grant, under whom the boy made rapid progress. When about ten years of age he was sent to the parish school of Old Deer, then presided over by Mr. Robert Wilson, who soon saw that there was the making of a scholar in the lad. ${ }^{1}$ The number of pupils who attended the parish schools of those days varied considerably in summer and in winter. Whilst the summer attendance at the Old Deer school was about eighty, in winter there were from one hundred and twenty-five to one hundred and thirty pupils on the roll. As one man single handed was unable to do anything like justice to such a number - especially if any were learning the higher branches - he was obliged to have recourse to a practice commonly adopted by parish schoolmasters in those days; namely, the employment of monitors to assist in teaching the junior classes for a part of the day. Young Davidson was thus employed, and from his knowledge and good humor he soon became a favorite alike with pupils and teacher.

As time went on and the lad advanced in learning, more time was needed for his school work. The master then took him to board in his house, and helped him in his studies for a couple of hours each evening in payment for his teaching work through the day. Young Davidson was exceedingly fortunate in his landlady, Mrs. Wilson, a person of unobtrusive piety, common sense, and kindliness of heart, who treated him in all respects as one of her sons. While the master taught him Latin, Greek, and mathematics, his wife initiated him in French, so that he was soon able to read that language with ease.

$1 \mathrm{Mr}$. Wilson still lives and flourishes, and it is from him that I have received these facts as to Davidson's boyhood. 
At the age of sixteen he left Deer School (October, I856) to attend the Bursary Competition at King's College, Aberdeen, and came out sixth in the list of honors, gaining a scholarship of fifteen pounds a year for four years. At the end of his first session he took the second prize in Greek, and carried off the Simpson Greek prize of seventy pounds at the close of his curriculum. In his second year he took the first prize in senior Greek, and Principal Geddes, then professor of Greek, spoke of him one day in his class as the best linguist he had ever taught. In his fourth year he was second in senior humanity, and fourth in logic and in moral philosophy. Toward the end of his college course he became acquainted with a youth, James Macdonell, at that time a young exciseman at Old Deer, afterwards a brilliant literary man. The two friends, Davidson and Macdonell, exercised a strong mutual influence, to the intellectual benefit of both.

Mr. George King writes to me:

"I saw much of Thomas Davidson while I was a student of medicine, and he rector of the old Aberdeen grammar school. We were not fellow-students. He was my junior in years, though senior in the university. He graduated in arts at King's College while I was still a student of medicine at Marishall College. I first got to know him through a man named Webster, a brilliant but flighty youth, who was not a university student but a great reader, and a wonderfully subtle and appreciative critic, especially of poetry. Davidson used to give simple suppers (the fare being coffee, bread, and butter) in his lodgings in Don Street, old Aberdeen, on Sunday evenings after church. The men who attended these meetings were John Macdonell (now Sir John, a master in chancery), and occasionally his brother James (subsequently on the staff of the Daily Telegraph, and then the Paris correspondent of the Times), the aforesaid William Webster, William Wallace (brother of Robert Wallace the Presbyterian 
minister, professor, journalist, and member of Parliament), Davidson's younger brother John, and myself. We were all regular attendants at the evening service of the Reverend George Mee, then a Baptist preacher in Aberdeen, but a native of Wales. Mee was a man of high attainments, and many of his sermons were brilliant literary performances. The conversation at these delightful suppers at first usually turned on the sermon we had all listened to, but afterwards it was likely to wander into discussion of the books and political events of the day, chiefly the former. One book that gave occasion for much talk was Gervinus's Lectures on Shakespeare. Another was Max Müller's Chips from a German Workshop. Carlyle and Tennyson afforded material for much animated talk. Davidson admired Carlyle less than the others did. In appreciating the more subtle beauties and suggestions of both Tennyson and Carlyle he fell short of Webster and James Macdonell, and they excelled him also in facility of expression. But Davidson surpassed us all most notably in scholarship. He was an admirable classic, and his knowledge of German was considerable. He had read more than any of us; although he had no knowledge of, or sympathy with, biological science.

His was a bright, kindly, and most lovable spirit; and I have often deeply regretted having got out of touch with my old friend. I went to India in I866, and from that time our intercourse practically ceased, my exile abroad lasting for thirty-two years."

Davidson graduated at the University of Aberdeen in 1860, carrying off, as stated, the Simpson Greek prize. That same year, after three months' absence, - when he taught in a boys' school at Oundle, Northamptonshire, - he went back to Aberdeen as rector of the old-town grammar-school, and session clerk of Old Machar parish. These posts (or rather this post, for they were joined together) he held for 
about three years. The school did not flourish under him, and he disliked the work of registering births, deaths, and marriages. He therefore resigned in August, 1863, "in consequence," he said, "of having received a situation requiring my immediate presence in England." This was at Tunbridge Wells, where he taught; but nothing that is authentic can now be gathered of these days.

It was virtually a farewell to Aberdeen, although he revisited the Granite City two years later, in 1865 , with Dr. Theodore Benn; again in 1870, and finally in 1882 .

After resigning the Aberdeen grammar school, and finding that he could do no better at Tunbridge Wells, Davidson went to Canada. He taught at Toronto, went thence to St. Louis (U.S.A.), and afterwards to Boston, where he met Longfellow. Through Longfellow's influence he was appointed to an examinership at Harvard University. He spent a year in Greece, chiefly at Athens, where he met Dr. Schliemann, the topographer and German explorer, from whom he received a bit of ancient ware found by the excavator in Agamemnon's tomb at Mycenæ, which he facetiously called Clytemnestra's teapot. At Rome he was introduced to his Holiness the Pope, and had an hour's conversation with him in Latin in the Vatican garden, an honor rarely granted to any except intimate friends. He also spent a year in the north of Italy, while writing The Philosophical System of Antonio RosminiSerbati.

Davidson has been written of by one who knew him well ${ }^{1}$ as within the circle of the twelve most learned men in the world. His learning was encyclopedic, and his culture almost universal. A great linguist, he had a knowledge of Philosophy in all its branches that was amazing. He was one of the distinguished students of the subject whom the University of Aberdeen sent out during the last quarter of the nineteenth century; but he was so humble and altruistic that very

1 William Clarke in The Spectator. 
few of his friends and acquaintances knew what treasures were stored within his brain and heart. More than any of the nineteenth-century thinkers known to fame, he lived and toiled for other people, and from first to last had no thought of himself. His modesty and generosity were monumental features of an outstanding personality. It might have been thought that after finishing his undergraduate career he would pursue the vocation of a university teacher of Philosophy, but the paths available to him were few and crowded. No vacancy occurred which tempted him to become a candidate for a Scottish university chair.

Besides, in these years he was rejoicing in his newly found freedom as a teacher; and he was, from first to last, a peripatetic, an intellectual free-lance, stimulating many minds in many lands, while waiting for the possibilities of future and larger work. He deeply loved and profoundly honored the mediæval universities of Europe, - those cradles and nurseries of learning founded in the so-called dark ages, - but he had little sympathy with a belated mediævalism, stationary, crystallized, and dominating our western ideals of progress. $\mathrm{He}$ thought that the students of some of our universities, no less than these institutions themselves, were occasionally indifferent to new light and progressive leading; and so he became a wanderer, like many of the ancient scholars, travelling from country to country in Europe. His modern instincts, however, drew him chiefly to America. It was his intellectual and social ambition to find a set of men and women who could be bound together in the freemasonry of a common thirst for that knowledge which leads to useful work and fruitful life. And it must be admitted, when all the errant elements in his career are eliminated, that he succeeded in inaugurating a "new fellowship" of the true, the beautiful, and the good.

Like Socrates, he never cared about rewards for instruction. Also, like Socrates, he had "many scholars, but no 
school" with entrance examinations, and well-fenced traditional avenues to success. His was an educative rather than an academic ideal. As an intellectual missionary, his aim was to get at the truth of things, with a view to the regeneration of society. He wished the elimination of error to lead to, and insure, the eradication of evil from human life. His unique advocacy of the philosophy of Religion, his defence of dualism against the monistic system of Spinoza, his glorification of individualism - dualistic yet socialistic - were notable amongst other efforts of his countrymen. But, as already said, he was a born wanderer. You met him, talked with him, were inspired by him; and next day you found that he had fled! He was like Browning's Waring, or the "one true poet whom he knew"; also like Matthew Arnold's scholargipsy. He felt, as very few have ever done, that he was matriculated as a continuous student in the great peripatetic university of the world. Taking up philosophy after philosophy, although he did not indorse any, he never dropped one. $\mathrm{He}$ assimilated the teaching of each and passed on ; but, above all things, he wished to make his speculative knowledge fruitful for subsequent work, and a stimulus to good fellowship and camaraderie. The very last to think himself an "angel of light," he was - without quite knowing it - an instinctively inspiring personality in every circle into which he came; and he has left the memory of a mediævalist panoplied in the guise of a nineteenth-century crusader. He lived to revivify some of the ideals of the Middle Age. An intellectual cosmopolite, as well as a teacher of those ethical truths to which our modern world has attained, and caring nothing for what is ordinarily considered success, he went on his way rejoicing - if possible to conquer - but careless whether he succeeded or failed, if only he taught. 


\section{CHAPTER III}

\section{FORMATION OF THE FELLOWSHIP OF THE NEW LIFE}

It may perhaps be said without exaggeration that at the meetings held in Thomas Davidson's rooms at Chelsea in 1881-1883 we find the fons et origo of the later nineteenthcentury ethical socialism of England. He was undoubtedly its pioneer, and for a time its center. He had returned from Italy, full of interest in the philosophy of Rosmini ; but the formation of a small society of like-minded persons for the reorganizition of individual life, and thereby the gradual uplifting of society to higher levels, was a much more intense desire with him than the prosecution of speculative study. He gathered round him more than a dozen sympathizers in these Chelsea rooms, where they held meetings for the discussion of problems and the realization of their aims; but, as time went on, inevitable differences arose within the group. There was a political section, and another that was more purely ethical. One of Davidson's aims had been to carry out the ideal of the "Institute of Charity." The political section influenced by Karl Marx, and the social democratic federation - broke away from this, and ultimately formed a new organization which they called "The Fabian Society."

Mr. Maurice Adams writes an interesting letter to me from Purley, Surrey, giving particulars as to the initiation of the Fellowship of the New Life, from which I extract the following:

"In the September of I 882, Mr. Davidson, being in London, gathered together a number of people interested in religious thought, ethical propaganda, and social reform, among whom 
I may mention the names of Messrs. Frank Podmore, Edward R. Pease, Havelock Ellis, Percival Chubb, Dr. Burns Gibson, $\mathrm{H}$. Champion, the late William Clarke, Hubert Bland, the Reverend G. W. Allen, and W. I. Jupp, Miss Caroline Hadden, Miss Dale Owen, and Mrs. Hinton. After many meetings he proposed the formation of a society for the cultivation of character, a complete education, and social regeneration.

The inclosed ${ }^{1}$ draft of principles, rules, and regulations, which he drew up in November for the guidance of the meetings in his absence, will give you a good idea of the objects he had in view.

The meetings held in Mr. Pease's rooms in Osnaburgh Street and elsewhere were rather indefinite in character, till Dr. Burns Gibson proposed the inclosed resolutions.

This led to a breach in the society, as you will see from Mr. Podmore's letter to Mr. Chubb, and the resolutions which he drew up forming the 'Fabian Society.'

The nine supporters of Dr. Burns Gibson's resolutions formed the nucleus of the Fellowship, which gradually grew in numbers.

The first manifesto was entitled 'Vita Nuova.' I inclose a copy, and also one of the enlarged manifestoes, a printed letter from Thomas Davidson (who was then in New York), with the manifesto and list of lectures of the New York Fellowship. The English Fellowship published a quarterly journal entitled Seedtime, which (as you will see from the final number) lived for eight years.

Thomas Davidson was one of the most interesting men I ever knew. Intellectually alive to the finger-tips, he had a fervid nature, and habitually lived in an atmosphere of elevated emotion. Nor was he, like so many intellectual men, lacking in will-power. On the contrary, his strong, earnest, and selfconfident nature made him occasionally somewhat dogmatic, overbearing, and intolerant of opposition.

\section{See page $2 \mathrm{r}$.}


In the early days of the Fellowship the members rather feared being so dominated by him as to have their own personalities dwarfed. In consequence, they vigorously asserted their own views; and at length, as you will gather from his letter, Davidson felt that the English Fellowship was not quite what he had hoped for.

He was so thoroughly individualistic that, in spite of his sympathy with the poor, and his burning desire for justice, he could never sympathize with the socialistic views of many of the English members, cherishing the idea that it was possible to remove social evils by individual remedies alone, or, at most, by voluntary coöperation.

He contended boldly for the necessity of a philosophic basis for religion, ethics, and social reform; but his philosophy was also individualistic and pluralistic, a kind of monadology. $\mathrm{He}$ was always full of ideas, and stimulating to the highest degree intellectually and morally.

Above all he was sincere and enthusiastic, hating compromises and the interpretation of creeds and formulas in a nonnatural sense. 'Intellectual honesty' was his watchword, and what he had perhaps most at heart."

Mr. Podmore's letter to Mr. Chubb, referred to by Mr. Adams, was as follows :

“ DeCEMber i6, i883.

Some of us, after talking the matter over, find that we cannot subscribe to the resolution moved by Dr. Gibson. At the same time we wish to have a society, only on more general lines. We are anxious not to have any discussions of any kind; and I shall therefore propose at the next meeting to leave to the subscribers to the new resolution the name 'Fellowship of the New Life,' and that a second society be organized - which will not necessarily be exclusive of the 'Fellowship' - on somewhat broader and more indeterminate lines, ... . it being open to any to belong to both societies." 
This "next meeting" was held on January 4, I 884, at which the above proposals were substantially agreed to; the old name retained by those who originally devised it, and a new organization constituted under the title of "The Fabian Society." The difference between them was mainly this, that the latter was more of a socialist movement, while the former was ethical and individual; although it was individualistic only as the majority of the new "Ethical Societies" were, or became. Its aim and outcome were social, but its basis and starting point were individual; and all its aims concentrated on the elevation of individual life.

The following was its original basis, as drawn up by Mr. Maurice Adams, and adopted on November 16, 1883:

We, recognizing the evils and wrongs that must beset men so long as our social life is based upon selfishness, rivalry, and ignorance, and desiring above all things to supplant it by a life based upon unselfishness, love, and wisdom, unite, for the purpose of realizing the higher life among ourselves, and of inducing and enabling others to do the same.

And we now form ourselves into a Society, to be called the Guild of the New Life, to carry out this purpose.

And so the two societies went to work, on independent but friendly lines.

At a meeting of the Fellowship, a constitution, or programme - the "Vita Nuova" - was drawn up and adopted, which is worthy of transcription here, as it was undoubtedly better in its first simple draft than it became in its subsequent enlargements in detail.

\section{Vita Nuova}

Object. The cultivation of a perfect character in each and all.

Principle. The subordination of material things to spiritual things.

Fellowship. The sole and essential condition of fellowship shall be a single-minded, sincere, and strenuous devotion to the object and principle. 
Intercourse. It is intended in the first instance to hold frequent gatherings for intimate social intercourse, as a step towards the establishment of a community among the members.

Designs. The promotion, by both practice and precept, of the following methods of contributing toward the attainment of the end: (I) The supplanting of the spirit of competition and self-seeking by that of unselfish regard for the general good; (2) simplicity of living; (3) the highest and completest education of the young; (4) the introduction, as far as possible, of manual labor in conjunction with intellectual pursuits ; (5) the organization, within and without the Fellowship, of meetings for religious communion, and of lectures, addresses, classes, and conferences for general culture, and for the furtherance of the aims of the Fellowship.

So far the original programme, or manifesto, as at first adopted; but as the conductors of this Fellowship did not date their prospectuses, it is somewhat difficult for an outsider, supplied with them now, to follow its development. It is Mr. Davidson's relation to it, however, that chiefly concerns us; and it may therefore be desirable to print the draft of its principles and aims, which was drawn up by him but set aside in favor of the above shorter and simpler form. Although never adopted, it casts much light on the mind and character of the writer. It is therefore printed in a chapter by itself. 


\section{CHAPTER IV}

\section{ORGANIZATION OF THE NEW FELLOWSHIP AS DRAWN UP BY THOMAS DAVIDSON}

\section{The Occasion}

Whereas, the end of all life is happiness, and the free development of all our faculties;

And whereas, this end can be attained only by bringing about an order of things in which there is harmony, depending upon insight into the nature of things, and a willingness to bring about that harmony;

And whereas, no system hitherto devised has accomplished this end, failing either through neglect to obtain the highest insight, or from a want of force to act in accordance with it ;

And whereas, therefore the world - notwithstanding the great advance in experience, knowledge, and appliances - is still as regards the majority of its people sunk in ignorance, superstitution, sin, and suffering ;

It seems desirable to a small number of persons to see whether the experience, insight, and moral force-accumulated and transmitted by the ages - could not be so formulated and applied as to bring about the desired harmony, and hence the conditions of a noble and happy life. They therefore set before themselves the following aims.

\section{The Principles}

I. Unsparingly to put aside all prejudice.

2. Through experience and study to acquire insight and knowledge.

3. To live openly. 
4. To banish all selfishness.

5. To be helpful and charitable as far as may be, intellectually, morally, and materially.

6. To make no compromise with evil.

7. To form a union on these principles and for their propagation, with a view to the realization of the highest ideal life, and to bring about the same conditions for others, and especially children, to do the same.

The immediate aims are brotherhood and education, to combine the greatest possible amount of personal liberty every man a law to himself - with all the advantages of intimate society, a monasticism of families. The members of the society enter it with the distinct understanding that the previous possession of such aims constitutes the condition of membership, which shall at all times be voluntary; and these shall be the chief aims in the life of each member, and shall rule the conduct of his life. While the society purposes ultimately to live in community, with a view to the bringing about the necessary conditions of education, the members at present propose to follow these aims as their avocations will allow. During this interval each member shall use every effort to realize in his own person the ideal proposed by the society, and - though it may be separated by distance - to live a common life of intercourse and mutual help. With this view it is proposed that each one should regulate his life in accordance with the following rules.

\section{Rules for the Guidance of Life}

I. To have as the aim of all free action; some portion of the aim of every member of the society being to maintain this, especially in the way of istudy.

2. To introduce regularity into his daily life, having a programme for each day. 
3. To review each day at its end, and to see with what success the programme has been carried out, and the purity of the motives of all actions performed.

4. To keep a record of each day, with all its incidents and valuable thoughts.

5. To communicate freely with all other members, when either intellectual and moral aid or encouragement is needed.

6. To take sedulous care of health, avoiding all unnecessary exposure, stimulation, or excitement, and in all ways to husband strength.

7. To avoid all gossip, evil speaking, and all societies having no serious aim.

8. To endeavor by positive efforts to obtain the enthusiatic approval of conscience.

9. In speech to be sparing of praise or blame.

Io. In life to aim at absolute truthfulness, simplicity, and chastity, in thought, word, and deed.

I I. To be uniformly courteous in word and deed.

12. To avoid all impure and doubtful literature and companionship.

\section{The Creed}

I. All that truly is, is eternal: such is every soul.

2. God is the Law of Being, which is Love.

3. The welfare of every soul depends upon its own action.

4. Blessedness is perfect accord with the Law of Being, which accordingly is reached by insight, and action in accordance therewith.

5. Hence the aim of science is to discover the laws of being, of art to embody them, and of morality to live in agreement with them.

6. It should therefore be the aim of each individual to develop himself in all these directions, never losing sight of life as a whole. 
7. All life must be religion; that is, action in view of the totality of conditions : this only is holy.

8. Prayer is silent meditation, and the direction of the soul upon the infinitude and grandeur of Being.

9. Public worship shall consist of all those means whereby the soul is stirred to enthusiastic sense of the omnipresence of Divine Law.

10. Life is of infinite value, and pessimism is intellectual blindness.

I I. All work that contributes to human wellbeing is honorable.

I2. The only title to property is labor.

13. In marriage, more than in all things, regard shall be had for the highest ends, and it shall never be a means to the indulgence of the flesh. Monogamy is the law.

I4. No one shall marry without the material resources necessary for such a step and its consequences.

15. Neglect of children is a crime of the first rank, and the society should see that the crime is prevented.

16. The greatest freedom of intercourse between the sexes is to be aimed at as conducive to these ends.

17. Every man during his lifetime shall have the right to the results of his labor; but these at his death shall fall to the society, except so much as is necessary to fulfill the responsibilities which he has undertaken by marrying.

18. All titles, social inequality, and family prestige shall be abolished.

19. Character and action, not wealth, are the grounds of distinction.

20. Every effort in the way of teaching and writing by members shall be undertaken in the name, and with the approval, of the society.

2I. Simplicity, combined with good taste, is the rule of dress. 
22. Except in the domestic circle there is to be no distinction between the sexes.

23. Principles, not persons, are to be authoritative. Great men are to be imitated, not worshiped.

24. All authority in the society, except that which is constituted by the society itself, is null and void.

\section{The Organization and its Stages}

The society shall date from January I, I883, but shall not be organized until a meeting of members can take place.

The society shall develop through the following four stages: (I) The tentative or novitiate stage for the first members, in which they try to live the new life; (2) the life of full members not yet living in community; (3) the life of the members living in community, but not independent ; (4) the life of the members living in an independent community.

All new members must undergo a novitiate sufficient to satisfy the executive of their ability to live the life of the community.

Nothing in this programme except the main principles and purposes shall be exempted from change, if such a change is seen to be desirable. 


\section{CHAPTER V}

\section{DEVELOPMENT OF THE SOCIETY}

As time went on the idea of a coöperative settlement for industry and education was mooted, and a somewhat elaborate scheme for "the establishment of an industrial, educational, and residential settlement in the neighborhood of London, on coöperative principles," to be carried out by the Fellowship, was drawn up and circulated. This was followed by "proposals for the establishment of a school" to promote the same ends.

The thirty-four numbers of Seedtime, - the organ of the New Fellowship, - ably written and edited, are a valuable memorial of its work. Like every other pioneer magazine, it was but for a time; but it did its work while it lived, and the seed it sowed is springing still, and will yield future harvests. Part of a characteristic letter from Mr. Davidson to its editor may be given here.

\section{“ 237 West I05Th Street, New York, November 25, 1889 .}

. . . I like your Seedtime, although it is not up to the mark of The Sower. You have n't a definite enough programme, and are too much carried away by the temporary reform wave of socialism. You are in the surge, not on the rock the Rock of Ages.

_- I suppose, tells you everything but the facts of his own popularity. All the same, he is very popular. Everybody loves him, and he will be a success here. I hope he will in time rise above his somewhat morbid idé fixe of state socialism into simple independence of thought, and be himself, not a paper wad in the tail of a popular kite. It is inexpressibly 
funny to find an admirer of Thoreau professing socialism. I shall expect soon to hear of a monk advocating the uxoriousness of Solomon. But, despite these inconsistencies, will make his way, and be very helpful to us all. His personality, which is a great deal bigger than socialism, or any other ism, will be his guardian angel till he reaches the heights of vision. ...."

There was a curious element of exactingness in Davidson, amounting in some instances to a quasi-tyranny, towards the friends who differed from him in opinion or policy, which led to transient friction. He was so anxious to have his ideals wrought out, and to have work done on the lines that commended themselves to him, that he could not complacently brook opposition. It was perhaps for this reason that his influence was stronger at times over the women students whom he taught than over the men.

$\mathrm{He}$ certainly wished the work of the movement which he started and organized in London to be carried out in his own special way; and he regretted the introduction, or at all events the prominence in it, of those who, as he put it, had "no motives higher than those of economic utility." $\mathrm{He}$ even wrote that if their voices prevailed, those "who desired something higher ought to secede and begin all over again for themselves." When he was wintering at Rome (I883I884), and received from London a fresh programme of the New Fellowship, he thought it good so far as it went, but found it "meager and indefinite." "It seems," he wrote "to be settling down into a kind of quietism, which, in my opinion, bodes ill." He was deeply grieved that some of its members wished "to discontinue him, on the ground that he had tried to set himself up as the "prophet ' of the Fellowship." $\mathrm{He}$ wrote that he was "quite willing to withdraw from anything but a sympathetic connection," as his work in the future would lie across the Atlantic. He wished all who knew of 
his relation to the society at its inception not to wound the feelings of those who had entered it since by any mention of those earlier years. "It has always been my earnest and expressed desire," he wrote, "that the society should feel itself to be without founders and without "prophets.'" $\mathrm{He}$ hoped, however, to find a duplicate of the Fellowship in the land of his adoption, and promised to send accounts of it to the old society.

Mr. Percival Chubb writes :

"Our differences never altered my fundamental feelings of admiration, respect, and gratitude, which he inspired from the first. I was and am more deeply indebted to him than to almost any man I have known. I can never repay the debt. ... I knew him from the time when he was living at Domodossola, and pursuing his Rosminian studies, i.e. just after the publication of his book on Rosmini's philosophical system. I was very close to him in the attempt to write out a new type of life ('Vita Nuova,' we used to style it), and through this association became the secretary of the Fellowship of the New Life, and also for a time of the offshoot society, the Fabian. His letters record pretty fully the phases of impulse and conviction through which he went at this time. I was at his summer school at Farmington and in the Adirondacks for two summers. I also know something of his last labors with the Breadwinners, because I continued a little of the work with one of his classes after he died." 


\section{CHAPTER VI}

ESTIMATES OF DAVIDSON BY PERCIVAL CHUBB AND FELIX ADLER

The previous chapter concluded with a letter from Mr. Chubb ; and as he wrote a memorial notice of his friend after Davidson's death, in The Ethical Record (of which he is editor), part of this estimate is now placed in a sequel chapter (although it anticipates some of his teacher's later work), so as to bring separate parts of Mr. Chubb's appreciation together as a whole.

Mr. Chubb wrote :

"He was a remarkable man, intellectually and emotionally ; intense in his convictions and in his likes and dislikes, largehearted and recklessly generous of time and strength to those who sought his help. He was especially attracted by promising young men, for whom he had a romantic feeling that was in the best sense Hellenic. There was scarcely a period of his life when he did not lavish upon some hopeful and needy youth the best of his intellectual powers and stores, often money from his none too copious supply, always an ebullient childlike affection and loyalty, an unselfish and delicate thoughtfulness.

Intellectually Mr. Davidson always bore the marks of his Scottish origin. He was modern in his equipment and in his outlook; but with this modernness was mingled a touch of the scholasticism and the sectarian fire, the parti pris, of a John Knox. He was almost fiercely affirmative of his own convictions; they were the bread of life to him. He boasted that he was sectarian; he always believed that his philosophy was the supreme way to salvation; and he was at all times an ardent, fearless, outspoken missionary in its behalf. What 
that philosophy was it would be difficult to formulate, for it underwent many changes. He remained a devout Aristotelian, and an arch-enemy of the Spenceriacs (as he called them) and Hegelians. He owed much to the mediæval men, - Aquinas and Bonaventura and Dante; and among his more modern devotions were those to Giordano Bruno, Leibnitz, Goethe, and Tennyson. His interests were centered in the greatest minds of history; and he had the distinguished amplitude, the large bearing, that came of daily converse with them.

He brought to the support of his views a surprising wealth of detailed knowledge, of which his marvelously tenacious memory gave him ready command. He was a master of many tongues, and read and spoke ancient and modern Greek with almost as great a facility as German and Italian. He had traveled much, and enjoyed converse with many distinguished Europeans. It was the very richness of his mental acquisition and the complexity of his nature - compounded as it was of both rationalistic and mystic elements - that stood in the way of a thoroughly clarified, consistent, and stable philosophy. He had an immense power of work, although the printed output of his life is not large, and does not do justice to his scholarly capacities. Some translations of verse and prose; a volume on the Parthenon frieze and other Greek themes; a presentation of Rosmini's philosophy, of which he may be said to be the discoverer for English-speaking people; volumes on Aristotle and Greek education, on the education of the Greek people (his best book, we think), on Tennyson's In Memoriam, and on Rousseau ; some articles in Warner's Library of the World's Best Literature ; and A History of Education, - these are his inadequate legacy. He left many lectures in manuscript, and it is to be hoped that the best of these will be published, with a memoir of his interesting life and personality.

He touched the ethical movement mainly on the side of its regard for practical well-doing, and was especially attracted by what he considered to be its sincere, undisguised, fearless, 
and yet courteous attitude towards conventional religion. Scholar and thinker as he was preëminently, he was always aiming, nevertheless, at practice, - dreaming Utopian dreams, and moving toward their realization. This gave him a vivid interest in reform and in modern sociology. He was the prime mover in starting the Utopian schemes of the Fellowship of the New Life in England and America. He nursed the hope at one time that his own beautiful acres at Keene, in the Adirondacks, might become the summer home of a band of idealists vowed to new, simpler, and nobler ways of living. Here he had his Summer School of the Culture Sciences, a quite unique establishment, that at one time carried a strong suggestion of such a Utopia.

But nothing was more admirably characteristic of the man than the labors which during the last two years of his life he carried on at the Educational Alliance on the lower East Side of New York. Here he had gathered about him, in peculiarly close bonds, a body of young Russian Hebrews, whom he endeavored to help to get culture in the broadest, manliest sense of the term. More important, we are led to believe, than any actual results in scholarship achieved was the powerful, transforming, personal influence exerted over these young boys and girls by a man who could show in such relationships a magnetic charm, a sympathy and tenderness of interest, a whole-souled devotion which will undoubtedly have left a deep mark upon many lives. The labor was a labor of love. The man's whole soul was in it. His feeling in regard to it is well indicated in a recent remark of his to a friend that the whole of his long life had been a preparation for just this. He died, leaving not only these young people, but others, youthful and aging, under obligations for all kinds of chivalrous service done to them. Their gratitude will assuredly follow him with their sorrow for his all too early death.

The mortal part of Thomas Davidson - no one, be it said, had a more impassioned, invincible faith in personal 
immortality than he - was buried at Glenmore in the Adirondack forest, where he sought summer peace while he lived. At the burial Dr. Felix Adler, always his good friend, delivered the following address :

'It is very still, and beautiful, and solemn here. The first premonitory pang of the frost has thrilled the trees, but has served only to deck them with an added if evanescent glory. The grand panorama of mountain and valley that opens out on every side, as we stand on this noble plateau, has never revealed itself, it seems to me, in more crystalline clearness than on this perfect day. The sunlight shines upon this bier covered by loving hands with autumn foliage and flowers. And, in the midst of this peace and beauty, in this grove, near to the house in which he dwelt all these years, you have selected the spot where shall rest the earthly part of Thomas Davidson, whom many of you revered as a master and loved as a friend, and whom all admired as a superior and exceptional man.

This is not the occasion to attempt, even in outline, an exact estimate of him as a thinker, as a scholar, and as a humanitarian. Doubtless an opportunity will be offered later on for competent judges to do justice to him in all these particulars, and to pay to his memory an adequate and discriminating tribute worthy of the contributions which he made to literature, to philosophy, and to the cause of practical beneficence. I speak here as a neighbor, as a friend, and as one who serves, for the time being, as a mouthpiece to voice the sentiments of hundreds of men and women who cannot be present with us, but who, in spirit and from a distance, mingle their tender farewells with ours. A man's thought is assayed by inexorable chemists, and the quantum of gold it contains is determined according to undeviating standards. The value of a man's work, too, on the whole, is tested by expert fellow-workers. But what a man is, as 
distinct from what he thinks and from what he does, - his character, the best part of him, - reflects itself somehow, with immediate, almost photographic distinctness, upon all who live with him and deal with him, be they lettered or unlettered, his equals or his inferiors in mental attainments. And it is of this generic impression, which every one received and could not fail to receive from Thomas Davidson, that I would lovingly speak.

There was a certain air of elevation, a certain tone of distinction, about him, which even the most ordinary could not but feel on coming into touch with him, like that which one observes among the high-born who are accustomed to move in the society of the great; only that, in his case, the great with whom he associated were the everlasting princes, the lords of wisdom, the prophets, the seers, the sages, and the saints. With them he kept company in his study, and when he emerged from it and entered into ordinary society and engaged in ordinary converse, the manners which he had acquired in that elect circle did not desert him, and somehow the afflatus of great ideas was about him even in the routine of daily intercourse. Justice, freedom, perfection, immortality; these words and what they stand for were as close to him as the thought of his daily wage is to the laborer, or of his hay is to the farmer.

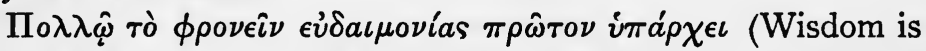
by far the major part of well-being). This line of the Greek tragedian applies to his life. To think wisely, to try to think so, was the greater part of his happiness. And this "trying" is to be understood in a severe and thoroughgoing sense. His scholarship was admired by all who knew him. His vast command of languages and literatures, ancient and modern, Greek, Hebrew, Arabic, Italian, German, etc., - his minute acquaintance with the recondite learning of the Middle Ages, all this was astonishing. But still more astonishing was it how lightly he carried this heavy baggage, how entirely he 
forbore to intrude or make parade of his great erudition, how completely he converted into the tissue of his own thinking the elements he absorbed from elsewhere: He explored the storehouses of the ancients in order to find therein the treasure which he could appropriate, and turn to account in the endeavor to live better, and to enable others to live better. $\mathrm{He}$ tracked his way through the wilderness of scholasticism in order to trace to their sources the streams of error which he believed to be still vitiating the life of to-day. To be honest with himself, to be sure that he had a right to an opinion, was the stringent rule to which he subjected himself. His scholarship, and the use he made of it, was the outcome of intellectual honesty.

The second quality which seems to me to have adorned his character to an exceptional degree was the plain-spokenness, the free and fearless avowal of his convictions. He did not fail, I think, in due respect for beliefs held sacred by others, but he esteemed it a right and a duty to express his own with no uncertain sound, without any truckling show of conformity or timid apology. He believed that the progress of mankind depends on the acceptance of true ideas, and the rejection of false; and he rightly thought that the inherent strength and truth of ideas can be fairly tested only if all earnest thinkers shall freely and courageously state the results of their thinking, without fear of the social or material penalties that may follow such avowal. In a world where inner convictions are so often veiled in timorous and guarded generalities, in a world in which the partial suppression rather than the full expression of the thoughts that relate to the highest interests of man is so often commended both by precept and example, his courage, his boldness, his perfect sincerity, his readiness to sacrifice interest to truth, appears to me to be one of his fairest titles to the respect of right-thinking men.

$\mathrm{He}$ had something of the Greek genius for friendship. $\mathrm{He}$ was attached to his friends, especially his younger friends, 
with a passionate devotion. His attitude toward guests and visitors was something unique. Who of us shall forget the radiant look of pleasure in his face, the hearty ring in the voice, the extended arms with which he welcomed those who came to share his ever generous hospitality?

But, above all, his charity was remarkable, a charity dictated by magnanimity; for his feelings toward the poor were such as only a great soul could be capable of. What he pitied in their lot was not merely and not chiefly their material want, though he was generous in supplying that also ; but his heart went out to them because of their lack of the mental and spiritual goods which make life large and fine. And this need he sought to fill and did fill without stint out of his own affluence, seeking to awaken the dormant soul in others, to draw them to his elevation; or, rather, when at his best, to quicken in them the power of rising through their own effort. And so we find that his last years were spent in dispensing this rich intellectual aid to those who eagerly craved for it and who so gratefully appreciated it. And in the "concluding chapter of his last book - a book written in the anguish of the terrible disease that was to terminate his career - he left as a legacy the idea of establishing this sort of charity on a grand scale; the idea of a college for breadwinners, intended to open to the toiling millions the world's best culture and to help to redeem them by quickening in them the springs of mental and spiritual power.

1. He loved these hills, whether it was that they reminded him of his native Scotland, or whether his soul, being attuned to the sublime, found a certain kinship in these large vistas, and his free spirit rejoiced in the freedom, the wild beauty, and the purity of nature here about him. He loved his Glenmore, and it is fitting that here at Glenmore the earthly part of him should find its rest. The eternal procession of the stars will pass nightly over his silent grave; the storms of winter will sweep; over this plateau; and the snow doubtless 
will drift, and heap itself high above this mound; then the spring will come, and cover it again with verdure and flowers. The seasons will come, the seasons will go; but he who once was the life of this place, emanating life, will appear amongst us no more. Yet in no sense can we think of him as wholly vanished. He himself believed strenuously that man is "an eternal being with an infinite task." And the thought of immortality seems to have been as certain to him almost as existence itself. But even from us who survive him he cannot entirely vanish. $\mathrm{He}$ has sown thought seeds that will flourish in many hearts. He has helped to shape lives that will never entirely lose the nobler imprint he has given them. $\mathrm{He}$ has kindled the torch of ideals that will never wholly be extinguished.'

Dr. Adler then read the following poem by Swinburne:

Whoso takes the world's life on him and his own lays down, He, dying so, lives.

Whoso bears the whole heaviness of the wronged world's weight And puts it by,

It is well with him suffering, though he face man's fate;

How should he die?

Seeing death has no part in him any more, no power

Upon his head;

He has bought his eternity with a little hour, And is not dead.

For an hour, if ye look for him, he is no more found, For one hour's space;

Then ye lift up your eyes to him and behold him crowned, A deathless face.

On the mountains of memory, by the world's wellsprings, In all men's eyes,

Where the light of the life of him is on all past things, Death only dies." 


\section{CHAPTER VII}

\section{LETTERS TO HAVELOCK ELLIS}

Mr. Havelock Ellis, who knew Davidson intimately while both were members of the New Fellowship in London, writes me from Carbis Water, Lelant, Cornwall, and sends me all the letters he received from him. Though they were thrown together for only a short period, Mr. Ellis saw a very characteristic aspect of Davidson, when he was making a valiant effort to affect the life of his time. He considered him a unique and magnetic personality rather than a great writer.

I have put together some extracts from these letters to Mr. Ellis, and add to them a chapter of reminiscences which the latter has sent to me. He wrote in April, I903: "I was one of the three young men whom Thomas Davidson gathered around him in London twenty years since, constituting the nucleus from which, indirectly, the Fabian Society sprang. ... I have always considered him one of the most remarkable men I have known, though my own relationship with him was brief."

To Mr. Ellis, Davidson wrote from Chelsea on October 3, I883:

"I do not know how you were affected by the discussion of last evening. As for me, it at once confirmed me in my belief in the need of a community, and showed clearly some of the most formidable difficulties in the way of such a thing; the want of a spiritual light, the childish prejudice against 'metaphysics,' the absence of whole-heartedness, the fear of ridicule. Kant and Comte have done their work, taken the sun out of life, and left men groping in darkness. A recent 
German book opens with the sentence, 'Kant must be forgotten,' and this I cordially echo. The present crude notions about metaphysics must be put away, and the fact clearly brought to light that without metaphysics even physics are meaningless, that that which appears also is, that beneath all seeming is that which seems. To me it is puerile to question this; but reactionary philosophies have brought many men to a different conclusion with what I cannot but consider a miserable result. You miss a positive basis in our little programme. The fact is there never can be any positive basis for anything but a metaphysical one, for the simple reason that all abiding reality is metaphysical; that is to say, lies behind the physical or sensuously phenomenal.

I hold that we know the metaphysical more clearly and more directly than the physical, and indeed know the physical only through it. I think, moreover, after last night's experience, we had better take the bull by the horns, and boldly say we accept the metaphysical basis. We gain nothing by compromise in this matter. You doubtless know that even J. S. Mill in his last days was forced to admit that without metaphysics we should never find a ground for anything. You are entirely right in saying that any attempt to build a system without new forces, that is, new metaphysical entities, is like building a house out of nothing. The religious basis which - whatever you may call it - you occupy, must, it seems to me, be metaphysical. Let us not, however, misunderstand this term by making it mean fantastical. It means simply the unchanging amid change, that which makes change possible. Change is utterly impossible except on the supposition that there is an unchanging subject of change. Let us say this, and then inquire what we know of this unchanging. I think we shall find that it is necessarily of the nature of spirit.

Would you be vexed if I recommended you to study Rosmini's works ? Leaving out the dogmatic part of them, I think they are the gospel of future thought. With your freedom from 
prejudice, your desire to do the best you know, and your human sympathy, you would, I am certain, find great satisfaction in them, and be able to free yourself from the last remnant of that terrible monism from which hardly any English thinker escapes. In return, I shall read Hinton with the utmost care. As is often the case with a man who changes his position in midlife, he seems not to have seen the whole truth at any one time, but to have seen it in two pieces without the connecting bond. Is not this so ?

I have heard of men not daring to call their souls their own, but I never knew a man before Mr. W- who openly professed that he did not. I think it is vain to try to work with men, however good, who have lost the religious sentiment."

"October 4. Since I wrote the above, I have had two most encouraging talks, one with Mr. Clarke, and one with Mr. Champion. Mr. Clarke is one of the thorough men, perfectly honest and simple, and he is with us. Mr. Champion was delightful, took the matter seriously, and promised to encourage his friends to go into the matter. Curiously enough, he and they have been thinking of the same thing. Champion is full of native religious feeling, and has some very practical notions. He took away my paper, the old programme, and your 'First Principles' to show to his friends, and will tell us shortly what is the result. As soon as I hear I shall arrange a meeting here, omitting the men of little faith. I am anxious to see you, and to bind again the broken threads of our progress." ...

In another undated letter written from Chelsea shortly afterwards, the following occurs :

"It is all in vain to imagine that we can have correct practice without correct thinking, and correct thinking implies correct metaphysics. ... A A life in which the deepest and highest thought was indifferent in relation to practice would 
be a life without intellectual endeavor, and without poetry. ... Is not the deepest of all bonds, and the purest intellectual sympathy, community of insight?"

Writing as one about to leave England and the circle of friends he had made in the New Fellowship, he said he "disdained all pretentions to leadership." Of one of the members he wrote: "There is a power of soul deep down in him, an infinite human tenderness that almost fascinates me. If you will work with him, you will find him a hero."

On October 20, 1883 , he wrote:

"Since I saw you I have read most of Hinton's Man, and his Dwelling-place. Hinton was plainly a man of genius, and of a great soul; but he lacked analytical power, at least when that book was written. He insisted upon the eternity of the spirit, but could not see what was involved in that admission. He seemed to think that something might 'happen' to the eternal at death.

You think, and rightly, that your 'action must be true,' but you are wrong in thinking that that is synonymous with 'must be determined by things as they are now.' In the true there is no now. Your action can be true only when it relates to things as they are in their eternal nature. There is no 'true,' except with reference to the eternal. I would give much if I could make you see that. 'Is' itself has no. meaning except as applied to the eternal. This is the reason why I keep repeating that we must build all moral and spiritual life upon the eternal and the metaphysical, and not upon the now or the then. Will you study Rosmini for a year or two? Will you give your spare time to him? If you do, I think you will see that he can reveal to you the 'unknown God' of Hinton. I have a note to-day from Mr. Channing, in which he speaks of Rosmini as 'the grandest, wisest, and profoundest philosopher of our age'; and he is right, Rosmini's analytical power was never equalled. 
You can now guess my answer to your second query. I say the habits of every one, children as well as others, are to be regulated with reference to their eternal essence, and not merely with reference to an abstract now, a word which can have no meaning except in relation to eternity. And by eternity I mean not endlessness, but the correlate condition of time, that which makes time possible. The moral law reads, 'Act with reference to the eternal.'

I agree most cordially with you when you say that the recognized things are not the good things; but $I$ am curious to know what you think the good things to be. I suspect you think they are the enjoyment of each passing 'now,' and entire self-forgetfulness. Here I cannot agree with you. To me they are the enjoyment of the eternal, and continual sacrifice of the temporal self to the eternal self. Morality means that, and nothing but that. But we must be careful not to fall into Buddhism and suppose that we are to sacrifice an eternal self to a monistic self in which all distinction is lost, and in which sacrifice of self would cease to be possible. Hinton continually falls into this grave error. The eternal is not the formless, and the unindividuated. It is the individuated, and eternally formed. You and I are eternal forms, whose inexhaustible taste with reference to each other is to penetrate each other through inexhaustible love and knowledge. ' God is love.' God is the loving, knowing interpretation of eternal forms. $\mathrm{He}$ is joy, life, light, 'letizia che trascende ogni dolzore.' We must never forget that. He is the ideality of which we are the reality. But if the reality should cease, so likewise would the ideality. $\mathrm{He}$ is the object to which we are subjects, infinite in multitude. As I have said often, He is the 'law of being,' and in that law we live and move and have our being. These are the convictions that inspire me: they are my life. Without them I should not care to live at all ; indeed I could not, in any wise sense, live at all. And if I can fully realize my cternity in this life, death will be of no 
consequence to me; indeed it is of very small consequence to me now. When a man has realized his eternity, flesh and blood are only obstacles to him, to his best efficiency. ..."

“ 75 Via Nazionale, Roma,

November 30,1883 .

... That this world is the only actual and eternal one is so plainly not true that I cannot imagine any serious man maintaining that it is. Either he is talking paradox intentionally, or else he does not know the meaning of the word he is using. Mr. Hinton plainly was in the latter predicament.... The truth is 'this world,' - the world of phenomena and change - is not actual at all, much less is it eternal. . . . We must distinguish the actual from the real, the eternal from the continuous. ... To say that 'everything of real spiritual value may be attained in this world' is to use words without meaning. The only thing of spiritual value is eternal self-possession, and to say that this can be attained in time is as untrue as anything can be. What is the use of an attainment that is lost the instant it is attained? For whom, or for what, is it attained? Are we mere rockets whose aim is to rise to a certain brilliant height, only to fall back instantly, like a stick into the dark? Those who say so are utterly and totally blind to the true life of the soul....

That the moral law is 'Act with reference to the eternal' is to me the deepest and most momentous of all truths. ... We must withdraw into the eternal, and work from that into endless time. For eternity is by no means endless time. Eternity is that in which there is no succession possible: endless time is the form of infinite succession. I do not see how two things could be more different, or how any difference could be more clear.

If the New Life means the destruction of habits then I have no desire to live it. My great aim in life is to form habits, permanent habits; e.g. habits of kindliness, habits of 
truthfulness, habits of openness, habits of painstaking, habits of breaking up habits when they are no longer useful. . . .

Life is not mere emotion, nor is there in emotion anything moral or immoral, else the lower animals would be as moral or immoral as man. There is an intellectual life as well as an emotive one, and it is the former alone that is distinctively human. I know how strong the tendency is, in these sentimental dallying days of ours, to lay stress upon emotion, and all forms of passivity, to the detriment of intelligence, insight, and all forms of heroic activity. This is even the curse of our time.... We cannot see what is essential without metaphysics. Without metaphysics there is no knowledge of essence, and we float upon a sea of unanalyzed sentiment and unrecognized tradition, without helm or compass. ..."

On February 18, 1884, he wrote from Rome that "to confound the eternal with the phenomenal is to me the worst of heresies."

Some reminiscences of his friend furnished by Mr. Havelock Ellis follow in the next chapter. 


\section{CHAPTER VIII}

\section{REMINISCENCES BY HAVELOCK ELLIS}

It was in the autumn of 1883 , when I was a medical student, that my friend Percival Chubb spoke to me with enthusiasm of the approaching visit to London of one Thomas Davidson, who had just published a book containing a new interpretation of the Parthenon, and was now arriving from Italy where he had been spending the summer in a house he had taken in Capri. A little while before, Chubb had spent some time with Davidson, and at this period regarded him as destined to become the moral regenerator of the modern world. It appeared that Davidson was willing - even eager - to gather around him a few young men in London, and to expound his ideas of "the new life." I soon met him at Chubb's rooms, and this proved the first of a series of meetings at which Davidson met various young men, - seldom more than one or two at a time, - many of whom afterwards became better known. Davidson was most at his ease in the presence of two or three young men whose attitude he believed to be sympathetic and receptive, and to whom he could set forth his views with a chance of finding active and intelligent disciples. His doctrine - at this time at all events - may be stated in a few words, as the absolute necessity of founding practical life on philosophical conceptions; of living a simple, strenuous, intellectual life, so far as possible communistically, and on a basis of natural religion. It was Rosminianism, one may say, carried a step further. He appeared to advantage on these occasions; his vivid personality, his intense earnestness, restrained eloquence, and personal magnetism were all brought to the service of his convictions concerning the necessity for a 
metaphysical basis to life. I use the word "conviction" deliberately. At bottom he, consciously and avowedly, based his metaphysical theory on an emotional conviction; and I still recall the fervor with which he would solemnly assure us that the universe answered to his description of it.

It was on his conviction, not on his knowledge, that Davidson asked us to rely. Of his learning he never made any parade; and I do not think it even occurred to me, at that time, that he possessed any unusual degree of learning. I noticed, indeed, that he was always interested in every subject I chanced to bring before him. I was at that time giving much attention to the writings, published and unpublished, of James Hinton; he was also interested in Hinton, and anxious to read a paper I had written on him, a paper which he pronounced - and I am not sure that there was not here a touch of deprecation - "very judicial." I chanced to refer to my friend and neighbor Roden Noel. "I am always hearing about Roden Noel," he said ; "tell me about Roden Noel." Again, I had made an analysis of In Memoriam a few years previously. That poem, he declared, had been a profound study of his own ; and contained, indeed, the whole of his philosophy. It so happened that William Morris was coming to read portions of his Sigurd at one of the meetings of a sort of ethical society, in which I was interested. Davidson admired Morris, and we asked him to preside at the meeting. I well remember the characteristically earnest and fervid way in which Davidson told how he had first read Morris's Earthly Paradise in a remote district of America; and the singular impressiveness of an incidental but very characteristic passage, in his remarks concerning the depths of misery to which he has sunk who has become "aweary of the sun." There was no affectation in this; it was merely an aspect of Davidson's eager, devouring interest in all the manifestations of life. I failed then to realize that had my own interests been different, or wider, I should still have found Davidson equally well-informed, and equally anxious to learn more. 
Doubtless he was not a scholar in the scientific sense of the term. He recalls, rather, those men of the Renaissance of whom Giordano Bruno was the supreme type, wandering philosophers who spent their lives in going from one great center of thought to another, devoured by intellectual passion, equally eager to learn and to teach. ...

I met him at a later date when passing through London on one of his mysterious missions, this time to Constantinople; and I remained associated with the Fellowship of the New Life, - a movement for putting social life so far as possible on an ethical basis, - which had grown out of Davidson's meetings with young men already mentioned. From the Fellowship of the New Life there split off, soon after Davidson left London, - as an attempt to be more practical, and more definitely socialistic, - the Fabian Society, which was destined to have a much more vigorous public life than the smaller parent association. There was no antagonism between the two societies, but with the Fabian Society Davidson himself had little or no sympathy, although he was, indirectly, the founder of it.

He failed to make me a disciple, but he taught me a lesson I have never since unlearned. Before I met him I thought that philosophical beliefs could be imparted, and shared; that men could, as it were, live under the same metaphysical dome. Davidson enabled me to see that a man's metaphysics, if genuinely his, is really a most intimate part of his own personal temperament ; and that no one can really identify himself with another's philosophy, however greatly he may admire it, or sympathize with it. This was a valuable lesson to learn, though it was not the lesson that Davidson desired to teach.

Davidson was never able to estimate accurately the inherent obstacles to the progress of his own schemes, nor to realize how they appeared to other minds. It was thus inevitable that he should meet with frequent disappointments and disillusions, although his energetic temperament enabled him to 
preserve an attitude of optimism. I can well believethough I have no definite personal knowledge - that this characteristic of his sanguine temperament sometimes led to misadventures. But, while he was never accurately adjusted to his environment, and constantly liable either to shock or to be shocked by it, he had no deliberate love of freedom. When he startled the peaceful school of philosophy at Concord by his comparison of the irony of Zola to the irony of Christ, he was himself surprised at the commotion he produced. He probably conceived that he was giving expression to an obvious verity.

It was as a personal force, rather than as a profound intellect, that Davidson made his mark on his time. It was this temperamental character that gave a curious, almost unique, imprint to his personality. He was well aware of his own emotional tendencies: I remember that he once referred to the attraction that mysticism had for him, as an attraction he had to guard against. Many of his characteristics were doubtless due to a certain struggle with his own exuberant emotionalism. His sense of the immense importance of education, training, and discipline, was rooted here. Doubtless, also, a certain formality in his literary work showed that he wished to keep a curb on himself. But the result was that Davidson never reached self-expression in literature. His personality - with that specially perfervid Scottish quality, which he possessed in so high a degree - was much more potent than his works indicate. The enthusiasm and conviction, with which he advocated more or less impossible and unfamiliar ideals, could not fail to exert a stimulating influence on all those who came near him. He helped to teach those who listened to him to think, even though it were to think that he was wrong, and to think why he was wrong. Few men, indeed, of his time were permitted to play a part so like to that of those early Greek philosophers whom he loved so greatly. 


\section{CHAPTER IX}

\section{THE NEW YORK BRANCH OF THE NEW FELLOWSHIP}

One of the first things that Davidson did when he reached New York was to found an American "Fellowship of the New Life" ; not exactly a branch of the English society of that name, but one similar in character, aims, and tendency. It was founded in I884, and as its prospectus contains a declaration of principles, differing in some points from that set down in the London programme, it may be reproduced with advantage, along with an official statement on the religion of the Fellowship, and a letter from its founder concerning the "Vita Nuova."

\section{Declaration of Principles}

\section{Name AND Domicile}

The Name of the society shall be THE Fellowship of THE NEw LIFE, and its Domicile shall be wherever two or three persons animated by its spirit shall unite and meet.

\section{SPIRIT}

The Spirit of the Fellowship, in all its sayings and doings, shall be intelligent love, that love which Jesus meant when he commanded his disciples to love one another, that love whereof the fruits are "joy, peace, long-suffering, gentleness, goodness, faith, meekness, temperance," and perfect purity and simplicity of life.

\section{PURPOSES}

The Purposes of the Fellowship shall be the cultivation of character in the persons of its members, and the attainment of whatever follows from high character. The ideal of character shall be perfect purity or holiness, including perfect intelligence, perfect love and freedom - 
that freedom which springs from perfect obedience to the divine laws of the spirit. Truth and love alone shall have authority in the Fellowship, and in all cases the material and fleshly shall be subordinated to the spiritual.

\section{METHOD}

The Method of the Fellowship shall be coöperation for the ends of holiness. Unwilling to stand or fall with the success or failure of any practical undertaking, it shall not, as a body, identify itself with such, but shall seek to remain a center of religious life and inspiration. At the same time, it shall encourage its members to form, in connection with it, and in its spirit, societies which shall do practical work in the way of lecturing, teaching, discussing and in other ways aiding in the elevation of all whom they can reach.

\section{BRANCHES}

The Fellowship may have branches wherever persons are willing to unite on the basis of its spirit, purpose, and method. Each branch shall regulate its own affairs.

\section{The Religion of the Fellowship of the NEW LIFE}

The Fellowship of THE New Life is essentially a religious society, that is, a society whose members seek to order their lives in accordance with the Supreme Will (by whatever name it may be called - God, Holiness, Intelligence, Love), in so far as that can in any way be ascertained. Its religion, however, in contradistinction to other religions, is purely one of attitude ; attitude of the whole human being, mind, affections, will. It seeks, through the persons of its members, to be receptive toward all truth, whatever its mediate source, responsive with due love toward all worth, and active toward all good. It believes that this triple attitude comprises the whole duty of man, and that this belief is at once the all-sufficient and unassailable creed. For, surely, no one can doubt that every human being ought to pursue all truth, to love duly all that is lovable, and to further, as far as he may, all good. And, again, the man who did these three things, would be performing his whole duty as a man. In one word, it may be said that the religion of the Fellowship consists of a determined endeavor to know well, to love well, and to do well.

In endeavoring to know well, the members of the Fellowship, far from depending solely on individual reason or experience, seek light 
and aid from every quarter ; from every age and people; from religion, science, and philosophy; from nature and art; from reason and faith. Knowing that their own mental and moral status, the very conceptions by which they interpret experience, and the thought by which they unite them into a known world, as well as the language by which they express all this, are not their own products, but are the outcome of a process of mental unfolding dating back far beyond the dawn of recorded history, and are to be understood only through a knowledge of this process, they can look only with pity upon those persons who, having no comprehensive acquaintance with the history of human conceptions, rashly undertake, with their crude notions, to pronounce upon the great problems of life and mind. They are, therefore, neither dogmatists, skeptics, nor agnostics, but reverent students of the world of nature and of mind, seeking to supplement their own experience and conclusions with the experience and conclusions of the serious men and women of all time. Inasmuch as they are not called upon to accept any special beliefs, but only to be honest and circumspect with themselves in accepting any belief whatever, it follows that no honest belief or unbelief need prevent any one from being a member of the Fellowship. The man who finds cogent reasons for believing in the doctrines of transubstantiation and the immaculate conception, and the man who finds it impossible to attach any definite meaning to the word God, are equally in their place in the Fellowship, provided they are equally sincere. But sincerity is not possible apart from a living desire for ever deeper insight, and a sympathy with those who sincerely hold opinions different from our own. There is no sincerity in accepting or maintaining a belief that has not been tested to the limits of our powers. The proper names for such acceptance are credulity and fanaticism. Knowing how often it happens that old and long-exploded doctrines reappear in new forms and become for a time fashionable, by reason of popular ignorance, the members of the Fellowship are not liable to be found among the followers of new prophets, or the purveyors of patent remedies for social ills. Their aim is to stand firm on a basis of knowledge amid the tumultuous sea of conflicting popular prejudices.

In their endeavor to love well, the members of the Fellowship seek to love wisely, - not only to cultivate the power to love, but to distribute love in proportion to the spiritual worth of things. Just as only a feeling, thinking being can truly love, so only a feeling, thinking being can properly be loved; and the deeper and broader the feeling and thought which being has, the more it is a being, the more it is capable of loving, the more worthy to be loved. Mere indiscriminate loving, vague philanthropic sentiment, and enthusiasm for abstractions, such as 
humanity, law, etc., it rejects as unprofitable and wasteful. True love is that which seeks the highest good of its object, and rejoices in that good. It is merely another name for a desire to realize and abide with perfection.

By doing good, the Fellowship means acting in accordance with the best knowledge and the widest, most discriminating love. It is only when a man has his head and heart well trained that he can act well. Without a comprehension of the end of all action, and of the various tendencies of different actions, he will act blindly from prejudice, passion, or impulse ; without well-regulated sympathies, all his actions will have a wrong emphasis and hence be abortive. Such wrong emphasis we see in all those philanthropic movements whose chief aim is men's physical comfort and the indiscriminate removal of that powerful natural corrective, suffering. With such movements the Fellowship, realizing how beneficial suffering may be, has no sympathy. Better to suffer and be strong, than to be comfortable and weak. While the Fellowship seeks to foster coöperation for good works, it hopes for its best results from individual character and effort. It seeks to avoid all publicity and to do its work quietly and unobtrusively in the hearts of men. It calls upon each of its members to be a living power for good, not only in one way or in one connection, but in all ways and in all connections, in the smallest things as well as in the greatest. Its ultimate aim is the good man and the good woman, the intelligent, loving, vigorous character, that seeks good and good alone.

Such is the Religion of The Fellowship of THE New Life, such attitude its only bond of union.

\section{EXTRACT FROM A LetTer From Mr. DAvidson CONCERNING THE NEW LiFE}

The way to begin the New Life, I believe, is to try to forget oneself, one's sorrows, one's annoyances; to count oneself happy, if he can have the approval of a good conscience and the sense of having furthered the good. The New Life, as I conceive it, is a new attitude of the intelligence, the feelings, the will - a desire to lay aside all prejudice and to know the absolute truth, a wide, sweet sympathy, recoiling at no sin, no suffering, no hardness of heart, but only at selfishness and meanness and lying, a firm resolution to do the best, as far as that is known, in the spirit of love. Such a life, $I$ know, is worth living. It is a life in which all wounds soon heal, and all scars are but brands of victory - legal tender for future blessedness. 
But the New Life is, in its outward form, more than this. It is an association for the cultivation of true insight, boundless sympathy, and devoted helpfulness. It is the absence of these that makes the old life so blind, so dreary and lonely, so unblest. Every human being ought to be a providence to every other, ready, as far as his powers go, to solve every dark problem, sympathize with every joy and every sorrow, however deep and agonizing, and satisfy every need. We are still living in willful ignorance of our own nature and in barbarous isolation with respect to each other. We wither in silent pain because we have not confidence in each other. In our agony we invent a God to do for us what we are too miserable and selfish to do for each other. We are so sluggish that we try to make a virtue of faith, instead of laboring earnestly to find out and communicate the truth. We are so selfish that we allow our neighbor to suffer, when we have the means to help him. We are so low spiritually that we doubt the infinite possibilities of being, and sink down into a contented or discontented materialism. We do not rise to a firm and abiding sense of our own dignity and infinite worth. All this, I hope, will be altered in the New Life, whether I succeed in doing anything to further it or not. I have only a clear insight as to what is necessary and a desire to do the best I can. I see that, if ever life is to be again wholesome and inspiring, we must have a new social order and a new education; an order in which each shall feel the burdens of all, and all of each; an education which shall aim at producing perfect characters, rich in insight, in love, in energy, scorning selfishness, impurity, and wrong.

I see no way in which these things can be reached but through a strong, combined effort on the part of those that firmly and earnestly believe in them, through a society, realizing in itself and in the relations between its members, that ideal which it recognizes as the highest. Such a society cannot be formed in a day, nor by any general vote or resolution. It must be done slowly and quietly, through the gradual formation of a nucleus of earnest men and women, resolved to live a noble life and to make the redemption of humanity from ignorance, selfishness, and vice the end of all their efforts, and ready to search out and communicate the means whereby this may be done. In the great work we need association, with division of labor. There must be some to discover principles, others to apply them; some to teach, others to labor with their hands. What we can do at present is to keep these ends steadily in view and try to make them clear to others; to interest other people in them and to form little societies for the study of the highest things, for religious sympathy, for mutual aid. All this we can do now - to-day - before to-morrow. 
And what if it be true that all great attainment calls for suffering, that such is the law of our being? Shall we slink back and tremble, and drug ourselves, like craven cowards? Never! The pure metal rings when it is struck, and the true soul finds itself and its own nobility often only in the throbs of pain and utter self-sacrifice. One true act of will makes us feel our immortality: alas! that we so seldom perform an act of will. In the face of an act of real will, heredity counts as nothing. What makes heredity tell is our own cowardice and sluggishness in not forcing children to conquer it, and also in not conquering it in ourselves. Heredity, like corruption, acts only when the soul is gone. It is utterly debasing to be bullied by heredity. The belief in its power "shuts the eyes and folds the hands," and delivers the soul in chains to the demon of unreality. The reason why people doubt about the freedom of the will is because they never exercise it, but are always following some feeling or instinct, some private taste or affection. How should such persons know that the will is free? Our time is dying of sentimentality - some of it refined enough, to be sure, but sentimentality - which destroys the will.

We are on our way to all that heart ever wished or head conceived. But the greater gods have no sympathy with anything but heroism. When we will not be heroic they sternly fling us back to suffer, saying to us: Learn to will! The kiss of the Valkyre, which opens the gates of Valhalla, is sealed only upon lips made holy by heroism even unto death.

The hosts of Ahura-Mazda are still fighting, and woe to us if we do not join them! It is the custom among the wise men of the world to laugh at all great heroism, all thirst for self-sacrifice; but we can afford to let them laugh. Somewhere in the shadow there are spectators who laugh at them, and will laugh when these have lost the will to laugh. The sons of Ahura-Mazda laugh forever, and there is no uneasiness in their laughter. Their laugh is the beauty of the universe.

But this will, perhaps, weary you and seem mere poetry to you. Poetry it is ; but, as Aristotle said long ago, "Poetry is more earnest and more philosophical than history." The true poetry of the world is the history of its spiritual life, and is as much truer than what is called history as spirit is truer than outward seeming. When shall we learn this?

Several societies for study, instructions, and practical work in connection with the Fellowship were soon organized, and series of lectures arranged. 
The prospectus of the seventh year gives a list of papers read, followed by discussion on "Theories of Ethics." Seven were devoted to ancient ethics, two to mediæval, and sixteen to modern ethics. That of the eighth year gives a list of twenty-five addresses and discussions on the "History and Science of Religion." 


\section{CHAPTER $\mathrm{X}$}

\section{THE SUMMER SCHOOLS AT FARMINGTON AND GLENMORE}

To carry out the idea of summer study - in philosophy, literature, sociology, and religion - away from the turmoil and distractions of city life, Mr. Davidson selected the small New England town of Farmington, where he gathered together a few friends in the year 1888 .

Farmington is thus described in the prospectus which he issued at New York :

\section{FARMington}

Farmington is a quaint, old, shady New England town, overlooking the Farmington and Pequabuck rivers, and affording beautiful and extensive views in many directions. It is on the New Haven and Northampton Railroad, about 30 miles from New Haven, 46 from Northampton, and 10 from Hartford. The town is about two miles from the station. The rugged hills and broad valleys about Farmington afford excellent opportunities for pleasant walks, rides, and drives, while the rivers are very convenient for bathing and boating.

The following is the prospectus for the third year (I890). The experiment lasted for three years. In 1891 it was absorbed in the school at Glenmore.

\section{Farmington Lectures on Philosophy and Ethics r 890 (third year)}

The First Morning Course will be devoted to the Philosophy of the late Professor T. H. Green. This philosophy takes a bold stand against the agnosticism and materialism of the time, seeking to show their inconsistency and insufficiency, and to replace them by a doctrine of reason and spirit, offering a solid basis for religion and ethics.

The Second Morning Course will treat of Functions of a Church and its Relation to the State. The six lectures will be given by six 
different persons representing as many different views, and will form a kind of symposium.

The First Evening Course will be devoted to the Greek Moralists, -(I) Eschylus, (2) Socrates, (3) Plato, (4) Aristotle, - and will attempt to show how the Greeks gradually rose from the conception of a life governed by external fate and authority to that of a life guided by internal insight.

The Second Evening Course will deal with Some of the Primary Concepts of Economic Science, - (1) Wealth, (2) Value, (3) Property, (4) Land, (5) Labor, (6) Capital, - and will aim at clearing these of the vagueness which at present attaches to them, and showing that they involve a recognition of man's moral nature. It will follow from this that economics cannot be divorced from ethics.

After each lecture an opportunity will be given for free discussion in which it is hoped that all persons present will take part.

\section{Morning Courses}

\section{The Philosophy of T. H. Green}

June 17. Green's Theory of Cognition and its place in the History of Thought. By Thomas Davidson of New York.

June 18. Green's Treatment of the Relation of Feeling to Reality. By H. N. Gardiner, Professor of Philosophy in Smith College, Northampton, Massachusetts.

June 19. Green's Ethical System. By Stephen F. Weston of New York.

June 20. Green's Ethical System viewed in its Relation to Utilitarianism. By W. Douw Lighthall, B.C.L., of Montreal, Canada, author of The Young Seigneur, Sketch of a New Utilitarianism.

June 23. Green's Political Theory. By Percival Chubb of London, England.

June 24. Green's Religious Philosophy. By John Dewey, Ph.D., Professor of Ethics, History of Philosophy, and Logic in the University of Michigan, author of Psychology, etc.

\section{The Relations of Church and State}

June 25. The Politico-Philosophical View. By Professor John Dewey, Ph.D. 
June 26. The Free-Religious View. By Reverend W. J. Potter, D.D., of New Bedford, Massachusetts.

June 27. The Historical-Philosophical View. By W. T. Harris, LL.D., Commissioner of Education, Washington, D.C. Editor of the Journal of Speculative Philosophy, etc.

June 30. The Humanitarian View. By H. D. Lloyd of Chicago, author of The New Conscience, etc.

July I. The Scholastic or Roman Catholic View. By Brother Agarias of the Brothers of the Christian Schools, New York, author of The Culture of the Spiritual Sense, etc.

July 2. The Unitarian View. By the Reverend A. N. Alcott, of Elgin, Illinois.

\section{Evening Courses}

I. The Greek Moralists

(By Thomas Davidson)

June 17. Eschylus. The Ethical Interpretation of Mythology.

June 18. Eschylus. Ethical Theory. Man's Relations to Family, Society, State, and God.

June 19. Socrates. The Relation of Intelligence to Moral Freedom.

June 20. Plato. The State as the Embodiment of Reason and Justice.

June 23. Aristotle. The Good. The Golden Mean. The Ideal Life. June 24. Aristotle. The State as a School for Life.

\section{Primary Concepts of Economic Science}

June 25. Wealth. By Percival Chubb.

June 26. Value. By W. M. Salter, Lecturer to the Chicago Society for Ethical Culture, author of Ethical Religion, etc.

June 27. Property. By Percival Chubb.

June 30. Land. By Stephen F. Weston.

July I. Labor. By Stephen F. Weston.

July 2. Capital. By W. M. Salter.

During the summer of 1889 , while the work was going on at Farmington, Mr. Davidson and a few friends informally visited the district of the Adirondacks, above and beyond the village of Keene, in order to prospect the locality, and see if 
it was a more suitable place for the formation of a summer school of study, than Farmington had been. In the succeeding year (1890) the scheme matured, although it still remained in a tentative state, and the following prospectus was issued.

\section{A Summer Course of Study in the ADIRONDACKS}

Last summer a small number of persons gathered at Glenmore, in the Adirondacks, and freely arranged their days in a way which was found to yield at once rational enjoyment, instruction, and physical exercise. The mornings were devoted to private study and reading, the afternoons to exercise - walking, driving, mountain climbing, tree felling, etc., and the evenings either to the discussion of some important work upon philosophy, art, ethics, or religion, or to music. Many of these evenings were spent round a camp fire. Among the works thus discussed in whole or in part were :

(I) Aristotle's Nicomachean Ethics.

(2) Professor Robertson Smith's Prophets of Israel.

(3) Professor Drummond's Philo-Judaus, or the Jewish Alexandrian Philosophy, in its Development and Completion.

(4) Goethe's Faust (three lectures).

(5) St. Bonaventura's Soul's Progress in God.

(6) T. H. Green's Prolegomena to Ethics.

(7) Mr. Edward Carpenter's England's Ideal.

(8) Mr. W. M. Salter's Ethical Religion.

The advantages of spending the summer in this way were so great that it has been proposed this year to extend them to a larger number of persons, that is, to offer them to all serious students, and particularly to teachers, who may desire to pass an agreeable and profitable summer at a very moderate expense. The instruction will consist of private aid to study, and of lectures. The former will be given in the forenoon, or during walks in the afternoon; the latter on four evenings in the week, and on Sunday morning. Three evenings a week Wednesday, Saturday, and Sunday - will be devoted to music and conversation. For the present the subjects of study will be limited to what, in contradistinction to the natural sciences, may be called the culture sciences - philosophy, religion, ethics, economics, politics, art, language, and literature - and their history. The choice to be made this year among these will, in large degree, depend upon the 
wishes of intending students and the capacity of obtainable instructors. It will materially aid the directors in making out their programme if intending students will communicate their preferences to the secretary as soon as possible.

Provision has already been made for instruction in the theory and history of philosophy, religion, ethics, economics, politics, art (Greek sculpture and piano music), language (comparative philology, Greek, ancient and modern, Latin, Italian, French, German, Anglo-Saxon, and Old Norse), and literature (Homer, Æschylus, Sophocles, Lucretius, Dante, Shakespeare, Goethe, and the English writers of this century).

The summer course will be divided into two parts, one covering July and August, the other September and October. The fees for instruction and lectures will be low, but must depend somewhat upon the numbers who attend. About April a detailed programme will appear, giving all necessary particulars in regard to instruction, accommodation, travelling, camping out, etc. Meanwhile persons desiring further information are requested to communicate with Thomas Davidson, 239 West 105th Street, New York.

\section{Glenmore}

Glenmore is a farm of one hundred and sixty-six acres, on East Hill, in the north end of Keene valley. It lies in the wilderness, on the foothills of Mount Hurricane, about two thousand feet above the sea level. Of its very uneven surface two thirds are covered with forest, while one is under cultivation. The farm is traversed by a large trout brook of the most picturesque kind, and is remarkable for the number of cold springs which water it. The neighborhood offers every opportunity for healthy exercise of all sorts. The scenery of the whole region is grand, and much of it can be enjoyed from different points of the farm. The air is pure and bracing and the heat moderate. Mosquitoes are rare. Altogether, it would not be easy to find a more delightful summer retreat.

I have seen the prospectuses for the seasons I890, I89I, I 892, I893, and I894. It is unnecessary to extract anything from them except a portion of the statement issued for sessions I89I and I892, the lists of "Lectures and Interpretations" (as they were called) by Mr. Davidson. The latter may be useful to many a lecturer of the future; they are therefore included in the appendix to this volume. 


\section{Glenmore School}

The subject of culture is man's spiritual nature, his intelligence, his affections, his will, and the modes in which these express themselves. This culture includes a history, a theory, and a practice, a certain familiarity with which must be acquired by every person who seriously desires to know his relations to the world and to perform his part worthily in those relations. The aim of the school, therefore, will be twofold, - (I) scientific, (2) practical. The former it will seek to reach by means of lectures on the general outlines of the history and theory of the various culture sciences, and by classes, conversations, and carefully directed private study in regard to their details. The latter it will endeavor to realize by encouraging its members to conduct their life in accordance with the highest ascertainable ethical laws, to strive after "plain living and high thinking," to discipline themselves in simplicity, kindliness, thoughtfulness, helpfulness, regularity, and promptness.

In the life at Glenmore an endeavor will be made to combine solid study and serious conversation with reinvigorating rest and abundant and delightful exercise. It is hoped that this may become a place of annual gathering for open-minded persons interested in the serious things of life, so that, being thrown together in an informal way, they may be able to exchange views and initiate sympathies better than in the class room or at the hurried annual meeting. The retirement and quiet of Glenmore seem especially favorable for such things, and the numerous picnics and evening bonfires in the woods offer provision for the lighter moods. Last year two plays were acted by members of the school, and it is hoped that a Greek play may be brought out this year.

The members of the school will have access to a large, well-selected library. Every meal at Glenmore will be opened with a few minutes' reading.

In the Scottish Review for January, 1892 , there is an article by Professor John Murray of Montreal, entitled "A Summer School of Philosophy," which gives an interesting account of the work at Glenmore. The first summer school, which was an American invention, was held at Concord, in Massachusetts, where the editor of the Journal of Speculative Philosophy, Mr. Harris, now the United States Minister of Education, took an active part, along with Thomas Davidson and others. It was pioneer work, and its success led 
Davidson to attempt a somewhat similar school at Farmington, in Connecticut. For several reasons the second experiment did not succeed so well ; and a third was started, and carried on with fresh missionary zeal by its founder, at Glenmore, in the Adirondacks. Glenmore is some twenty miles west of Westport, on Lake Champlain, and two thousand feet above the sea level, at the northern end of the Keene valley. The attractions of the scenery were great, hill and dale, field and forest intermingled. The original farmhouse of Glenmore was bought, with extensive acreage around, and additional wooden cottage buildings were put up, while some of the students camped out in tents. Interesting descriptions of the place and its attractions are given by some of the students in these pages (see Chapters XI and XII). The teaching session lasted only for the two months of July and August, but arrangements could be made for earlier or later residence. It was a home of simple living, assiduous study, and bright fellowship. There was a morning call by horn at half-past seven, breakfast at eight o'clock, preceded by two or three minutes' reading by the dean. Lectures began at half-past nine. Two were given in the forenoon and one in the evening, each followed by half an hour's familiar discussion of the question that had been raised. The subjects of lecture were various; for example, Aristotle's Metaphysics and Politics, Hegel's Philosophy of Spirit, The Comparative History of Religion, Spenser's Faërie Queene, Tennyson's In Memoriam, The Psychology, the Ethics, and the Metaphysics of the Will. In the lecture room the following device was inscribed on the

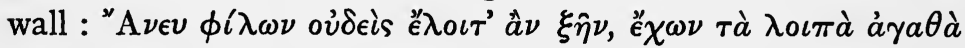
$\pi a ́ \nu \tau a$ (Nic. Eth., VIII, I) (Without friends no one would choose to live, even with all other good things). Perhaps the chief characteristic of the teaching given in this school was the thorough discussion of the great books themselves - the books that were referred to and commented on, not the mere reading of a written commentary upon them. There were 
conversational lessons in French, German, and Italian. Then there were afternoon walks, Saturday rambles, and evening concerts. There was no pedantry of any kind. Unconventionality reigned. Students dressed in easy summer attire. There was no display and no flirtation. The stimulus of the life of the place was immense.

One of his student friends at Glenmore writes to me:

"When I first met Thomas Davidson he was interested in the Nationalist movement, a kind of socialism that had arisen from the publication of Bellamy's Looking Backward. He left it immediately afterwards, because his name had been published with regard to some action in connection with it, without his being consulted ; and he afterwards became antagonistic to every form of socialism, considering that it was a return to militarism, and subversive of true liberty of the individual. . . .

There were inconsistencies in his likes and dislikes; e.g. I sometimes wondered why he objected to Marcus Aurelius, and to Matthew Arnold. Kind as he was to children, he was a stern disciplinarian; and nothing roused him more than to hear it said, 'Poor child, let her have a good time!' A time of laziness, a do-nothing-ness was a bad time. He occasionally made fierce attacks on frivolity in conversation as indicating low aims in life, and so unsparing was his censure of it that women students sometimes thought it scarcely polite!" 


\section{CHAPTER XI}

\section{RECOLLECTIONS OF GLENMORE BY MARY FOSTER}

The work of Thomas Davidson in his Summer School of the Culture Sciences at Glenmore can best be recorded by those who were pupils, or comrades, in it. I therefore give that record very largely in the words of those who were members of that school, rather than weave their detached reminiscences together in a restatement of my own. Two of the women students - Miss Mary Foster and Miss Charlotte Daley - have sent me extensive notes from which I make extracts, Miss Foster's notes being concerned more especially with the daily life at Glenmore, and Miss Daley's with the teaching.

Miss Foster spent four summers at the school, and knew most of the people who surrounded Mr. Davidson in these years. From her paper, which she calls "Mr. Davidson and the Life at Glenmore," I take the following:

"I first met Mr. Thomas Davidson in New York in I890, and at a meeting of the New Fellowship I made acquaintance with the friends who had entered actively into his endeavors after higher aims in life.

In the previous year Mr. Davidson had purchased a farm at East Hill, near Keene in the Adirondack Mountains, and a preliminary informal meeting had been held there that summer. He was now about to go up into the mountains to prepare the camp, which he had named 'Glenmore,' for a more formal gathering of students; and with this in view the members of the Fellowship presented him with a large tent, for use until additional buildings should be put up and 
made available for such guests as desired outdoor life during their sojourn.

It was an interesting experience to come into contact with this group of people and their remarkable leader, devoted as they all felt themselves to be to high social and intellectual ideals. Their hope was by individual effort to promote simplicity of life, together with a sincere pursuit of truth, and by association to increase their capacity for such work. 'The Religion of the Fellowship consisted,' they said, 'of a determined endeavor to know well, to love well, and to do well.'

Mr. Davidson was in many ways eminently fitted to devise and carry out such a scheme, being endowed not only with a remarkable personality but with a power of influencing others intellectually which I have never seen equaled.

I have always felt that the first year at Glenmore (in I889) must have had a peculiar charm of its own, the charm incident to pioneering. The community 'waited on itself' to a much greater extent than in later years, and there seems to have been a very pleasant feeling of fraternity among them. The farmhouse parlor had to be used as lecture hall, dining room, and general sitting room; and I think that many of the guests slept in the barn on balsam boughs. The ladies often made pillows of the balsam needles, while reading was going on ; and they all experimented in cooking and washing. In the afternoons they united in such undertakings as deepening the bathing basin in the brook, cutting through the fallen trunks on the Hurricane trail, and clearing certain spots in the woods of old stumps and underbrush so that social gatherings could be held, or tents erected there. There was also the whole surrounding region to be explored, and choice spots were to be discovered and opened out.

Many of the evenings were spent round a camp fire, and works on Philosophy, Art, Ethics, and Religion were freely discussed. Other evenings were devoted to music, or recitation; 
and all the proceedings were on a less formal scale than was necessary later on, when the number of students had increased.

It was in the third year of the work at Glenmore that I paid my first visit to the place. I went up the Hudson by boat, then by train from Albany to Westport on Lake Champlain; thence a drive of about twenty miles carried me into the heart of the mountains, through lanes thick with flowers and ferns, to the hearty greeting awaiting me at Glenmore.

The only buildings at first noticeable were the log farmhouse, a plain modern building opposite, - which was the dining hall, with four bedrooms over it, built in 1890 , - and an old barn. Some friends, who were lodging in the farmhouse, received me, while a servant blew a horn; upon which Mr. Davidson descended the hundred and twenty foot declivity, from his abode in higher regions, to add his warm welcome. I was immediately invited to ascend the hill to the lecture hall ; this could be done by the steep face of the cliff, or partly by the road leading to the trail up Mount Hurricane. One thus reached a level open space, in the front of which, and commanding a magnificent view of the mountain and valley, the lecture hall had been erected that spring. Like all the other buildings it was of wood. It contained a spacious room having a large open fireplace, with dogs for burning large logs, and a brick chimney. Behind this, on the south side, were two bedrooms, and stairs ascending to Mr. Davidson's private rooms, which opened on a large veranda, and also to seven other bedrooms designed for the accommodation of guests. On two sides of the building there was a wide piazza, where hammocks could be swung. From here, later on, we often watched the sunset clouds or the aurora borealis, and listened to the boys' singing of college songs. A few paces to the south, in the shade of the wood, was the simple two-roomed cottage in which Mr. Davidson had lived two summers with Mr. Percival Chubb. 
The road by which I had come led immediately into the woods clothing the ravine (or gulf, as it was called) and made a gradual descent, crossing the stream below by a picturesque bridge; then, doubling upon itself, it passed in front of the Willey House, a local hotel, and descended parallel to the stream, until it reached the village of Keene - the post and shopping town - I IOo feet below.

Just above the bridge was the meeting place of two streams, and in the main stream further on was an island, the space round which had been cleared of underwood and fallen branches. Here, under high trees and among rugged boulders, with the brook leaping by in a series of small cascades, wooden seats had been constructed, and it was amid such surroundings that festive gatherings were held. Directly above this spot the bed of the brook had been deepened so that an excellent basin for bathing was formed. That it was not spacious enough to swim in mattered little, since even in the warmest weather the water, running under trees all the way from its numerous sources, was of so low a temperature that no one could remain in it for many seconds at a time. For a quick plunge, however, it was most invigorating and delightful, and the basin was a favorite resort.

I arrived on June 26 , and found a fair number of guests already assembled. Several ladies had built cottages for themselves on the estate. There were two of these halfway up the hill, between the farmhouse and the lecture room, and at the top of a clearing on the north side was a hut, afterwards owned by Dr. W. T. Harris. Several more sprang up later and added much to the picturesqueness of the settlement. On the margin of the gulf Mr. Stephen Weston's tent was pitched. Two boys with their tutor occupied another, and Professor John Dewey had built a house on his own land low down on the other side of the stream.

The school opened on July I, and lectures were given in the mornings of five days in the week at IO and II.I 5 A.M., as 
well as in the evenings at 8 P.M. Meals were served in the dining hall, breakfast being at 8 A.M., dinner at I P.M., and supper at 6 P.M. Dairy produce, eggs, and wild fruit were abundant, but meat was sometimes difficult to get, and by many deemed unnecessary in the pure, bracing air of the mountains.

On the first Saturday - a day when no lectures took place - there was a housewarming at the lecture hall. This was decorated for the occasion, chiefly with various trailing species of club-moss common in the woods, and a bonfire was lighted outside.

Mr. Davidson's Sunday lectures were on Tennyson, Goethe, or Dante. He also gave some readings, and the singing of hymns or poems was arranged before the lecture. Sometimes at these Sunday gatherings he would expound a psalm, or other portion of the Hebrew Scriptures.

People staying at the Willey House, or summer boarders at any of the neighboring farms, would also attend, so that there was quite a large congregation. The inhabitants of the district were all either Roman Catholics, or Seventh-Day Baptists, and there were no places of worship except of these denominations. Even when the school was no longer in session, Mr. Davidson always gave some teaching on Sundays, generally in the evenings, to the smaller audience that still surrounded him.

On Saturdays, if there was no festive function at Glenmore, the guests could arrange excursions to the lakes, mountains, and waterfalls of the district. Lake Placid, Whiteface Mountains, Ausable Lake, John Brown's grave, and many other places of interest were within a drive ; and a neighboring farmer had set up an extra 'team' to accommodate the guests on these occasions, as well as to fetch them to and from the station.

The walks in the immediate vicinity were also very delightful. Opposite Glenmore, beyond the Willey House, 
were two round-topped hills, called Great Crow and Little Crow. Irreverent students of the first year at Glenmore had attempted to fix upon them the names of Soda and Potash, much to the disapprobation of Mr. Davidson, who suggested Ben More and Ben Ledi. On the edge of the woods that crowned Little Crow was a huge boulder as big as a small cottage, with wooden steps by which to ascend it.

On rare occasions a general walk or stroll would be taken, with the privilege of Mr. Davidson's company; and it was then amusing to notice the behavior of his beautiful collie, named Dante, who, true to his instincts as a shepherd's dog, did all he could to keep the party together, and objected to their straying or lagging behind.

In these regions very little wheat or barley is grown, but buckwheat and oats are common, and on every farm we saw long rows of Indian corn. Between these rows pumpkin vines flourished, and in the autumn left their splendid golden balls over the whole field.

The primeval forest still held full sway on the more remote slopes of the hills, but near the farms the younger growth consisted of the paper birch, the common poplar, spruce firs, and the sweet balsam firs. Pine trees were not so common. At the borders of the woods there were maples and other soft-wood trees.

By I893 a new dining hall had been built, and on the walls were hung many interesting pictures, with portraits of people who had come into contact with Mr. Davidson. All these perished in the fire that destroyed the block of buildings a few years ago.

It was outside this building that we assembled for the eighto'clock breakfast, and the guests were not often visible before that hour. Occasionally an early bather might be seen, or those few who invited health by walking barefoot in the dew, a delightful practice inaugurated by a German doctor, who had been at Father Kneipp's sanatorium in Austria. In the 
first years a horn, as used on the farms around, and later, a bell, summoned the visitors from tent, cottage, and lecture hall to breakfast. All meals were preceded by a brief reading by Mr. Davidson from some work on Ethics, Philosophy, or Religion. By 8.30 we were away at our studies, or tidying up our dormitories, until Io o'clock, when the lecture began, often with a second at I I o'clock. Dinner was at I o'clock, after which Mr. Davidson and many of the party took a short rest before engaging in further study, or in the outdoor exercises of the afternoon. There were plenty of charming places for hammocks among the trees, and sometimes private-study groups met in the woods or at some one's hut. Supper was at 6 o'clock, leaving more spare time, which was often employed in watching the sunset, and in talking or singing until the hour for the evening lecture. The students were not expected to attend all the lectures, five a week being the minimum exacted of them. Young people, not sufficiently advanced for the courses in Philosophy and in the Culture Sciences, were expected to pursue other studies under the tuition of some of the older members.

In the short American summer evenings it was generally dark when lectures were over, so that lanterns were necessary. Dr. Mann proved himself a benefactor to the community by making a better path through the wood that lay between the lecture hall and the lane, and by adding a railing at one side. This bore the inscription at the foot, "The Ascent of Man,' and at the top, 'The Descent of Man.'

After the session of the school was over, and while perhaps eight or a dozen guests still lingered at Glenmore, Mr. Davidson would give many delightful informal talks on matters philosophical. It is never to be forgotten how in those quieter times we sat listening to his conversation at the breakfast table, sometimes for two hours after that meal was really over, - a delight that was never ours when many guests were present. 
The delivery and the dispatch of letters were irregular at Glenmore, and few cared whether or not they got any newspapers. For our mail we depended upon the convenience of the neighboring farmers, who frequently had errands to Keene; or upon the willingness of some guest to walk down the I Ioo feet into the valley, and to return through the silent woods after nightfall, a weird and impressive experience.

Saturdays were, as I have said, our free days, and they were often devoted to long walks. A favorite excursion was the ascent of Mount Hurricane, the trail up which passed through Glenmore. There were three miles of walking along a narrow forest path with occasional crossings of a rushing stream, till you reached a height, often swathed in clouds, where the lichens hung thickly on the trees, and the mosses underfoot were deep. At the last spring, before leaving the woods to ascend to the summit, we used to stop to fill our water cans. Then we would emerge upon the open face of a mountain 3763 feet high, whence one of the finest views in the Adirondacks is to be obtained. Toward the north lies Canada; Lake Champlain and the hills of Vermont are to the east; while on the south, and west, a splendid range of local mountains stretches before you. The botanist can enjoy the Alpine vegetation which is to be found at this height.

Sometimes a party arranged to sleep on the summit of Hurricane, so as to see both sunset and sunrise. Blankets were brought up, and the boys collected fir branches for beds, and other wood to keep a fire during the night. There were several bonfires each summer on the island near the bathing place as an accompaniment to singing and other entertainment. A few concerts were also given in the lecture hall, at which the songs of Scotland were sung; and occasionally Mr. Davidson indulged us with his inimitable recitations of Scottish ballads. One year he gave a charming account of the life and poetry of Lady Nairne, illustrated with music. Discussions were also held on special subjects, such as free 
will, socialism, and vegetarianism. It was an interesting occasion when the boys at Glenmore gave a masquerade in the woods round the spring, near which Mr. Davidson's bungalow was afterwards built.

Mr. Davidson often entertained, under his own roof, friends from Keene valley or the Willey House, as well as the students at Glenmore; and there was frequent interchange of courtesies between our camp and friends near St. Hubert's, Keene Heights, twelve miles off, where many members of the 'Ethical Society' surrounded Dr. Felix Adler. They had a lecture hall in which Mr. Davidson was in request, and he used to speak there at least once in the summer.

It was in the early summer of 1893 that Mr. Davidson's bungalow was built in a retired spot in the wood on the other side of the trail from the lecture hall. It was finished before the school opened, and those who were spending June at Glenmore helped him to carry across his extensive library. A path less abrupt than the very steep one to the farmhouse was needed, and another one diverging from it to the lecture hall. These works were undertaken by some of the residents. Trees were cut down, and the path along the sloping side of the hill was shored up. Large stones were found to bridge the rivulet that trickled down by the side of the lane, and pathways were soon made for philosophers to walk in.

An open glade stretches along the crest of the hill from Mr. Davidson's bungalow to the east, and it is on the border of this that his body now lies buried. In the autumn the place is a blaze of golden-rod, and there is a picturesque rock at the further end where harmless snakes make their home. Part of this glade is very swampy, and at night fireflies may be seen pursuing the small water insects that rise from it. The carriage way to Mr. Davidson's house crossed this swamp in an uncomfortable and unsafe manner; and it occurred to the members of the school to build a wooden bridge, which would not only improve the road, but be a pleasant feature 
in the landscape. Large trees were felled by Mr. Davidson, Dr. Edward Moore, and others; while the ladies sawed smaller branches into lengths suitable to form crosspieces in corduroy fashion. The railing on each side was constructed in an elaborate pattern of the choicest branches of paper birch that could be found, and finally a Virginia creeper was brought up from the valley to grow over it.

It is not easy to sum up the methods and results of Mr. Davidson's teaching. Delightful as a lecturer, he was even more charming in conversation. A strong personal magnetism enabled him to become a welcome vehicle for the conveyance of truth and the disclosure of wisdom.

In the years 189 I to 1895 , when I saw most of him, he discoursed much on the universality of Spirit, and on the necessity for each individual to evolve an ordered world in his or her own consciousness, the ethical life depending on the completeness and harmony of such a world.

His aim in organizing a school of philosophy was to impart the instruction of which he felt that the educated classes stood so greatly in need; and he wished to do this in healthy and beautiful surroundings, under simple conditions of life. He hoped that the good of the whole school would be striven after by each individual, and that through mutual helpfulness, and by pursuing work and pleasure together, an unselfish spirit would be fostered. He used to refer to the ideal of life among the Greeks, pointing out that this implied the free enjoyment of life apart from its practical side; which included such things as earning a livelihood, politics, education, and religious observances. On the other hand the ideal life was a contemplative one, and was to be distinguished from mere play and amusement; there was no phrase he objected to more than 'having a good time.' All free enjoyment was to be rational. It was not easy to get together many people who were able to live up to this ideal ; and it must be feared that the embodiment of his School of the Culture Sciences fell far 
short of his conception of what it should have been. But it is certain that, in the course of his busy life and frequent travels, he came into contact with many individuals who derived much inspiration from his teaching and conversation; and that they were by him imbued with a new, and higher, conception of their responsibilities in life." 


\section{CHAPTER XII}

CHARLOTTE DALEY'S RETROSPECTS OF DAVIDSON'S TEACHING

Miss Charlotte F. Daley, West New Brighton, Richmond County, New York, was a student-friend of Mr. Davidson, and she has supplied me with reminiscences from which I make some extracts. She has voluminous notes of the lectures of her master, and has written an account of the manner and method of his teaching, as well as of what she has called the "psychological foundations of education and society." As I have made use of other accounts of his " manner and method," in this chapter I shall in part briefly summarize, and in part transcribe, what Miss Daley has sent me as to the matter of his teaching. He taught her, she says, that "a true Science and a true Philosophy are two phases of the same thing; and that we cannot have either the one or the other without having both, although they are neither identical nor separable." His first principle was "a fundamentally two-phased being and becoming-to-be; neither of which can be identified with the other, or divorced from it."

I have two letters from Miss Daley, from which I extract the most relevant paragraphs. Other passages I have summarized, as I could not print the letters as a whole.

"Dear Mr. Knight :

I first met Mr. Davidson at the Concord School of Philosophy in 1884 , and ever since that time I have been his pupil, though not his disciple. He refused to have disciples, insisting that every one should 'think whole-thoughts' for himself. 
He was not a system-builder, and he purposely left no fully elaborated philosophy. "There have been too many systems of philosophy already,' he said to me. 'In the very nature of things there can be nothing final. It is not my duty to draw conclusions for any one. What I want to do is to help people to think for themselves, and to think round the circle, not in scraps and bits.'

He was too scientific a scholar merely to memorize a book, or a system of philosophy, without self-verification, and he exhorted his pupils to work in the same spirit. He was the most truly religious man, and at the same time the freest thinker, that I have ever met. He was the one, because he was the other. I think that the first two chapters of his History of Education, read in connection with three other papers, the first on Intellectual Piety, the second on Education as World Building, and the third on American Democracy as a Religion, with a few abstracts from his $K^{\prime}$ 'usseau, will give a clear insight into his first principles, his psychological and theological foundation. Mr. Davidson was not trying to develop a new system of Philosophy, nor to establish himself as an authority, but to be a thinker and actor, and to help others to think and act. He held that every human being should be a philosopher ; that is, should strive to know what is the ultimate ground of that which is, and not attempt to reason from insufficient knowledge."

In a second letter Miss Daley says :

"I can tell you something of what Mr. Davidson taught, and I send you a syllabus and bibliography of his conversationlectures on The Origins of Modern Thought. ${ }^{1}$ I speak of these because Mr. Davidson taught us that one of our chief needs to-day is the investigation, in a fearless and truth-revering spirit, of those ancient concepts on which the modern world is sustained.

1 See these in the appendix to this volume, page 215. 
In the lectures to his class, and in his conversations with the several members, Mr. Davidson outlined the history of thought in the western world, showing the source of much of it in the eastern. I am at a loss to say which was the more valuable side of his work in these lectures, the manuscript notes from which he read, or the oral commentary which accompanied them. In both he had no resemblance to the ordinary college lecturer, and he was the only teacher I ever had who did not condescend to the alleged incapacity of a woman's mind. Both in class and in conversation he brought out the fundamental characteristics of ancient and mediæval life, and by contrasting these with the essential principle of modern life-especially that upon which the United States as a nation is based - suggested lines of social reform which our mediævalism prevents us from either seeing or applying.

Mr. Davidson held, and taught, that society has reached a stage which demands not only a revision of economic concepts, but a restatement of all the concepts upon which its life is based, for we are in a new world. It is man as man, with a higher human and divine consciousness, that now demands consideration before the supreme court of reason. Our failure to deal successfully with our present conditions is due to an antiquated notion of what man is, and what he is destined to become; so that a radical reform, a complete upclearing is necessary. The best hope of our time is not in its existing philosophy. It is rather in the new interest that is taken in children (in whom we can study scientifically 'origins' as well as (developments '); and in psychology, although it must be admitted that we have a somewhat soulless psychology. But this is largely because most people will not ask fundamental questions.

In the course of a lecture on Goethe's Faust Mr. Davidson said : 'The great Mephistophelian error is to think the primitive condition of a thing is its true condition.' In stating his own view he frequently made use of Aristotle's conception of 


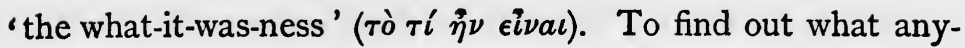
thing really is, is to find its 'what-it-was-ness.' But when engaged in this search, he would say to us, 'Don't throw upon the present the darkness of the past, but throw back upon the past the light of the present. It all comes to this : we find in the highest spiritual society that now is the developed essence, the evolved root-principle, the what-it-was-ness of the lowest. To say - as some psychologists do - that nature reveals no spiritual intent, while we arbitrarily exclude from nature its highest manifestations, is fatal alike to adequate knowledge and to a comprehensive view of education. We must always remember that the supernatural is the higher natural.'

Passing from theoretic to more practical matters, I have heard Mr. Davidson accused of arriving, in his later years, at negative conclusions. I saw him grow, from much with which he began to more with which he ended, through nearly seventeen years of advancing experience. He certainly reached conclusions which contradict the opinions of those who imagine it possible to make a final inventory of all that is embraced in self, or God.

On one occasion he said, 'Nothing can free the intellect and enable it to act with perfect liberty, except clear, unwavering insight; it is that which distinguishes worth from worthlessness. ... Truth is entirely independent of you and me; it is our business to find it out.' Again, 'Truth is the correlate of knowledge; you can't know anything that is n't true, and yet intellect is the cause of truth itself.'

He wrote: 'By intellect as distinct from reason I mean the primitive faculty which grasps the essential and ideal unity of the universe, which makes it possible for us to transform our groups of sensations into things, and look at them as something distinct from and independent of ourselves; in other words, to look at them as objective. ${ }^{1}$ Though Kant

1 See Intellectual Piety; also Education as World Building. 
ruined the language of philosophy by putting reason above intellect, he was the founder of all modern thought that is worth anything. In the history of philosophy he was the successor of Socrates. Twist and turn as we please, there is no getting away from Kant's conclusion that without the power of the mind to make its world we could have nothing but chaos. ... We make our world - not, observe, the world that the body lives in - when we have intelligence of, or predicate anything of, the outer world. We begin not with construction, but with reconstruction. When we have intelligence of ourselves we predicate being of feeling. Intellect says, This is, or this ought to be. Desire says, Would that this were. Will says, Let this be done. The will, as will, is not free, although freedom exists. Intellect is the freeing power; and it is folly to talk of free will, so long as we have not free intellect. Obligation constrains the good will through intelligence and love, or through love guided by intelligence.

Furthermore, note well that you cannot separate the human from the divine, and place them over against each other, as Xenophanes set the one and the many, the relative and the absolute; as Plato set the ideal and the real; as the Hebrews before Christ set God and man; and as dogmatic Christianity has tried to set them. God and man are correlates, and correlates, as I have repeatedly said, are neither identical nor separable. There cannot be a man without a God; and man is as necessary to God as God is to man, or there could be no revelation or manifestation of either. In the existence and the corelationship of the finite and the infinite, we have a fundamental dualism, but we have it also in that double concept of the self which runs through all the social world. "Thou shalt love thy neighbor as thyself," our love for self being the form by which to measure what we owe in love to our neighbor; but we cannot do this unless in practice we obey the precept "Know thyself !" We stand here between the personal - and more than personal - God on the one 
hand, and our neighbor on the other ; and it is sheer hypocrisy to claim that we love God while 'we do not love our neighbor as ourselves.'

Although Mr. Davidson tried to show that in the very nature of things there can be no final system of Philosophy, he has left us a better psychological and theological basis than we possessed before ; and in the forming of these fundamental principles he was helped by the great thinkers of all ages. He made use of Bonaventura's ${ }^{1}$ fine philosophy, and Rosmini's keen insight, but he did not accept all their conclusions. $\mathrm{He}$ had received much from our ancient Jewish heritage, and seemed to know the Hebrew Scriptures by heart, as well as the New Testament. The pre-Socratics were not a 'rubbish heap' to him. He knew them all, and used them step by step, as well as their mediæval and modern successors.

I wish it were possible to follow the evolution of the world's thought as he unfolded it to us, but I am mainly anxious to emphasize his conclusion, which was this, that each one of us may say truly, 'I am a two-phased sensibility, modified in innumerable ways by influences which I do not originate.' The whole question of obligation and responsibility begins here. We do not originate these influences, but we react upon them. We do not construct the outer world, but we reconstruct it, and we begin to reconstruct it as soon as we perceive it. 'Strange is that blindness of the intellect,' says Bonaventura, 'that does not consider that which it sees, and without which it can know nothing! . . '

Sincerely yours,

$$
\text { Charlotte F. Daley." }
$$

1 He translated Bonaventura's Soul's Progress in God, and sent it to the Journal of Speculative Philosophy, July, 1887 . 


\section{CHAPTER XIII}

\section{LECTURES TO THE BREADWINNERS}

The aim of this experiment in New York to bring some culture into the lives of working men and women, "the breadwinners," as Davidson called them, is best unfolded in his own words. Referring to the lectures which he gave to the Russian Jews at the Educational Alliance in East Broadway, on the "Problems which the Nineteenth Century presents to the Twentieth," and the private discussions which followed the lectures, he wrote:

"In these discussions I had come to know to some extent the character, aspirations, and needs of the young people whom I undertook to instruct. I saw that they were both able and earnest, but carried away by superficial views of a socialistic or anarchist sort, greatly to their own detriment and to that of society. My first object, therefore, in taking up this class was to induce its members to study and think out carefully the problems of sociology and culture, in accordance with the historic method, and so to impart to their minds a healthy attitude towards society, to do away with the vengeful sense of personal or class wrong, and to arouse faith in individual effort and manly and womanly self-dependence. I desired, moreover, to give them such an outlook upon life as could lift their lives out of narrowness and sordidness and give them ideal aims. Finally, I wished to train them in the use of correct English, both written and spoken. My method of instruction consisted in gaining their confidence, and making them do as much as possible. I also tried to impart impetus, and give direction. In spite of a little distrust on their part at first, I soon gained their confidence, and even their affection; 
while they performed the tasks set them with a will and perseverance that were really admirable."

The class from which his pupils came were working tradesmen and tradeswomen of the Jewish community, some of them exceedingly poor; but, as one who knew them put it, they "represented the best element amongst the Russian Hebrews, who, though poor, have the scholarly instinct of the race, intense loyalty to their people, and an ideal beyond worldly success." The same chronicler writes, "He said to a friend a short time before his death that he thought the whole of his life had been a preparation for just this work."

The fact that a Thomas Davidson Society exists and flourishes in New York, and that it is even more ardent in the pursuit of the ideals he set before it than it was in his lifetime, is the best tribute to him that could possibly exist ; nobler far than any temporary fame as a writer of books. The tie which united lecturer and audience was that of teacher and taught; and the teacher-friend used occasionally to invite these city pupils out to his summer home in the mountains, where their delight in nature, and the free, unsophisticated life of the place, was intense. One of them, writing to friends in the New York home he had temporarily left, dated his letter " Heaven, Aug. I4th, etc."

No better account of the New York experiment has been given, and no more authoritative one is possible, than that contained in an address on "Some Ideals and Characteristics of Thomas Davidson," delivered by Mr. Morris R. Cohen, the continuator of his work, at a memorial meeting held in East Broadway, on October 26, I90I. As it contains portions of letters written by the founder of the school to his classes, I cannot do better than republish part of it. Mr. Cohen wrote :

"Those who knew Thomas Davidson will understand that it is utterly impossible to give anything like an adequate 
summary of his life or character. The life of a truly great man cannot be ticketed or labeled. Nevertheless, there are certain traits of his character which are especially significant for those of us who are trying to continue his work.

To my mind his most fundamental characteristic was that he lived philosophically on a truly large scale. He lived for the really great things of life; and stood far above the petty issues, and the petty rewards, for which the multitude is always struggling. He refused to be dragged into any of the insignificant muddles of the day, but constantly strove to be on the great streams of reality. None but the highest enjoyments and motives had any existence for him. Above all, he judged actions by their eternal results. He lived for eternity; and that is why the effects of his life cannot die.

The life of Thomas Davidson was essentially a heroic life. Though as I knew him, one of the most sympathetic souls that ever trod this globe, he had no sympathy with anything unheroic. He had a generous faith in human nature, believing that there are heroes and heroines now, more than ever before, to be found in every street and on every corner, and that it is only our own blindness that prevents us from appealing to the heroic in them. It was just because he led this large life, and expected it of every one else, that it was more than a liberal education in itself to have been intimately acquainted with him; and we cannot do better than attempt to continue his work, judging ourselves by the standards by which he would have judged us, and thus stimulating ourselves to ever greater hopes and tasks.

There is a tendency nowadays, especially among 'practical' people, to look down upon all attempts to grapple with the deep problems of existence. Mr. Davidson showed in clear and unmistakable terms that it is only sheer sloth and cowardice that can urge us to declare certain problems insoluble, before we have exerted all our efforts to solve them. And he also showed how absolutely futile must be any attempt to 
solve our problems as 'East-Siders' without taking into consideration our problems as men and women. Now as ever the commandment holds true : 'Seek ye the kingdom of God, and his righteousness, and all the rest shall be added unto you.'

He taught that the highest reverence is due to human reason; that the highest duty is to search for the truth with unbiased mind; and that the highest courage is to follow the truth always and everywhere, regardless of where it may lead us.

With all his deep erudition he did not overestimate the value of learning. He was interested in knowledge only as a motive to right living. He insisted on our becoming acquainted with every branch of human knowledge, - Science, Philosophy, Art, and Literature, - but only because they help us to lead rational lives.

$\mathrm{He}$ also realized that mere knowledge alone will not enable us to solve the profound problems of life ; that sympathy is an essential part of a right attitude to the riddles of the universe. You must tune up your heart to catch the music of the spheres. But above all he realized that we do not truly know until our so-called knowledge is tested in real life, that life cannot be learned merely in the study without experience in the arena of life itself, that wisdom is not to be obtained from text-books, but must be coined out of human experience in the flame of life.

This is what led him to the idea of establishing a Breadwinners' College. In his letters to the class he pointed out the great defect in the ordinary College and University education, viz. 'that it stops with knowing, and does not go on to loving and doing. It therefore never is really appropriated, for knowing that does not pass into act and habit is never ours, but remains an external thing, a mere useless accomplishment, to be vain about.' ' If every one of you,' he wrote to us, 'would translate his or her knowledge into love and work, [then] we should have an Educational Institute, a 
Breadwinners' College - call it anything you like - such as the world has never yet seen, an Institution which will teach men and women to become public-spirited, generously cultured, pure and high-minded, an institution which will help more than anything else to banish ignorance and moral poverty.'

Such an Institution Thomas Davidson wanted us to form, and such an Institution will be formed if we are true to ourselves. . . .

Our own little society already does something to combine the advantages of the College and the Church with those of the home. We form a School in so far as we help each other to master the world's wisdom and learning - a Church in so far as we encourage each other to form and to live up to the highest ideals - a Home in so far as we try to cultivate among ourselves those deep, cordial relations which unfortunately are seldom found outside of the home.

In one of his earliest letters to us Thomas Davidson writes : - There is nothing that the world of to-day needs so much as a new order of social relations, a new feeling between man and man. We may talk and teach as long as we like, but until we have a new society with ideal relations and aims we have accomplished very little. All great world movements begin with a little knot of people, who, in their individual lives, and in their relations to each other, realize the ideal that is to be. To live truth is better than to utter it. Isaiah would have prophesied in vain had he not gathered round him a little band of disciples who lived according to his ideal.... Again, what would the teachings of Jesus have amounted to had he not collected a body of disciples, who made it their life-aim to put his teachings into practice ?' $\mathrm{He}$ was bold enough to think that the new view of the world, the modern scientific view, makes it possible 'to frame a new series of ethical precepts which should do for our time what the Deutronomic Law did for the time of Isaiah, and the 
Sermon on the Mount for that of Jesus.' And he was even more bold to state his conviction that 'it is impossible to reach a better social and moral condition, until we have rationally adopted an entirely new view of life and its meaning; a new philosophy truer and deeper than any that has gone before.'

To those who are a little skeptical he says: "You will perhaps think I am laying out a mighty task for you, a task far above your powers and aspirations; but it is not so. Every great change in individual and social conditions - and we are on the verge of such a change - begins small, among simple, earnest people, face to face with the facts of life. Ask yourself seriously, Why should not the coming change begin with us? You will find that there is no reason why the new world, - the world of righteousness, kindliness, and enlightenment, for which we are all longing and toiling, - may not date from us, as well as from anybody.' 'A little knot of earnest Jews has turned the world upside down before now. Why may not the same thing - nay, a far better thing happen in your day and among you? Have you forgotten the old promise made to Abraham, "In thy seed shall all the nations of the earth be blessed "?' Quoting from Lowell,

We see dimly in the present what is small and what is great, Slow of faith, how weak an arm may turn the iron helm of fate,

he added, 'It may be our weak arm if we will it.'

It was this large outlook, based on history and philosophy, which made Thomas Davidson despise all our modern palliatives, and petty remedies, for social ills. He had no sympathy with the efforts of those who, not knowing how to educate the masses of the people, offer them petty amusements to keep them off the streets and away from the saloons. He did not believe in trifles. He stood for the highest culture for the breadwinners, for the people who have to 'go to work' early. He was convinced that the way to lift the people above their degrading and vicious lives was to give them an intelligent 
view of the world, which will offer them an inspiring outlook on life. 'One intelligent glimpse of the drama of life,' he said, 'will quench all the desire for the pleasure of the dive and the prize ring.' The whole history of education, according to him, points to the educational institution of the future as the Breadwinners' College, where culture will be learned by the great body of the people who are engaged in the actual business of life; and who, becoming early acquainted with 'life's prime needs and agonies' are far better prepared for true education than the idle young men who attend our ordinary Colleges and Universities. The Breadwinners' College will be an institution which will teach a man to take an intelligent view of his surroundings, of what goes on in the world and has gone on in it, and will thus help him to lead a simple, upright life, useful, tasteful, and above all, self-respecting. Then only will he be fit for the various personal, domestic, political, and social duties demanded of the complete man. Without an intelligent outlook on society (based on the study of its history) it is impossible to take an intelligent interest in it, and hence our corrupt politics; without an understanding of the meaning of the great institutions under which we live, men are not fit to become their supporters. Only by dispelling ignorance as to the vital questions of life can we hope to make the lives of men possessed of meaning and dignity.

There is another characteristic of Thomas Davidson which ought not to be left out of sight, and that is his rare tact, - the skillful way in which he managed to hold the balance between opposing forces, between Individualism and Socialism, between freedom and order, between the old and the new. His expressions indeed sometimes leaned one way and sometimes another, but at bottom there was an unshaken equipoise. Some thought him an extreme individualist. And indeed he did champion the integrity of man against all idols. In this practical and scientific age there is a tendency to lose sight of the individual 
man amidst natural forces and scientific laws. He boldly stood by that characteristically Hebrew saying, 'The Sabbath was made for man, not man for the Sabbath.' He recognized that science, institutions, and doctrines exist for man, and not man for science, institutions, or doctrines. He regarded the individual man as a holy temple, and believed that nothing in the universe was holier. Yet he was the last man in the world to underestimate social action. He realized full well that every soul which has found what it deems higher truth must seek to form an association, to found a brotherhood, in order to realize that truth. Without such an organization little can be done, for unless we can stand strong in the sympathy of a band we are apt to fall back into accustomed paths.

He knew how to hold the balance between the old and the new. This is perhaps best shown with reference to our more immediate problems of the East Side. The most important practical question on the East Side is undoubtedly the strained, I might say the tragic, relation between the older and the younger generations. The younger generation has, as a rule, been brought up under entirely different circumstances from those of its elders, and therefore naturally entertains radically different aims and ideals. The older generation does not sympathize with these new ideals, and in the ensuing giscord much of the proverbial strength of the Jewish family is lost. This is fraught with heartrending consequences. When the home ceases to be the center of interest the unity of life is broken, and the dreariest pessimism and cynicism may follow. Of course our elder and wiser friends tell us that the fault is entirely with the younger people - but that does not solve the problem. You cannot and must not expect the younger people to become false to their own best insight at the very entrance of life!

Thomas Davidson taught us to see in this conflict a manifestation of the feud between the old and the new which has 
shaped history. He impressed upon us the necessity of taking an honest position in this conflict, respecting the rights of both. He pointed out to us that we have no right to break away from the past, until we have appropriated what we can of its experience and wisdom ; and he also taught us to recognize that there is a law of love besides the law of truth, and that the former has its rights even besides the latter. But while we must aim to understand the position of the old and to sympathize with it, we must hold on to what seems to us the higher truth. He taught us to be reverent to the past, but above all to be loyal to the future, to the Kingdom which doth not yet appear.

In the words of Tennyson :

Not clinging to some ancient saw,

Not mastered by some modern term,

Not swift nor slow to change, but firm:

And in its season bring the law,

That from Discussion's lip may fall

With Life, that, working strongly, binds -

Set in all lights by many minds,

To close the interests of all."

In the memorial volume on Davidson by Professor Charles M. Bakewell, his friend and literary executor, entitled The Education of the Wage-Earners, a Contribution toward the Solution of the Educational Problem of Democracy, by Thomas Davidson, there is a very full account of this great experiment in New York City, the larger part of the volume (Chapters II, III, IV, and V) being in Davidson's own words. The fifth chapter contains an excellent introduction on his life and philosophy; and the sixth, and last, traces the story of the movement after its founder's death.

Before reading this book, the preface to which is dated August 5, 1904, I had received from Mr. Cohen a paper written by Mr. Davidson in September, r899, which explains his aims and ideals; and, although much of it is stated in 
another form in Mr. Bakewell's book, those who are interested in the movement may welcome a briefer outline in the words of the founder. It is as follows :

\section{“The Higher Education of the Breadwinners}

September, 1899.

It cannot be said of our people that they are backward or niggardly in the matter of education. In no country is so much money expended upon schools and colleges as in the United States. And yet our people are very far from being educated as they ought to be. Ignorance is still widespread, and not only the ignorant, but the whole nation suffers in consequence. In spite of our magnificent system of public schools and our numerous colleges and universities - over five hundred in all - the great body of our citizens lack the education necessary to give dignity and meaning to their individual lives, and to fit them for the worthy performance of their duties as members of the institutions under which they live. Our public schools stop short too soon, while our colleges do not reach more than one in a thousand of our population. Moreover, neither school nor college imparts that education which our citizens, as such, require - domestic, social, and civic culture. What is imparted is defective both in kind and in extent.

There are three kinds of education, which ought to be distinguished, but which at present we do not distinguish with sufficient care: (I) culture, that is, the education necessary for every human being, in order that he may be able worthily to fulfill duties as a member of social institutions ; (2) professional training, necessary for the earning of a livelihood; (3) erudition, demanded by those who would advance science, or give instruction in it. It is regrettable that both in our schools and in our colleges these are hopelessly mixed up, and that the first receives but scanty attention. 
Even more regrettable is the fact that our schools and colleges, for the most part, confine their attention to persons who have nothing to do but study, who are not engaged in any kind of useful or productive labor. This results in two evils : (I) education, for the great body of the people, must stop at an early age, since the children of all but wealthy families must go to work as soon as possible, few of them reaching the high school, fewer yet the university, or professional training school ; (2) education is withheld just from those who are in the best position to profit by it; for every teacher with sufficient experience knows that people who have a knowledge of practical life and its duties are far better and more encouraging pupils than those who have not.

It thus appears that social and civic culture is largely neglected in our educational institutions, and that it altogether fails to reach those who are best fitted to profit by it. In a word, the culture calculated to make the wise and good citizen is almost nonexistent. We have good artisans, good merchants, good doctors, good lawyers, etc., in abundance, but we have few persons of liberal culture, and still fewer who can worthily fill important offices in society and state, or who can even cast an intelligent vote for such. Fewest of all, those who understand how their lives affect the general welfare, whence the money they earn comes, and whether or not it is an equivalent for benefits conferred upon society.

Thus it comes to pass that the lives of the great mass of our citizens are unintelligent, narrow, sordid, envious, and unhappy, and that we are constantly threatened with popular uprisings and the overthrow of our free institutions. Thus, too, it comes that our politics are base, and our politicians venal and selfish. The laboring classes are, through want of education, easily cozened or bribed to vote in opposition to their own best interests, and so to condemn themselves to continued slavish toil and poverty, which means exclusion from all share in the spiritual wealth of the race. 
There is, at the present time, perhaps no individual problem in our country [so pressing] as that of the higher education - the intellectual, moral, and social culture - of that great body of men and women, who, from a pretty early age, have to spend the larger portion of their time in earning a livelihood. These include not only the working classes so-called - the skilled and unskilled laborers - but also the great majority of the wage-earners of every sort, and not a few of the wage-givers. All these need a larger world, a more ideal outlook, such as education alone can give, not only to impart meaning and dignity to their life of toil, but also to enable them to contribute their share to the well-being of society, and prevent it from falling back into violence and barbarism.

It is true that, in the last few years, considerable efforts have been made to provide the breadwinners with opportunities both for professional training and for higher culture. In our larger cities "university extension" has been introduced, training schools have been opened, and evening schools and lectures on a large scale established. Of these efforts there is nothing but good to say. They are, however, a promise rather than a fulfillment, a beginning and little more. They must be greatly extended and systematized before they can meet the needs of the breadwinners. The training schools are, of course, an unmixed good, and we only require more of them; but the university extension, to a large extent, imparts a sort of education that is not demanded, and fails to give much that is demanded, while both it and the evening classes and lectures are deficient in system and unity of plan. Neither has a distinct aim, and neither sufficiently controls the work of the pupils. Worst of all, both exclude from their programmes some of the very subjects which it is most essential for the breadwinners to be acquainted with - economics, sociology, politics, religion, etc. 
Of the three kinds of education, the breadwinners need only two,-(I) technical training, ${ }^{1}(2)$ intellectual and moral, or social training. ${ }^{2}$ The breadwinner, if his work is to be effective, and equivalent to a decent livelihood, earnable with a moderate expenditure of time and energy, must have skill; otherwise he will have neither time nor energy left for any other sort of education. Spare time and energy are prime elements in the whole question. In any just order of society each member will receive from society a just equivalent for what he contributes to it. If he is so unskilled that his work is not equivalent to a livelihood, he has no right to complain when he suffers want. It must therefore be the aim of every one who would humanize and elevate the breadwinners to see that they have skill enough to earn their daily bread without depriving themselves of free time, and energy to devote to living and spiritual culture.

Supposing now that all the breadwinners were in this condition that, being able to earn a living in, say, eight hours a day, they had considerable free time; they might still remain uncultured and sordid, their tastes vulgar or depraved. They might still have little rest and joy in life, little inspiring outlook. They might still not be valuable members of society. We have not done our whole duty by the breadwinners when we have made them comfortable, - we must go further and make them cultured and wise.

Now what must be the nature of such culture and wisdom? We may answer, Such as shall enable their recipients to play a worthy and generous part in all the relations of life and to

1 A clear distinction should be drawn between manual training which should be imparted in the common schools to all children without distinction, as part of their general education, - and technical training which should be given, as a preparation for a special profession, to those intending to follow that profession.

2 I do not mean that any one should be shut out from erudition. I mean that erudition is not a necessity for the breadwinner. I think, too, that all distinction between liberal and illiberal professions should be blotted out. 
enjoy those high satisfactions that come of such worthiness. We may express this otherwise, by saying that they must be such as to enable a man to know and understand his environment; to take an intelligent interest in all that goes on, or has gone on in the world; to enter into lofty personal relations, and to live clean, tasteful, useful, self-respecting lives. The relations for which culture should prepare are: (I) personal, (2) domestic, (3) social (including economic), (4) political. It would be possible to arrange a system of education on the basis of this classification; but it is not necessary to do so. The different relations, however, ought to be kept in view in arranging any course of culture studies.

Perhaps the following curriculum, extending over three or four years, might meet the needs of the breadwinners in the present condition :

I. Evolution : its theory and history.

2. History of civilization.

3. The system of the sciences.

4. Sociology.

5. Political theory and history.

6. History of industry and commerce.

7. History of education (psychology).

8. History of science and philosophy.

9. History of ethical theory.

Io. Comparative religion.

I I. Comparative literature.

I2. History and theory of the fine arts.

In following out this curriculum the greatest care should be taken to avoid any imposing of any special theory or doctrine - religious, political, economical, etc. - upon the pupils. All theories should be freely discussed without bias, party spirit, or passion, and every effort made to elicit the truth from the pupils themselves. The important thing is that they should learn to think for themselves, and thus become morally free. With a view to this the work of the teacher should 
consist mostly in direction and encouragement. The less he does himself, and the more he makes his pupils do, the better. Lecturing should be resorted to only by way of introduction; then the seminary method should be followed. As a rule, some handy, compact, epoch-making book should be made the basis of work, for example, Aristotle's Politics for political theory and history; then a list of books should be given for the pupils to analyze, epitomize, and criticise in written essays, to be read and discussed before the class. Then when difficult points come up or deeper researches have to be made these should be assigned as subjects for special essays. In this way a wide knowledge of each subject and of its literature will be gained and a deep interest aroused. 1

The curriculum as a whole will impart just the unitary views of the world and its agencies which will give meaning and zest to the individual life and make the good citizen.

At the close of each study the pupils should be asked to sum up, in a brief essay of not more than five hundred words, what they have learned from it. This will take the place of an examination.

Having settled what kind of culture is necessary for the breadwinners, we must next consider how it may be best brought within their reach. For this, two things above all are necessary: (I) that they should know what is proposed, and recognize its value; (2) that they should have spare time, energy, and convenience for continued study.

The former of these aims may be reached through the public press - newspapers, magazines, etc. - and through lectures, which are here in order. It is needless to dwell on the efficiency of the press in bringing things before the public; but a few words may be said about lectures. It would be of the utmost moment to arrange for a course of ten lectures, covering as many weeks, and given on some convenient

1 I employed this method in my class last winter with considerable success. 
evening ${ }^{1}$ when most of the breadwinners of the neighborhood could attend. The following are suggested as titles for such lectures:

I. The present state of education among the breadwinners, and their opportunities for obtaining higher education. What the schools do.

2. The education needed by the breadwinners, and how it must differ from school and college education.

3. The education needed by the individual, in order to lift him above narrow, sordid ends.

4. The education needed for the ends of the family.

5. The education needed for the ends of civil society, for the tradesman, the merchant, etc. (I) Tech"nical education. (2) Moral training.

6. The education needed by the citizen.

7. The need of unity, system, and aim in education. The defects of our present education in this respect.

8. How can education be carried into the home?

9. The state's duty in regard to the culture of the breadwinners.

I0. A scheme for a breadwinners' culture institute, to be established in every township and in every city ward, to supplement our public schools.

I cannot but think that, if such a course of lectures were given at a convenient time by competent persons, carefully reported in the daily newspapers, and afterwards printed in the form of a cheap book, it would meet with a hearty response from the breadwinners.

It is necessary, not only that breadwinners should be brought to desire higher culture, but also that they should have the time, energy, and convenience to acquire it. How this is to be done is one of the great social questions of the day, and one that I do not purpose to answer here; but of

1 Or on Sunday afternoon. There could hardly be any more religious work han this. 
two things I am morally certain: (I) that it cannot effectually be done by any legislation in favor of an eight-hour working day, or anything of that sort; and (2) that, if the breadwinners made it evident that they desired free time in order to devote it to self-culture, from which they are debarred by long hours of labor, public sentiment would soon insist that such time should be accorded them, and provisions made for such culture. One main reason why the demand for shorter hours meets with comparatively little response from the public, is the prevalent belief that a very large number of breadwinners would make a bad use of the spare time, spending it in saloons and other coarse resorts. Labor, it is said, is better or more profitable than idleness and saloon life. And there is some reason in this. Spare time demanded for culture would most certainly be accorded, and it will, I think, hardly ever be obtained on any other plea. I need hardly add that spare time would bring with it spare energy; for it is the long hours that exhaust the energies.

Along with time and energy the breadwinners must have home conveniences for study. Many of course have these, but many have not. In crowded rooms or apartments in tenement houses it is hard to find a quiet corner for study, and the public libraries and reading rooms offer conveniences for but a small number. This state of things must be remedied, and, I think, would be remedied as soon as there was any genuine desire for culture. Persons inspired by this would refuse to live where they could not have conveniences for study, and would thus be brought to demand a higher standard of living, a thing altogether desirable. At the same time public reading rooms would doubtless increase.

At the present time we hear a great deal about saloon politics and the corruption that results from them; and manifold efforts are made to start rivals to the saloon, which a very reverend bishop has told us is the poor man's clubroom. It is sad to think that the bishop is right, and that the 
poor man has not been able, thus far, to establish any other sort of club room. It is my firm belief that the successful rival of the saloon will not be the coffee room, the reading room, the pool room, or the concert room, but the lecture room and the school room, with their various appurtenances and opportunities. I believe that we shall never be able to put a stop to the deleterious effects of the saloon upon individual, domestic, social, and political life, until we establish in every city ward and in every village a culture institute for the great body of the people who are engaged in business during the day, - an institute composed of three parts : (I) a technical school, ${ }^{1}$ (2) a civic-culture school, and (3) a gymnasium. Such institutions must sooner or later be established by the state, and supported by public funds as part of the system of public education; but at present it is well that they should be undertaken by private effort, and their utility, yea, their necessity, clearly shown. The Educational Alliance is in a position to take an important step in this direction, and it can do so by establishing a system of evening classes with a programme such as I have sketched, and appealing to the breadwinners by a course of lectures of the nature I have indicated.

[Signed] Thomas Davidson."

1 An excellent model for this is the London Polytechnic (in Regent Street), which owes its existence to the energy and generosity of one man, W. Q. Hogg. It has several rivals in London now. 


\section{CHAPTER XIV}

LETTERS FROM DAVIDSON IN REFERENCE TO HIS WORK ON MEDIÆVALISM

So far back as December 7, 1882, long before we met, I had a letter from Mr. Davidson in reference to his book on Rosmini, which he sent from 75 Via Nazionale, Rome, and in which he said:

"... I am really very desirous that the system of this philosopher should be brought to the attention of men fitted to judge of its value. A life of Rosmini is about to appear, and this new essay in English is more than half printed. I am now engaged on a translation of the Psychology, which I think is Rosmini's most important work. This will appear, I trust, in the course of next year.

Could you not find a place for a Rosmini among the great names of your philosophical series? ${ }^{1}$ If you could, this would bring the system within the reach of a wider public than could be done by any means I can now think of. Will you, at your leisure, tell me what you think of the suggestion?

I should like also to make another. I have for many years been working up Heraclitus (see my article on him in Johnson's Encyclopadia), and I should be very glad if you could give my work on him a place in your series. It is considerably advanced and could be ready for the press in six months. I have also collected materials for a work on Parmenides, whose fragments I translated (in hexameters) and published many years ago in the Journal of Speculative Philosophy. ..."

1 The series of Philosophical Classics for English Readers, which I organized and edited, and of which Messrs. Blackwood were the publishers. 
I was unable to include Rosmini in the series of books on the philosophers which had attracted Davidson's eye, while Heraclitus and Parmenides lay outside its province as designed by me. But when I was trying to organize another and a larger series, on Philosophy in its National Developments, I tried to enlist his services, and offered him the subject of "Mediævalism." The following was his reply.

“ Keene, Essex County, New York, September 8, 1894.

Your letter of August 28 reached me yesterday, and nothing could have been more opportune. My book on The Education of the Greek People, and its Influence on Civilization will be out in a few days, and I sail for Europe on the $25^{\text {th }}$ of this month. Although I am at work on a little volume on Plato, intended as a companion to that of Wallace on Aristotle, there is no hurry about that, and I can probably write you a volume of the size of those in the Philosophical Classics Series ${ }^{1}$ before I return home.

I have been working for fifteen years on Mediævalism, and indeed had planned a volume such as you propose. My aims this winter will bring me to the libraries of London, Paris, Berlin, and Rome, and I shall therefore have the best opportunities for reaching original sources of information. I shall therefore be glad to undertake the volume you suggest.

But I shall have to obtain more details with regard to the limits of my task : how it is to relate itself to that of Wellhausen, for example, and whether I am to say anything about Patristicism.

My book on Rosmini, chaotic as it was, has not been without its effects, I think. But there is a mine there which has never been fully worked, and which well deserves working.

1 The volumes were to be more than double that size; and as the subject grew on his hands, Mr. Davidson wished two volumes for it. 
In my lectures I am always emphasizing the view that philosophy, education, etc., cannot be studied apart from the entire life of the people among whom they arise and live. I am therefore in entire sympathy with your general idea, and shall carry it out con amore.

Are you to have.a volume on modern Italian philosophy? It will deserve treatment, I think. . . ."

His subsequent letters to me on the subject of this work were as follows :

$$
\begin{gathered}
\text { " io Craven Street, Strand, London, } \\
\text { October 12, 1894. }
\end{gathered}
$$

... I reached this Babylon on the $3 \mathrm{~d}$, and have been toiling away in dirt and fog ever since. ...

I have with me a delightful young friend, a Ph.D. of Harvard, the ablest philosophical student they ever had there. May I bring him to see you?

I have brought a box of mediæval books with me, and shall soon settle down in Berlin to write my book. But I cannot begin till I know my limits, e.g. whether I am to include Patristicism or not. ... ."

" EDEN Hotel, Rome, December 25, 1894.

. . My book has been progressing, and I have collected numerous important documents on mediævalism, both here and in Berlin. I find I must become thoroughly acquainted with Arabism before I can go any farther. Fortunately, a good many books are appearing on that subject; but I am going to Cairo next week to make myself directly acquainted with it. ${ }^{1}$

I saw a good deal of Pfleiderer, Von Hartmann, etc., in Berlin, and here I am seeing Ferri almost every day. . . ."

1 His visit was for the purpose of speaking Arabic, while studying Arab and Eastern life, as much as for examining manuscripts or consulting books. 
"Hotel Suisse, Rome, April 12, 1895.

... I hope I shall be allowed to produce a book in two volumes, since in less than that it is impossible to do justice to mediæval thought.

Though I have been ill all winter, my book has made some progress, and I have collected many books that will be of great value to me. ..."

“ Keene, Essex County, New York, May 30, 1895.

... I shall divide my subject pretty much as you suggest. It goes naturally into two well-defined parts, sundered by the introduction of the complete Aristotle into the West. But I shall tell you more of this later on. I am now at work on the earlier part, and it interests me intensely. It is only now, when we are coming to know the Arab thinkers, - through the publication of Dieterici, Müller, etc., - that its full significance, and bearings, can be seen. My Arabic studies are doing me yeoman's service now."

[After mentioning, and characterizing, seven writers who might be intrusted with a volume on the Philosophy of America, he continues:] "Come to America, and let me entertain you for a few weeks in the mountains; but do not come in March. Even April is too early for this part of the continent. You might spend a couple of months in Florida, and then come here in June, when the mountains are in all their glory. March is too late for comfort in Cairo. It was hot enough even in February, when I left. ..."

\section{“ Keene, Essex County, New York, October 6, 1895 .}

... My book is growing very satisfactorily. ... Inasmuch as the presence of dogma, or foregone conclusions about the highest things, is what distinguishes mediæval 
thought, taking the place of natural spirit, I am obliged to account for dogma, and the fact of its authority; and this will occupy a good part of the first volume, which cannot, I am sure, reach further than Charlemagne or Abelard. That volume, therefore, might be entitled Mediceval Thought up to the Rise of Rationalism in Abelard; and the second, Mediceval Thought from Abelard, and the Rise of Rationalism down to Descartes. I may add a brief chapter on Rosmini and modern mediævalism. Alas! that the philosophic value of the classical mediæval philosophy stands in sad disproportion to its literary bulk. The achievements of Thomas Aquinas, for example, can be dismissed in a few pages; while Roscelinus, and William of Ockham will require a good deal of attention. ...

Perhaps I ought to warn you that much of my book will necessarily be deemed heterodox. I am dealing with philosophy, not with theology, and therefore of course with simple historic truth. I shall treat Hebrew and Christian thought with the same freedom as that with which I treat Greek thought; sympathetically, but unawedly. ... .

[In this letter - in answer to a question by my publisher as to his principal works, to be mentioned in the prospectus of writers for the series - he gives a list of nine of them to choose from, as follows :]

(I) Rosmini's Philosophic System.

(2) The Parthenon Frieze, and other Essays. (3) Prolegomena to In Memoriam. (4) Aristotle, and the Ancient Educational Ideals. (5) The Education of the Greek People, and its Effect on Civilization. (6) The Fragments of Parmenides : translation and commentary. (7) The Grammar of Dionysius Thrax : translation and commentary. (8) The Eleventh Book of Aristotle's Metaphysics: translation and notes. (9) The Place of Art in Education." 


\author{
"Hurricane Post Office, \\ Keene, Essex County, New York, U.S.A., \\ September 6, 1896 .
}

... My book progresses, but it grows terribly on my hands, and the condensing is no easy matter. I must include in it a brief account of Arab thought, if I am to make the second period of scholasticism intelligible. I am not sure but you would do well to let me expatiate on Oriental thought, exclusive of the Hindu, even if I should need another volume. I have given most of this summer to Arabism, its nature and sources, and am thereby enabled to present the whole course and character of scholasticism in a new light. I am indeed enabled to show the meaning and necessity of the entire movement. In any case please don't arrange for an Oriental volume until I explain farther to you how much I am forced to include in my work, in order to give it meaning. My book, as I think I told you, will practically be a History of the Rise and Fall of the Principle of Authority in Thought. In mediævalism authority, or dogma, takes the place of national spirit; and so I am bound to account for it.... It is difficult to say when my book will be finished, but I am working on it as hard as I can. It is a big subject; and the Vorarbeiten are not numerous, or good. The ordinary histories are mere congeries of facts, without internal connections.

I shall be extremely glad to see you in America, and to welcome you to Glenmore. I come here in May and leave in November, and you shall be very welcome any time in between. The best-known 'philosophers' often find their way here, and one or two of them have summer houses. The Adirondacks are superb in scenery, and the air is unequaled. I am two thousand feet above sea level. May is the worst month in the year for you. September is not much better. And it is against the law for you to come on an arrangement made abroad. That, even in the case of the clergy, is construed as an 'importation of foreign labor'! 
One New York congregation was fined a thousand dollars for infringing this law!"

“The Mansion House, Brooklyn, New York, February 12, 1896.

... I have written out a first draft of my whole book in the form of lectures, so as to get its articulation clearly before me; and have also elaborated the first part of it. But the material and the interest grow as I proceed; so that I do not get on so fast as I wish. The result will be all the better for that, however...."

“ KeENe, June 16, 1896.

....For the real understanding of mediæval thought a great deal has to be done at both ends of it. We have plenty of descriptions of mediævalism, but not one of them tells us why it was what it was; and yet that is the important thing. ..."

"Keene, Essex County, June 6, 1897 .

... I have been almost completely used up with the 'grippe' (I have now had it eight times), but my book is progressing. Certain parts of it are well advanced; but until I undertook it I had no notion of the difficulties besetting the task, nor the amount of research and labor involved in it. I have bought and read hundreds of books in the last two years, and the bottom is not reached yet. The fact is, there are no Vorarbeiten; indeed, there is no single book that really gives an intelligent, enlightening view of mediæval thought. I could easily abridge Stöckl, ${ }^{1}$ or expand Ueberweg-Heinze, ${ }^{2}$ but that would be useless hack work. What I am trying to do is to give a living picture of dogma-limited mediæval thought in all its relations and ramifications, showing its connection with Greek, Roman, Patristic, and Arabic thought,

1 Stöckl, A., Geschichte der Philosophie des Mittelalters.

2 Ueberweg-Heinze, Grundriss der Geschichte der Philosophie. 
and its influence on modern thought. I wish to do something that will be a lasting contribution to science, and a basis for farther work. The subject is extremely interesting, and well worth all the labor expended on it.

I fear I must spend a month in the British Museum before I can finish the first volume. I am thinking of coming over in October. I came near paying a thousand dollars for a copy of Migne the other day, but it escaped me...."

"Pelham Manor, Westchester County, New York, February 13, 1898.

[Explains delay. The working part of the establishment at Glenmore was burned to the ground in the summer of I 897, entailing very considerable loss. To make this up Mr. Davidson was obliged to do "some immediately paying work" during the following winter, and accordingly he wrote a book on Rousseau's educational system. Resuming work on the History of Mediaval Thought, he restates his difficulty.]

The truth is, this history has never been written in any intelligible way, and I am trying to do that thing. It requires patience, both on your part and on mine. . .."

It is unnecessary to explain how this book on Mediævalism, and the series of which it was to have formed a part, never appeared. It is rather a long story, and is scarcely relevant to Davidson. But students of philosophy will be interested in the glimpses which these letters give of the rise and progress of a great undertaking; and the general reader will obtain some side lights on the nature of the problem, as it gradually shaped itself in the mind of the writer. I may mention, moreover, that $I$ have seen and examined in manuscript the notes of a series of thirty-seven lectures on the "Philosophy of the Middle Ages," delivered at Glenmore, and taken down by a very competent student. They could not be printed as they 
now stand; but if other students took down similar ones (as many doubtless would), and if all were submitted to a competent editor, - as the manuscript notes of the lectures on "Logic" and "Metaphysics," by Sir William Hamilton at Edinburgh, were handed over to Professor Veitch and Dean Mansel, - a work of real and lasting merit might be constructed. 


\section{CHAPTER XV}

\section{PROFESSOR WILLIAM JAMES'S REMINISCENCES}

My dear Professor Knight :

Cambridge, Boston, October 21, 1903.

You ask me to contribute to your book something reminiscential about Thomas Davidson, and I am glad to do so. It will do him no honor not to be frank about him. He handled people without gloves himself, and one has no right to retouch his photograph until its features are softened into insipidity. He had defects and excesses which he wore upon his sleeve, so that every one could see them immediately. They made him many enemies, and if one liked quarreling he was an easy man to quarrel with. But his heart and mind held treasures of the rarest. He had a genius for friendship; money, place, fame, fashion, and other vulgar idols of the tribe, had no hold on his imagination; he led his own life absolutely, in whatever company he might find himself ; and the intense individualism which he stood for and taught always, is the lesson of which our generation stands perhaps most in need. All sorts of contrary adjectives come up as I think of him. I will shrink from none, extenuating nothing, but trying also not to exaggerate.

To begin with, there was something rustic about him, which suggested to the end his farm-boy origin. His voice was sweet and its cadence most musical, and the extraordinary sociability of his nature made as many friends for him among women as among men; he had, moreover, a sort of physical dignity; but neither in dress nor in manner did he ever grow quite "gentlemanly" or "Salonfähig" in the conventional and obliterated sense of the terms. He was too 
cordial and emphatic for that. His broad brow, his big chest, his bright blue eyes, his volubility in talk and laughter told a tale of vitality far beyond the common; but his fine and nervous hands and the vivacity of his reaction upon every impression suggested a degree of sensibility which one rarely finds conjoined with so robustly animal a frame.

The great peculiarity of Davidson did indeed consist in this combination of the acutest sensibilities with massive faculties of thought and action. It is a combination apt for experience and suffering; but when the thoughts and actions are important it gives to the world its greatest men.

Davidson's native mood was happy. He took optimistic views of life and of his own share in it. A sort of permanent satisfaction radiated from his face; and this expression of inward glory (which in reality was to a large extent structural and not "expressive" at all) - strangely enough, the slight intermittent strabismus outwards with which one of his eyes was affected added to it - was displeasing to many new acquaintances, who held him, on account of it, to be intolerably conceited. This impression of self-conceit was not diminished in their eyes by the freedom with which he contradicted, corrected, and reprehended other people. I recollect that a lady, who found nothing in her with which to meet this radiancy of his, said that he affected her as if he were a red-hot stove in the room, and always made her wish to get away from his presence. A longer acquaintance invariably diminished this impression of conceit, but it must be confessed that Davidson never was exactly humble-minded, and that the solidity of his self-consciousness withstood strains under which that of weaker men would have crumbled. The malady which finally killed him (a complication of bladder troubles) is notoriously one of the most exhausting to the nervous tone to which our flesh is subject, and it wore him out before it ended him. He told me of the paroxysms of motiveless nervous dread which used to beset him in the night watches. 
Yet these never subdued his stalwart individualism, or made him a "sick soul," in the theological sense of that appellation. "God is afraid of me" was the phrase by which he described his well-being to me one morning, when his night had been a good one, and he was feeling so hearty that he thought he might recover.

There are men whose attitude is always that of seeking for truth; and men who, on the contrary, always believe that they have the root of the matter already in them. Davidson was one of the latter class. Like his countrymen, Carlyle and Ruskin, he felt himself to be in possession of something, whether articulate or as yet unarticulated by himself, that authorized him (and authorized him with uncommon openness and frequency) to condemn the errors of others. I think that to the last he never fully extricated this philosophy. It was a tendency, a faith in a direction, which gave him an active persuasion that other directions were false, but of which the central insight, never fully formulated, remained in a state which Frederic Myers would have called subliminal. $\mathrm{He}$ varied to a certain extent his watchwords and his heroes. When I first knew him all was Aristotle. Later all was Rosmini. Later still Rosmini seemed forgotten; and I never learned just what point of view replaced that synthesis for Davidson. Thomas Davidson was ever and always individualistic and pluralistic, yet never the sort of empiricist which, to my mind, pluralists and individualists ought by right to be. He knew so many writers that he grew fond of very various ones, and had a strange tolerance for systematizers and dogmatizers whom in consistency he should have disliked. Hegel, it is true, he detested; but he always spoke with reverence of Kant. Of Mill and Spencer he had a low opinion; and when I lent him Paulsen's Einleitung in die Philosophie (then just out), as an example of the kind of eclectic empiricism that seemed to be growing, and with which I largely sympathized, he returned it with richer expressions of disdain than 
often fell even from his lips: "It's the shabbiest, seediest pretence at a philosophy I ever dreamed of as possible. It's like a man dressed in a black coat so threadbare as to be all shiny. The most poverty-stricken, out-at-elbows thing I ever read," etc. The truth is that Davidson, brought up on the older classic traditions, always kept near them. He was a Platonizer. His acquaintance with physical science was almost wholly due to later "popular" literature, and he never outgrew those habits of judging by purely æsthetic criteria, which men fed more upon the sciences of nature are so willing to dispense with. Even if a philosophy were true, he would fail to relish it unless it showed certain formal merits and pretensions to finality.

His own philosophy was, I think, what to the last he set most store by; more than by the prodigious erudition which came to him so easily. The erudition probably interfered with the articulate working out of the philosophy. Associations came in such abundance when he thought of anything that he got diverted by them; and, although up to a certain point his writing was always admirably clear, I used to think that I could recognize the very page where he had ceased to think perspicuously, and the end of his articles was often, to my taste, anything but transparent. His intellect in any case was not analytic, and perhaps analysis is what is most required in pure philosophy.

But I am describing him too much from the standpoint of my own profession. It is from the point of view of a vessel of human life that he ought to be taken. I first heard about him in 1873 from Mr. Elliot Cabot, who praised his learning and manliness and great success with pupils. In another year he came to Boston, ruddy and radiant, and I saw much of him, though at first without that thoroughness of sympathy which we afterwards acquired, and which then made us overflow, on meeting after long absences, into such laughing greetings as " $\mathrm{Ha}$ ! you old thief! Ha! you old blackguard!"- 
pure "contrast effects" of affection and familiarity overflowing their limit. At that time I saw most of him at a little philosophical club which used to meet (often at his rooms in Temple Street) every fortnight. Other members were W. T. Harris, G. H. Howison, J. E. Cabot, C. C. Everett, B. P. Browne, and sometimes G. H. Palmer. We never worked out unanimous conclusions. Davidson used to crack the whip of Aristotle over us; and I remember that whatever topic was formally appointed for the day, we almost invariably wound up with a quarrel about space perception. The club had existed before Davidson's advent. The previous year we had gone over a good part of Hegel's larger logic under the self-constituted leadership of Messrs. Emery and McClure, two young business men from Quincy, Illinois, who had become enthusiastic Hegelians ; and, knowing almost no German, had actually possessed themselves of a manuscript translation of the entire three volumes, made by an extraordinary Pomeranian immigrant named Brockmeyer. They were leaving business for the law, and studying at the Harvard Law School; but they saw the whole universe through Hegelian spectacles, and a more admirable homo unius libri than Mr. Emery, with his three big folios of Hegelian manuscript, I have never had the good fortune to know.

I forget how Davidson was earning his subsistence at this time. He did some lecturing and private teaching, but I do not think they were great in amount. In the springs and summers he frequented the coast and indulged in long swimming bouts and salt-water immersions, which seemed to agree with him greatly. His sociability was boundless, and his time seemed to belong to any one who asked for it.

I soon conceived that such a man would be invaluable in Harvard University; a kind of Socrates, a devotee of truth and lover of youth, ready to sit up to any hour and talk with any one, lavish of help and information and counsel, a contagious example of how lightly and humanly a burden of 
learning might be borne upon a pair of shoulders. In faculty business he might not run well in harness, but as an inspiration and ferment of character, and as an example of the ranges of combination of scholarship and manhood that are possible, his influence among the students would be priceless. I do not know whether this scheme of mine would under any circumstances have been feasible. At any rate, it was nipped in the bud by the man himself. A natural chair for him would have been Greek philosophy. Unfortunately, just at the decisive hour, he offended our Greek department by a savage criticism of its methods (originally drawn up, I believe, as a report to our overseers) which he had published in the Atlantic Monthly. This, with his other unconventionalisms, made advocating his cause more difficult, and the university authorities never, I believe, seriously thought of an appointment for him.

I think that in this case, as in one or two others like it which I might mention, Harvard University lost a great opportunity. Organization and method mean something, but contagious human characters mean more, in a university. A few undisciplinables like Davidson may be infinitely more precious than a faculty full of orderly routinists. As to what he might have become under the conventionalizing influences of an official position, it would be idle to speculate. As things fell out, he became more and more unconventional, and even developed a sort of antipathy to academic life in general. It subdued individualism, he thought, and made for philistinism. He earnestly dissuaded his young friend, Bakewell, from accepting a professorship; and I well remember one dark night on East Hill, after a dinner at Mr. Warren's, the eloquence with which, as we trudged downhill to Glenmore with our lantern, he denounced me for the musty and moldy and generally ignoble academicism of my character. Never before or since, I fancy, has the air of the Adirondack wilderness vibrated more repugnantly to a vocable than it did that night to the word "academicism." 
Yet Davidson himself was always essentially a teacher. He must give forth, inspire, and have the young about him. After leaving Boston for Europe, returning to New Jersey, and founding the Fellowship of the New Life in New York, he hit upon the plan which pleased him best of all. In $1892,{ }^{1}$ or thereabouts, he bought a hundred or two acres on East Hill, which closes the beautiful Keene valley in the Adirondacks on the north, and founded there, at the foot of Hurricane Mountain, his place Glenmore and its Summer School of the Culture Sciences. Although the primeval forest has departed from its immediate vicinity, the region is still sylvan, the air is sweet and strong and almost Alpine in quality, and the mountain panorama spread out before one is superlative. In organizing his settlement, Davidson showed a business faculty which I should have hardly expected from him. He built a number of houselets, pretty in design and of the simplest construction, and disposed them well for effect. He turned a couple of farm buildings which were on the ground into a lecturing place and a refectory; and there, arriving in early April and not leaving till late in November, he spent the happiest portion of all his later years, surrounded during the summer months by colleagues, friends, and listeners to lectures, and in the spring and fall by a few independent women who were his faithful friends, and who found East Hill a congenial residence.

You will no doubt have received an account of the workings of Glenmore from some one who frequented it in summer. My own visits were too early or too late for the school to be in session. Twice I went up with Davidson to open the place in April. I well remember leaving his fireside one night with three ladies who were also early comers, and finding the thermometer at $8^{\circ}$ Fahrenheit and a tremendous gale blowing the snow about. Davidson loved these blustering vicissitudes of climate. In the early years the brook was never too

$$
\text { 1 1889. - ED. }
$$


cold for him to bathe in, and he spent hours in rambling over the hills and through the forest.

His own cottage was full of books, whose use was free to all who visited the settlement. It stood high on the hill in a grove of silver birches, and looked upon the western mountains ; and it always seemed to me an ideal dwelling for such a bachelor scholar. Here in May and June he became almost one with the resurgent vegetation. Here in October he was a witness of the jewelled pageant of the dying foliage, and saw the hillsides reeking, as it were, and aflame with ruby and gold, emerald and topaz. One September day in 1900, at the "Kurhaus" at Nauheim, I took up a copy of the Paris New York Herald, and read in capitals: "Death of Professor Thomas Davidson." I had well known how ill he was, yet such was his vitality that the shock was wholly unexpected. I did not realize till that moment how much that free companionship with him every spring and autumn, surrounded by that beautiful nature, had signified to me, or how big a piece would be subtracted from my life by its cessation.

Davidson's capacity for imparting information seemed endless. There were few subjects, especially humanistic subjects, in which at some time or other he had not taken an interest; and as everything that had ever touched him was instantaneously in reach of his omnipotent memory, he easily became a living dictionary of reference. As such all his friends were wont to use him. He was, for example, never at a loss to supply a quotation. He loved poetry passionately, and the sympathetic voice with which he would recall page upon page of it - English, French, German, or Italian - is a thing I shall always like to remember. But notwithstanding the instructive part he played in every conceivable conversation, he was never prolix, and he never "lectured."

From Davidson I learned what immunities a perfect memory bestows upon one. I never could discover when he amassed his learning, for he never seemed occupied. The secret of it 
was that any odd time would do, for he never had to acquire anything twice over. He avoided stated hours for work, on principle.... Individualist à outrance, Davidson felt that every hour was a unique entity to whose claim on one's spontaneity one should always lie open. Thus he was never abstracted or preoccupied, but always seemed when with you as if you were the one person whom it was then right to attend to. It was this individualistic religion that made Davidson so indifferent, all democrat as he nevertheless was, to socialisms and general administrative panaceas. Life must be flexible. You ask for a free man and these Utopias give you an " interchangeable part," with a fixed number, in a rulebound social organism. The thing to aim at is liberation of the inner interests. Given a man possessed of a soul, and he will work out his own happiness under any set of conditions. Accordingly when, in the last year of his life, he proposed his night school to young East Side workmen in New York, he told them that he had no sympathy whatever with the griefs of "labor," that outward circumstances meant nothing in his eyes, that through their individual wills and intellect they could share, just as they were, in the highest spiritual life of humanity, and that he was there to help them severally to that privilege.

The enthusiasm with which they responded speaks volumes both for his genius as a teacher, and for the sanity of his position. Leveller upwards of men as Davidson was, in the moral and intellectual manner, he seemed wholly without that sort of religious sentiment which makes so many of our contemporary democrats think that they ought to dip, at least, into some manual occupation, in order to share the common burden of humanity. I never saw him work with his hands in any way. He accepted material services of all kinds without apology, as if he were a born patrician; evidently feeling that if he played his own more intellectual part rightly, society could demand nothing further. 
His confidence that the life of intelligence is the absolutely highest made Davidson serene about his outward fortunes. Pecuniary worry would not tally with his programme. $\mathrm{He}$ had a very small provision against a rainy day, but he did little to increase it. He would write as many articles and give as many lectures, talks, or readings every winter as would suffice to pay the year's expenses, but would thereafter refuse additional invitations, and repair to Glenmore as early in the spring as possible. I could not but admire the temper he showed when the principal building there was one night turned to ashes. There was no insurance on it, and it would cost a couple of thousands of dollars to replace it. Excitable as Davidson was about small contrarieties, he watched this fire without a syllable of impatience. Plaie d'argent n'est pas mortelle, he seemed to say, and if he felt sharp regrets he disdained to express them.

No more did care about his literary reputation trouble him. In the ordinary greedy sense he seemed quite free from ambition. During his last years he had prepared a large amount of material for that history of the interaction of Greek, Christian, Hebrew, and Arabic thought upon one another before the revival of learning, which was to be his magnum opus. It was a territory to which, in its totality, few living minds had access, and in which a certain proprietary feeling was natural. Knowing how short his life might be I once asked him whether he felt no concern lest the work already done by him should be frustrate from the lack of its necessary complement, in case he was suddenly cut off. His answer surprised me by its indifference. He would work as long as he lived, he said, but would not allow himself to worry, and would look serenely at whatever might be the outcome. This seemed to me uncommonly high-minded. I think that Davidson's conviction of immortality had much to do with such a superiority to accidents. On the surface and towards small things he was irritable enough, but the undertone of his 
character was remarkable for largeness and equanimity. $\mathrm{He}$ showed it in his final illness, of which the misery was really atrocious. There were no general complaints or lamentations about the personal situation, or the arrest to his career. It was the human lot and he must even bear it, so he kept his mind upon objective matters.

But as I said at the outset the paramount thing in Davidson in my eyes was his capacity for friendship. His friends were innumerable, - boys and girls, men and women, Jews and Gentiles, papists and protestants, married and single, and he cared deeply for each one of them, admiring them often too extravagantly. How can we describe those recurrent waves of delighted laughter which characterized his greetings, beginning from the moment he saw you, and accompanying his words continuously, as if his pleasure in you were interminable? His hand, too, stretched out to you when yards away, so that a country neighbor said it reached farther than any hand he ever met with. The odd thing was that friendship in Davidson seemed so little to interfere with criticism. Persons with whom intercourse was one long contradiction on his part, and who appeared to annoy him to extermination, he none the less loved tenderly. " He's the most utterly selfish human being" (I once heard him say of some one) "whom I ever knew, and comes from the most illiberal and narrowhearted people, - and yet he's the dearest, nicest fellow living." His enthusiastic belief in any young person who had a promise of genius was touching. Naturally a man who was willing, as he was, to be a prophet, always finds some women who are willing to be disciples. I never heard of any sentimental weakness in Davidson in this relation. They warmed themselves at the fire of his personality, and he told them truths without accommodation. "You're farther off from God than any woman I ever heard of." "If you believe in a protective tariff you're in hell already, although you may not know it." "You had a fine hysterical time last night, did n't 
you, when Miss B — was brought up from the ravine with her dislocated shoulder?" To Miss B_— herself he said, "I don't pity you. It served you right for being so ignorant as to go there at that hour." Seldom did the recipients of these deliverances seem to resent them.

What with Davidson's warmth of heart and sociability I used to wonder at his never marrying. Two years before his death he told me of the reason, his unfortunate young love affair at Aberdeen. Twice in later life, he said, temptation had come to him, and he had had to make his decision. When it came to the point he had felt each time that the earlier tie was prohibitive. "When two persons have known each other as we did," he said, " neither can ever fully belong to a stranger. So it would n't do! It would n't do! It would n't do!" he repeated, as we lay on the hillside, in a tone so musically tender that it chimes in my ear still, as I write down his confession. It can be no breach of confidence to publish it ; it is too creditable to the profundity of Davidson's moral nature. As I knew him, he was one of the purest of human beings.

If you ask me what the value of Thomas Davidson was, what was the general significance of his life apart from his particular work and services, I shall have to say (for personally I never gained any very definite light from his more abstract philosophy) that it lay in the example he set to us all, of how - even in the midst of this intensely worldly social system of ours, in which every interest is organized collectively and commercially - a single man may still be a knight-errant of the intellectual life, and preserve freedom in the midst of sociability. Extreme as was his need of friends, and faithful as he was to them, he yet lived mainly in reliance on his private inspiration. Asking no man's permission, bowing the knee to no tribal idol, renouncing the conventional channels of recognition, he showed us how a life devoted to purely intellectual ends could be beautifully wholesome outwardly, and overflow 
with inner contentment. Fortunately this type of man is recurrent, and from generation to generation literary history preserves examples. But it is infrequent enough for few of us to have known personally more than one example. I count myself happy in having known two. The memory of Davidson will always strengthen my faith in personal freedom and its spontaneities, and make me less unqualifiedly respectful than ever of "civilization," with its exaggerated belief in herding and branding, licensing, authorizing, and appointing, and, in general, regulating and administrating the lives of human beings by system. Surely the individual person is the more fundamental phenomenon, and the social institution, of whatever grade, is secondary and ministerial. The individual can call it to account in a deeper sense than that in which it calls him to account. Social systems satisfy many interests, but unsatisfied interests always remain over, and among them interests which system as such violates. The best commonwealth is the one which most cherishes the men who represent the residual interests, and leaves the largest scope to their activity. I may say that Davidson seemed to find the United States a more propitious commonwealth in this regard than his native land, or other European countries.

Yours always truly,

William JAMES. 


\section{CHAPTER XVI}

\section{RECOLLECTIONS BY WYNDHAM R. DUNSTAN}

Davidson and I first met in London in I88I, when a few of us were actively engaged in promoting the study of philosophy in London by founding the Aristotelian Society, a project in which Davidson took great interest, although he was debarred from taking much part in our proceedings owing to his few and infrequent visits to London. The friendship thus begun continued, in spite of separation for periods of years, until his death in 1900 .

Davidson was one of the most learned and versatile of men. His knowledge ranged over general philosophy, metaphysics, art, archæology, and literature ; and was bounded by no language. His linguistic powers were remarkable. He had no difficulty in conversing in Latin, ancient and modern Greek, Italian, German, and French. $\mathrm{He}$ was so conversant with Greek and Latin literature and ideals, and his discussion of these subjects was so intimate and complete, that he gave the impression of having lived in those ages. There were moods in which he himself lost all touch with the modern world, and his thoughts occurred to him in the ancient tongues. At one period of his life he was subject to something in the nature of catalepsy, and those about him have told me that on recovering from these states he invariably spoke in Greek or Latin; and on one occasion he was found walking with merely a blanket round his shoulders. He explained that he had put on his toga to go to the bath. I mention this incident in order to emphasize one of the chief characteristics of the man, namely, his intense sympathy with ancient life and thought. 
The extent of his philosophical reading in all languages was remarkable. He had no mean knowledge of archæology, as is evidenced by his essays published in I 882 on the Parthenon frieze and other subjects, and his contribution to the discussion which arose on the restoration of the Venus of Milo proposed by Kossos (Academy, I882, pp. 273-274).

His knowledge of English Literature, both in verse and prose, was as considerable as his appreciation of that of other nations. He knew Shakespeare as well as he knew Dante; and no one who had heard him read Shakespeare could fail to be impressed by his mastery of every shade and intricacy of meaning. Keats was one of the English poets in whom he delighted; and his marvellous memory enabled him to recite without hesitation those pieces of literature which had made the greatest impression on his mind. I shall never forget his giving me during a walk the greater part of King Lear, and on a subsequent occasion an impressive rendering of Keats's The Eve of St. Agnes and the Ode to a Grecian Urn.

He knew Dante intimately and wrote a translation and commentary of Scartazzini's Hand Book, which was published in 1887. His knowledge of the history of education is not to be measured by his small though excellent work on this subject. $\mathrm{He}$ was deeply interested in educational progress, and especially in the development of the Froebelian system.

Simple music gave him great pleasure, but he was not musical in the ordinary sense. Politics had little interest for him. His views on current subjects were strongly liberal, and individualistic. He had no belief in socialistic schemes, and was a strong opponent of the later German socialism. He took great interest in scientific work, especially when it touched philosophy ; but except from the mathematical side he knew little of its detail.

In personal appearance he was tall, broad, and of heavy build, with reddish hair and complexion, and a flowing red beard, careless in matters of dress and appearance, but 
brimming over with geniality. Born in Aberdeen, he exhibited many of the physical and mental characteristics of the northern Scot, though, probably from residence abroad, he had lost nearly all trace of the familiar accent. Warm-hearted and generous alike to the good qualities and deficiencies of his friends, he was forcible in stating his opinions and strenuous in argument, especially when opposed, on which occasions a hot temper might reveal itself; but he had no touch of malice or uncharitableness in his nature. As a friend he was devoted and self-sacrificing. Although not attached to any church, Davidson was a deeply religious man, with a firm belief in God in a somewhat pantheistic sense, and an equally firm conviction as to immortality. Writing to me from Capri in 1883 he said: "To me, for one, the eternity of the individual soul is no dogma, but a fact as clearly demonstrated as any in mathematics. And not only so, but it is the most important of all facts, and the one we can least afford to be in doubt about. False philosophy, subjectivism, materialism, and the rest, have rendered the demonstration of the eternity of the individual so difficult that it has become a sort of mark of intellectual superiority either to scout the question altogether, or to talk about it in a jargon which is nothing less than dishonest. It seems strange that while so much attention is being given to the laws of forces which are only of doubtful existence - such as those of the atoms and molecules of gases, - so little should be done to understand that force of which we are directly conscious, the force which is our own soul."

Those who are familiar with Rosmini's restatement of the doctrine of the actus purus of the schoolmen will recognize Davidson's acceptance of this view, to which, so far as I am aware, he adhered to the end of his life.

In I88 I Davidson was a recent convert to the philosophy of Rosmini, an Italian priest who was a reformer within the 
Church of Rome and in this connection best known in this country, his work entitled The Seven Wounds of the Holy Church having been translated into English with a preface by Canon Liddon. Rosmini was, however, also a metaphysician of a high order. His System of Philosophy and Psychology was translated into English and edited by Davidson. The philosophy of Rosmini may be regarded as a restatement of the scholasticism of St. Thomas and the schoolmen, in the light of Hegelianism and later German philosophy. Such a system had every attraction for Davidson. Deeply versed as he was in Greek philosophy, with a profound knowledge of Aristotle as well as of St. Thomas Aquinas and the schoolmen, and thoroughly imbued with the classical spirit, Davidson welcomed Rosmini's system as a means of reconciling the older philosophy and the later German metaphysics, which he had also mastered, and whose subtlety he fully appreciated and admired; though he refused to accept them as a system of philosophy capable of being made the basis of ethical and practical action.

The following extracts from some of Davidson's letters to me are characteristic and interesting, as showing his philosophical position.

"I am interested to hear that you are reading Spinoza's Ethics. It is the most wonderful piece of dogmatism perpetrated in modern times. Hegel calls it der wesentliche Anfang alles philosophisches. ... I do not find any difficulty with Spinoza's "substance," but this comes from my familiarity with the Greek ov $\sigma i a$ and $i \pi \pi^{\prime} \kappa \epsilon i \mu \epsilon \nu o \nu$ and the scholastic actus purus. In my opinion it is the want of power to grasp the concept - this concept of an immanent nontransient act that leads modern thought so wildly astray into all the vagaries of relativity. Get once into your mind the thought that being is an act (not an action) and all the talk about universal relativity becomes pure nonsense. The questions how we come to 
cognize substance, and what substance is when it is cognized, are very different although they are almost always confused. It is entirely true that without light I should never become conscious of darkness, but after I am conscious of darkness I can think of it perfectly well without thinking of light at all. In the same way, though it requires one or more of those transient actions which we call properties or accidents to make me conscious of the immanent act we call substance, nevertheless, once I am conscious of substance I can think of it perfectly well without the notion of accident. The transient exists only to make us conscious of the eternal. . . Hegel's account of Spinozism is not bad. Have you read what Goethe says about the effect on him, in Dichtung und Wahrheit?"

As to Kant he writes: "I am rather amused that you could read so much of the Kritik. After one has discovered its fundamental error the rest are seen to follow naturally and are hardly worth going into. Since the world began there never was such a piece of huge, solemn humbug as German philosophy. The land of beer never did produce but one great thinker and that was Leibniz."

A metaphysician who had read deep and widely, and an acute dialectician, Davidson's guiding motive in later life was, nevertheless, the practical one of founding a new society on an intellectual basis. In earlier life he had made himself acquainted with the best that had been said and done in religion, philosophy, art, and literature, and his rare intellectual ability, his remarkable power of memory and exposition, and his attractive personality combined to make him feel that he might be able to bring into existence a new brotherhood which in time might grow and exercise a profound influence for good. Ultimately this lofty ambition actuated all that Davidson undertook. He surrounded himself with a group of young men of intellectual distinction to whom he looked for aid in this work, and he rallied about him some of his older 
friends who in various ways were to give him help. Impatient of traditions and conventionalities of all kinds he ultimately saw his best chance of success in America, a country to which he had always been much attracted. He writes to me: "A few of us are seriously thinking of attempting to unite on the highest grounds for mutual help toward a rational life and for the bringing about of the conditions necessary in order to make that life possible for people generally. Don't be frightened if the theory at first seems Utopian. That word is generally pronounced with a sneer; but after all it is a Utopia that we want. I, for one, utterly despair of reforming men by legislation which at best only takes from one selfish horde and gives to another. What we ought to do is to let all reasonably liberal government alone and make use of the freedom and protection they afford in order to unite for the purpose of making life what it should be. I know of nothing so well worth doing, nothing that would give life so much elevation, as the formation of a society for the purpose of making every man as far as possible the heir of all the moral, artistic, and intellectual property of the race."

And again in a later letter: "I think the time has come for formulating into a religion and rule of life the results of the intellectual and moral attainments of the last two thousand years. I cannot content myself with this miserable blind life that the majority of mankind is at present leading and $I$ do not see any reason for it. Moreover I do not see anything really worth doing but to show men the way to a better life. If our philosophy, our science, and our art do not contribute to that, what are they worth?"

Davidson's attachment to Rosmini's philosophical views had led some to suppose that he might eventually join the Church of Rome, which he respected and in a sense even venerated, and which had given every encouragement to his work on Rosmini. It was certainly an interesting spectacle in the early eighties to find Davidson in friendly communication 
with the Pope and the Cardinals in Rome and received lit. erally with open arms by the priests and votaries of the Rosminian order throughout Italy. I spent the summer of 1882 with him at his villa above Domodossola, near the Rosminian monastery to which we constantly went to discuss philosophical questions with the learned fathers of the order, with whom Davidson was on the most friendly terms; though, so far as I am aware, he never attended any of their religious services. Between him and Pope Leo XIII there was much common intellectual ground. Both had consummate knowledge of Aristotle and the schoolmen, both were anxious to influence through philosophy the materialistic trend of current thought, and both had been influenced by the Rosminian philosophy. During my visits to Davidson in Rome and in Domodossola I saw much of those who represented the intellectual movement in the Roman Church, to whom Davidson was a persona grata as a layman who understood and sympathized with the philos. ophy to which they looked for a justification of the doctrines of the Holy Church. I have, however, no reason to believe that the idea of accepting the religious doctrines of Rome was ever present to Davidson's mind. Certainly no one who knew him could consider such an event even as a possible contingency. However this may be, ten years later, in 1894, he writes to me: "Have you read the Pope's last Encyclical on the reunion of Christendom? If not, do so; it is wonderful in its way and may mean something. I shall be in Rome in the spring. And how good it would be again to play cicerone to you in the 'eternal city'! Many of my old friends there are dead and gone; but enough are left, I trust, to make a stay pleasant and profitable in social ways. I am afraid I shall be less popular than I used to be in Catholic circles, seeing that I have not been converted within the proper time limits. But there are circles of far greater interest in Rome. Since I came here I have written an article on the 'The Democratisation of England' for the Forum. I rather think 
you will like it. I have tried to be very fair. I am soon going to write one on the present condition of Germany - and it will not be flattering!"

We were in Rome together in 1895 . Davidson was again full of his plans for the formation of an intellectual brotherhood. His lectures in the States during the winter had been well attended, and the summer school he had started at Glenmore in the Adirondacks was growing in popularity, and was rallying round him thoughtful men and women from the American cities. "America," "Intellectual free thought," and "Individualism" were now his watch-words. Two years later, in the summer of I897, I stayed with him at Glenmore when the summer school was in full activity, Davidson living in a wooden house on the summit of a hill, surrounded with his books, whilst in and around the village visitors from various parts of the States had taken primitive accommodations for the summer. The community met daily in a large building where meals were taken together, lectures were given by Davidson and his friend, and readings and discourses took place. Our host was at once the philosopher, friend, and counsellor, and evidently exerted a great influence on those who thus came into close contact with him. The photograph of Davidson sitting outside his home at Glenmore was taken about this time, and was given to me as a memento of my visit.

To me, as to several of his friends, it seemed that Davidson's striking abilities might have found expression in a more suitable environment, and that the work he was doing might have been left to others to do. Efforts to induce him to return to university life, where his great knowledge and influence would have been turned to the best account, were of no avail. His aversion to tradition and convention had become more intense and he felt that university life was no longer possible for him. With his great andj versatile learning and his rare intellectual distinction there was associated a paltry nomadic tendency as well as a strong desire to be influenced 
by as well as to influence current thought at all its centers. His life for years had been divided between New York, London, Rome, Paris, and Berlin. In these and other places he had his friends who always welcomed his periodical visits and were glad to hold converse with his vigorous mind. For money and worldly position he had no concern whatever. His permanent means were very slight indeed, and his simple tastes enabled him to depend upon the precarious and small pecuniary results of lecturing and writing.

Davidson wrote a clear and forcible style, but those who know only his more serious contributions to philosophical literature would scarcely believe that he could also write with brilliancy in a lighter vein. For some years he was an occasional contributor, often anonymous, to a large number of magazines and reviews both in this country and in the United States. The article now reprinted, entitled "A Summer Solitude in the Italian Alps," appeared anonymously in I882 in the Pall Mall Gazette. It gives a delightful description of his life at Domodossola. Another article, "A Lodging with a Greek Priest," appeared in the same place in the same year. I have selected these two articles as representing Davidson's versatility and the charm of his style, as well as his power of picturesque description. Davidson was a voluminous and delightful correspondent. For many years he and I corresponded with regularity, and I have given some excerpts from his numerous letters.

Reference has been made to Davidson's wide acquaintance with poetry. He himself wrote verse occasionally and some of it was printed anonymously. The sonnet appealed to him as a mode of expression, and in concluding this brief sketch I cannot do better than quote a sonnet Davidson wrote soon after the death of Arthur Amson, a young student to whom he was devotedly attached, and whom he took with him to Leipzig, to study archæology under Overbeck, where he died

1 See Appendix D, page 231. 
at the age of twenty. This sonnet was printed in the front of the volume called The Parthenon Frieze and Other Essays, which has a touching dedication to Amson.

Upon a broken tombstone of the Prime,

When youths, who loved the gods, were loved again

And rapt from sight, two human forms remain.

One, shrunk with years and hoary with their rime,

Gropes for the hand of one who sits sublime

And, calm in large-limbed youth, prepares to drain The cup of endless life. In vain! in vain!

He cannot reach beyond the screen of time.

So, Arthur, as our human years go by,

I stand and blindly grope for thy dear hand,

And listen for a whisper from thy tongue.

In vain! in vain! I only hear Love cry:

" He feasts with gods upon the eternal strand;

For they in whom the gods delight die young." 


\section{CHAPTER XVII}

THE MORAL ASPECTS OF THE ECONOMIC QUESTION: A LECTURE READ BY MR. DAVIDSON BEFORE THE FELLOWSHIP OF THE NEW LIFE, IN NEW YORK

In considering this subject, I shall set out with two assumptions: first, that human life does not consist in material possession; second, that it does consist in free spiritual activity, of which, in this life at least, material possession is an essential condition.

If there be any one here who does not admit these postulates, any one who holds that human life consists in having and holding, and not in being; that man lives to eat, and does not eat to live a human, that is, a rational life ; if there be any one who holds that political economy is the whole science of human life, then no conclusion at which I may arrive will have any meaning or cogency for him.

There are certain great advantages in the division of labor, and especially of scientific labor; but there are also certain great disadvantages. If we look closely at these, we shall find that the former are mostly in the way of material results, the latter in the way of spiritual ones. There can be no doubt that by dividing labor - whether industrial, artistic, or scientific - we obtain larger and, to some extent, better immediate results than we should if every man performed every kind of labor. Ten men devoting themselves each exclusively to one trade will produce more and better results than if each undertook to exercise all the ten trades. So likewise ten scientific men, devoting themselves each exclusively to one branch of science, will attain greater and more 
accurate results than if they scattered themselves each over ten branches of science. But in both cases these manifest advantages will necessarily entail certain disadvantages. The man who devotes himself exclusively to one trade will have a much narrower range of developed capabilities, a much dimmer notion of the relation of trade to trade, and be much less independent of social arrangements than if he could exercise ten trades, even in an indifferent manner. So likewise the scientific man who spends his whole life in studying one branch of science - say astronomy or mathematics will have a much narrower culture, a much vaguer notion of the whole range of science, and of the interrelation of its various parts, than if he were fairly well conversant with ten branches of science. I know a man who has ladled tar for over thirty years, and he does it to perfection; but, if there were no tar ladling to do, I doubt whether he could make his living. On the other hand, I once knew a man in a wild region of Minnesota, who built his own house, having first made his own bricks, and felled and sawed his own wood; who dug his own well, made his own pump and put it in, built his own barn, cultivated his own farm, caught his own fish, built the steamer that crossed the neighboring lake (all but the engine), made sets of teeth, was dentist and physician to the people for leagues around, and preached every Sunday to his neighbors. This man was, of course, intelligent, shrewd, and independent. He did nothing supremely well, but he did everything fairly well ; and lived a good, healthy, active, manly, human life. I need not say that he was a Yankee. In like manner I know a man who, though one of the first astronomers of our day, is in reality an intellectual child and a boor, with no broad or humane notions about anything; and I could name another man who, though knowing no science supremely well, has so much knowledge about all the sciences that his opinion regarding any scientific question, whether in the region of physics, morals, or metaphysics, is of great value. He is a man of culture. 
It appears then that by division of labor, while there may be much economic gain, there is considerable intellectual and moral loss. Such division, while adding to man's possessions, tends to dwarf and cripple him. It is perhaps worth while to inquire at what point the loss exceeds the gain, and to stop division of labor just short of that point. . . .

Political economy has thus far begun at the wrong end. It has assumed certain economic conditions, and asked what is their natural result; afterwards accepting the result, and the conditions, as if they were necessary. A true political economy will begin by stating what sort of possible result we wish to reach, and then inquiring under what economic conditions this result can be best realized. For political economy is a practical science, and not merely a theoretical one. It is a deontologic science, a science of what ought to be, and only indirectly an historical science, a science of what is or has been. Political economy is a branch of Ethics, not a branch of natural science like zoölogy, with which a certain superficial and arrogant school of thought classes it.

One of the avowed and cardinal assumptions of the political economy of selfishness is this, that every man tries to obtain as much of the means of satisfaction as he can, with the smallest possible amount of labor. Along with this it makes the tacit assumption that means of satisfaction are wealth, and that the more material wealth a man has the greater is his power of satisfying his desires. It makes also the further assumption that trouble and labor are synonymous terms, and hence that labor is pain, submitted to only for the sake of subsequent pleasure.

Now all these assumptions rest upon a mere fundamental assumption that man is simply an animal whose sole desire is to satisfy his animal appetites. But I set out with the contrary assumption that man is a rational being whose true satisfaction is found in spiritual activity. Spiritual activity, let me now add, consists of three things, - first, pious intelligence; 
second, unselfish love; third, practical energy ; guided by intelligence and love to universal ends. Upon my assumption all the three assumptions of the economy of selfishness fall to the ground, being entirely incompatible with a moral element in man's nature. Let us consider these assumptions, beginning with the second.

Is it in any sense true that, to a moral being, the only means of satisfaction is wealth, and that the more wealth he has, the more readily he can satisfy his desires? Is it true that all satisfactions can be obtained for material wealth? Is it true that even any of the highest satisfactions can be bought for it? Will wealth buy a pure heart, a clean conscience, a cultivated intellect, a healthy body, the power to enjoy the sublime and the beautiful in nature and in art, a generous will, an ever helpful hand; these deepest, purest satisfactions of human nature? Nay, not one of these things can be bought for all the wealth of ten thousand worlds; and not only so, but the very possession of wealth most fre'quently stands in the way of their attainment. It is easier for a loaded camel to pass through the little night-gate, called the Needle's Eye, than for a man loaded with wealth to enter the city of true, human, spiritual satisfaction. The material will not buy the immaterial, for they have no common meas. ure; and all man's deepest satisfactions are drawn from the immaterial. There is not a virtue, or a high human satisfaction, that has not been attained without wealth, and very few of them have been attained with it. This is an old story, taught as a lesson for thousands of years ; but we have hardly yet begun to learn it. What shall it profit a man if he gain the whole world, and be a mean, contemptible, human pig, finding satisfaction only in varnished swinishness? My God! I had rather be a free wild boar, basking and battening in the breezy woods, without a soul and without a mind, than, having a soul and a mind, prostitute them in grovelling for wealth, and craving the satisfactions which it can give. 
It is not true, then, that wealth is the only means of satisfaction, or that true human satisfaction bears any ratio to wealth.

Again, is it true that labor is necessarily trouble and pain? Let us see. I know of no sadder and more humiliating reflection upon the position of labor in our time and country, no clearer proof of the moral degradation entailed by our present economic system, than the prevalent conviction that labor is pain and trouble. We hear a great deal declaimed about the honorableness of labor, as if that were a fine new sentiment instead of being something which it is a disgrace ever to have doubted; but we hear hardly a word about the delights and satisfactions of labor. And the reason is, alas! that there are no delights or satisfactions in it.

But is this state of things a necessity? Or is it only a temporary result of an evil system? There is not a shadow of doubt about the matter. Labor is not in itself pain and trouble, and it is only a wicked and perverse economy that now makes it so. Labor, on the contrary, under a wise economy, is to every rational being a pleasure; not something to be avoided, but something to be sought. Labor with a view to good ends is rational man's natural occupation. . . .

To say that wealth is whatever is useful or agreeable, or to say that wealth is whatever has an exchange value and satisfies desires, is no human definition of wealth. The former is a foolish, the latter a mere animal, definition. There is no definition of wealth possible save in terms of man's moral nature. That, and that alone, is wealth which contributes to develop and elevate that nature. If we confine the term "wealth" to material things, its true definition will be this : Wealth is the sum of those things which possess exchange value and which contribute directly or indirectly to increase man's spiritual and moral power. This it is, and neither vague usefulness, nor the power to gratify desires indiscriminately, that constitutes true wealth. 
The whole of our current political economy is vitiated by this initial animal, immoral definition of its subject. Some strange results follow from it. Wealth being in the last analysis that which satisfies desires, the man who seeks wealth is simply seeking to satisfy his desires; but, inasmuch as that is the characteristic of animal nature, it follows that man, in laboring to obtain material; possessions, has no aim higher than the animals have. In so far as a man 'seeks the means of satisfying his desires, and not the means of furthering ends which he clearly sees to be good and universally beneficial, in so far he is an animal and a slave, and not a man at all....

What, think you, is the fundamental cause of all our present economic troubles, - our strikes, our boycotts, our socialisms, our anarchisms, etc.? Is it not the simple fact that wealth, being regarded either as an end in itself, or as a means of satisfying desire, is pursued for purely selfish ends, without any regard to public well-being, or to spiritual and moral progress, which is inseparable from public well-being ? . . .

Had men holding an exalted and spiritual view of man's nature not been so much occupied with the next world as to lose sight of the interests of this, but had early taken to the study of political economy, as they are now being compelled to do at this late hour, the science might have been developed on the true basis of man's entire nature, instead of upon the animal basis of selfishness....

When the new political economy comes to be applied human life will concentrate itself, first of all, about the school - not the school of to-day, but the school of the future, in which not merely the memory and the tongue, but every faculty of heart, head, and hand will be trained, exercised, and developed. Closely connected with the school, and, indeed, forming its public hall, will be the church, wherein the God worshipped - worshipped with rational, heartfelt admiration, and not with slavish, formal lip-service - will be 
the trinity of justice, love, and helpfulness. Opening out from this church will be an art gallery containing the noblest and most inspiring works of human genius, and a theater wherein the deepest and most moving problems of human life will be presented by art, in living forms, to eye and ear. Secondary and subordinate to all these will be the factory and the store, yea, even the court of justice.

Cities whose centers are schools, and which are built not with a view to wealth-making so much as with a view to health and beauty, will stand not upon low, marshy, malarious ground, but upon heights swept by bracing winds, and commanding a free outlook into the great world. . . .

The remedy for our present evils, and for many others that must come upon us sooner or later, lies in enlightening the public mind; and the first step towards this will be the casting aside of our present immoral and selfish political economy, our present views regarding the nature and uses of wealth, and the replacing of them by an economy which places in the foreground the moral aspects of every economic question, and considers wealth solely as a means for the advancement of man as man, in all human virtues and perfections. . . . In other words capital will no longer be the mother of wealth, and labor of poverty. 


\section{CHAPTER XVIII}

EXTRACTS FROM LETTERS SENT BY THOMAS DAVIDSON TO MORRIS R. COHEN AT THE BREADWINNERS' COLLEGE, NEW YORK

In the preface to this volume, and in Chapter XIII, reference has been made to Davidson's interest in the breadwinners of New York. His chief friend and assistant among the Russian Jews who formed the center of that organization was Mr. Morris R. Cohen, through whose kindness I have received the following amongst other letters, written to him by Mr. Davidson.

“Hurricane, Essex County, New York, May $7,1899$.

... The man of reflection is not apt to be the man of action; and yet it is just he who ought to be so. It is the philosopher who ought to be the king. And yet just because philosophers have not been careful to cultivate their wills, they have always been bad kings; and kingship has been usually left to men deficient in insight and power of thought. But I do not believe that this need be always so. The difficulty arises from the fact that our philosophies, thus far, have been too abstract, ideal, and Platonic ; concerning themselves with things and conditions too far remote from human experience, instead of with experience itself. This again has been largely due to the fact that all original thinkers have found the world in possession of certain ancient and traditional ideals, which it was regarded as impious to disturb, and that, therefore, they have had to betake themselves to unreal regions, philosophical and social Utopias. Even to this day there is no philosophy of actual experience, no working theory 
or norm of life, based upon the results of carefully digested science. Indeed, such philosophy is the great desideratum of our time, and the future will belong to the man who can furnish it. Such a philosophy will make men of strong wills, just because it will make them realize that thought, apart from action, is mere impotent flapping of wings in vacancy.

The philosophers of the future will, like the early Greek philosophers, be men of action, the founders of societies, the chief agents in all social reform. They will be loyal, not to the past, but to the future - to the social order that is to be.

Fourteen years ago I found Mr. — very much where you are now. He was much of an ascetic, had read a great deal in a desultory way, and was very open-minded. His difficulty was that he had never applied himself sternly to accurate hard work. I said to him: "You will never be of much use in the world till you discipline yourself, and pursue some course of study with unflinching tenacity until you have mastered it.' And I quoted to him Goethe's words : 'Do one thing well, and that will be to thee the pattern of all things that are well done.' He took my advice, went to college, living on next to nothing, and did four years' work in three. I need not tell you the rest. He has for several years been professor of Ethics in - University, and has now come away, casting off his academic shackles, and preparing to enter the great field of toil for humanity. Go and do thou likewise ; there is nothing to prevent you. Gis not the only young man whose whole life I have changed by a word spoken in season.

What you say of college study is but too true. It is mechanical and formal, and does not build up in the soul an ideal world, realizable in life. It leaves that to the rabbi and the priest; and they, for the most part, try to build up an ideal that is no longer realizable. All the more need for a new sort of education, a need which you may help to satisfy. 
You see where I am trying to lead you. First you must discipline yourself by accurate and continuous study. For this purpose there is nothing better than Latin or Greek. Next you must get a comprehensive view of man's nature and of the whole course of his evolution, so that you may be able to recognize your own part in the great human drama as well as the plan of that drama generally. You must avoid all one-sidedness, all over-devotion either to past or to present. You must correct Karl Marx by Isaiah, and vice versa. If you do this loyally and persistently, the meaning of life will gradually break upon you, and you will find yourself filled with a hope, and animated by a courageous purpose which will make earth a heaven to you. If we cannot make heaven here, I see no guarantee that we shall be able to make it anywhere. When you have reached this point you will be fit to teach, that is, to create a newheaven and a new earth in the souls of your pupils: for that is the true meaning of teaching.

Your friend,

Thomas Davidson."

My dear Fellow :

"Hurricane, Essex County, New York, May 14, 1899.

It was very good to get your long and serious letter, and I have read and re-read it with care. I am glad to have you look upon me as a father. . . .

I recommended Latin as a study, not on account of its literature, but because it is the best study I know for disciplining the mind, for imparting to it grasp, accuracy, and persistence. For you it would be an admirable study. . . . And, after all, if we use the term in a broad sense, Latin has a splendid literature. Think of the Roman historians and, above all, of the jurists! The Code of Justinian is one of the greatest works in the world. Then, nearly all of mediæval literature is in Latin. To the man who does not know Latin, 
one of the greatest ages of the world, the age of growing humanism, is a closed book. . . .

It is a great mistake to think that any modern language can take the place of Latin. And you can still learn it. You are young, and brave; and even if you are 'constitutionally nervous,' that will pass away when you can be persuaded to take plenty of vigorous outdoor exercise, which, indeed, for you is an absolute necessity, if you mean to do anything in the world. Twenty-five years ago I adopted a Jewish boy of genius, and sent him to Leipzig to study. He had a brilliant career, but died at the end of two years, mainly, I believe, because he refused to take the necessary exercise. One of my books is dedicated to him. I hope a man so loyal to truth as you, so willing to abandon prejudices, is not going to cling blindly to old, monotonous habits, however inveterate. Here is a fine chance for the exercise of redeeming will.

It is well that you should feel strongly about the injustice which prevails in the world. There is much of it; but, unless your feeling takes form in study and in action, it will only make you an unhappy, querulous misanthrope. All feeling that does not issue in action is morally injurious. It is always wrong to brood in sloth. Every feeling of injustice ought to be supplemented by a resolution and an effort to right the injustice. Otherwise the soul becomes morbid. Railing at wrong is a melancholy business. Let us fight for right.

Let me kindly counsel you not to study Spanish now; it is not worth your while. Spanish literature has no single work of the highest order. Priestcraft and superstition have paralyzed Spain, and now she is dying. Don Quixote is a much overpraised book, and can be read in English as well as in Spanish. If you wish, and have time to learn a modern language, let it be Italian, which has a glorious literature and is the most beautiful of languages.

I am afraid that the study of the history of philosophy may, for a time, confirm you in a feeling which you now seem 
to have, and which is not unnatural, namely, that philosophy is, mostly, a mere collection of discordant opinions, none of which have any claim to scientific truth. This is not so. Philosophy has a real history, but it is not easy to dig it out, and very few ever come to grasp it. Yet to the patient student who, setting aside names and popularities, persists in following the gradual evolution of human thought, there finally comes the insight that, despite all apparent contradictions and confusions, dogmatisms and scepticisms, thought has steadily developed; and that we are progressing toward a comprehension of the world, that is, toward a production in consciousness of unconscious processes. . . .

There is not the slightest need for scepticism, dogmatism, or ' will to believe.' These are merely the refuges of sluggish and inaccurate thinking. The human mind is quite capable of solving all its own problems, and reaching truth and joy. But before such solutions can have a value for humanity, or be the means of doing away with the injustice which so tries your soul, there must be a new apostolate, a new race of prophets. . . :

Then you will see the element of truth there is in your plea for extremists. There are two elements necessary for the truly great man, the permanent benefactor of the race: (I) a vision of truth applicable to his own time; (2) enthusiasm for the spread of that truth. Hitherto these elements have rarely, if ever, been combined in one man. The great thinkers have rarely been enthusiasts; the enthusiasts, like Isaiah, Mohammed, etc., have not been great thinkers. This is the reason why their work has been good but for a short time, and then has become evil. You need not be told that Judaism and Islam are, in our day, the greatest obstacles to civilization and universal justice. They bar the way to enlightenment by encouraging sluggishness of intellect, and the belief either that we cannot solve our problems, or that their solution has been miraculously revealed. And yet these religions were once of great benefit to the world. The enthusiast - 
extremist, if you like - of the future must combine his enthusiasm with clear intellectual insight and wide knowledge, and then his work will endure without becoming an obstacle to progress. Good-bye.

Ever yours affectionately,

\section{Thomas Davidson."}

"Hurricane, Essex County, New York,

My dear M May 29, I 899.

... That you are attached to socialism neither surprises nor disappoints me. I once came near being a socialist myself ; and, indeed, in that frame of mind founded what afterwards became the Fabian Society. But I soon found out the limitations of socialism, and so I am sure will you, 'if you are true to yourself.' I have not found any deep social insight, or any high moral ideals, among the many socialists I know. I believe that your views and mine are not widely different, all the same. We both believe that the present economic and moral condition of society is bad and needs reforming. We both believe that this can be done only through an increase of social sentiment, of brotherly relations. We both believe that economic improvement bought with moral deterioration or with loss of freedom is undesirable. We both see, I take it, that when society is social enough to adopt socialism it will be ready to adopt something better, if such presents itself. Further, I suppose, we both see that mere economic socialism - that is, the owning of all the means of production by the state - would not necessarily insure economic well-being, that Crokerian socialism, for example, would be sure to do the opposite. Socialism could not abolish 'bossism,' but would rather increase its opportunities and power. Lastly, we both hold, I trust, that any social or economic arrangements which do not carry with them the assent of the great mass of the people, but are octroyés from above, are enslaving. I am free in a social order only when it is the expression of my rationality, 
and gives me scope for the fullest exercise of all my powers. What you believe in relation to socialism more than this, will you kindly tell me?

Historically, nations have been great, I believe, in proportion as they have developed individualism on a basis of private property. ... If socialism once realized should prove abortive, and throw power and wealth into the hands of a class, that class would be able to maintain itself against all opposition, just as the feudal chiefs did for so long. Feudalism was socialism; that is often forgotten.

But one fact must strike you forcibly, that economic wellbeing does not insure moral nobility. Our wealthy classes are a standing proof of this. In fact, I think that wealth is more fatal to morality than poverty is.

My own belief is that the way out of our difficulties is not through any increase of state functions, but through a slow growth of the moral sense, and the social spirit. Having these, we shall easily get socialism, or anything else that is desirable ; without them, never. . . .

I should like you to ask yourself how you are certain that there existed a world long before you were born, and what sort of a world there would be if you subtracted from the world that you know and can talk about, all that is your feeling. It will be well to answer the second question first. Here again the 'tyranny of ideas' is playing a part and concealing from you the great truth of personal immortality. You must come to see that there is no world at all without you. Your grandfather, whom you have made interesting to me, is not a mere memory, but an external, living soul, a god in the making, as all gods are. And you must not confound feeling with consciousness, which is distinction among feelings. You have existed from all eternity, else you would n't exist now, but you have not been conscious from all eternity. You are not conscious in deep sleep; yet you are and feel, else you could n't be waked. The child in the womb is not conscious, 
yet it is very busy building up a body. And even now you digest, breathe, make your blood circulate, etc., without consciousness. Nay, you often walk unconsciously. 'Before Abraham was, I AM,' said Jesus of Nazareth. It is a great satisfaction to be thoroughly convinced of one's immortality; and one may easily be so who thinks logically. I don't know what Weltschmerz is, and I have no fear of death, or of anything that may come after. I AM! As Manto, in Faust, says : Ich harre mich umkreist die Zeit. . . . I am sure that if the conviction of immortality would make your life 'full of joy,' I can procure you that joy. It must be dreary to go through life feeling that it ends in a hole in the ground; that however noble a character one may have built up, with pain and sore toil, it all goes out like a blown candle. I am glad to say I know that view is not true; and I know that no great soul has ever held it. If I have drawn out a spark of your affection I will guard it as the most sacred of things. I can say in return that you are very dear to me, and that I am

\section{Your loving friend,}

\section{Thomas Davidson."}

"Hurricane, Essex County, New York,

My dear —_: June I 2, I 899 .

Your good letter is here, and I have read it with great pleasure. I like your defense of your views, though I cannot share them. Honesty and sincerity are the first of virtues, and it is better to be a little over-ready than to be timid and backward. After all, each one has to work out his own world in his own way. It would be a great pity if you should drop a placard so long as you feel justified in wearing it. I shall be surprised, if the experiences of the years to come do not make you feel that the tyranny of ideas is, for the most part, the result of placard-wearing, or sectarianism.

I have for years been at work on a History of Mediaval Thought, and have come to the conclusion that all the good 
in Christianity came from its ethical principles, all the evil from the placard-wearing of its professors. And I know many placard-wearing socialists who openly declare they would persecute, if they had the power; persecute wealth, individualism, and Christianity.

It does not seem to me that you have quite answered some of my questions in regard to the external world. The assertions you make are correct, but they do not touch the real points, which are: How do we come to assume an external world? What does that world consist of when we subtract from it all that is due to our sensibility? To what is that world external?

You are altogether mistaken in thinking that $I$ am an idealist. I have fought idealism for forty years with all my might.

You are still bothered by the notion of matter, and you are in good company. I suggest that you try to formulate to yourself not what matter is, but what you know it to be. Subtract from it what is your subjective feeling, then tell me (I) what is left, (2) how you know it is left, (3) whether the process by which you know it is a valid one. You confess you do not know what matter is : how do you know that it is?

I feel that it is a little unfair to fire these questions at you, before you have read Hume and Kant, and fully grasped their problem, but I am so anxious that you should have the joy of believing in the immortality of the individual that I allow myself to do so. Perhaps I might ask another question : How do you distinguish between the world and your experience of the world?

I have no difficulty in understanding your antipathy to certain 'types' and institutions; but I am sure that antipathy and hatred are not comfortable or profitable inmates of the human soul. They are very blinding, and they do not help us in dealing with their objects. Croker and his crowd are undoubtedly bad men; but for that reason they need our 
help. Such help may indeed take the form of punishment, but that should be inflicted in love, and not in hate. I have never found anything gained by hatred. After all, even Croker is our brother man, and many others would do just what he does if they had the ability. The great difficulty is that what Croker wants everybody wants. One reason why the Christians succeeded was that they showed contempt for what other people wanted. They said to the rich: 'Keep your riches and take ours; we have treasure in heaven.' They discredited wealth, and in the end made the rich ashamed of themselves. Now although a certain amount of property is necessary for a healthy, full life, yet overweening wealth should be despised; and the man who hoards should be unpopular. We are all to blame for the estimation in which wealth is held. We place the economic too high.

Your friend,

Thomas Davidson."

Dear Morris :

"Chatwold, Bar Harbor, Maine, October 24, I 899 .

Your letter made me very happy. I am so pleased to think that your class begins to-day, and I trust that it will meet your highest expectations. You have now an excellent chance to show what you can do, and I hope you will do it.

It will be great if you can show what progress really is : advance in being, that is, in insight, sympathy, and helpful will.

You know, of course, that the true teacher is not an apostle, or an advocate ; that he keeps his own views in the background, and strives merely to help his pupils to insight of their own. In the end, as Carlyle said, 'It does not so much matter what a man believes, as how he believes it.'

Be willing that your pupils should contradict you, and come to conclusions entirely different from yours, even on points that seem to you essential. 
Don't be too anxious to make them come to conclusions. Allow facts to simmer in their minds, till time and reflection can do their work. I am,

Yours affectionately,

$$
\text { Thomas Davidson." }
$$

[No date.]

"... 'What is the rational basis of morality?' Like you, I have never found an answer to that question in any book. I have, however, worked out one for myself, which I think satisfies all reasonable demands, and rests upon a basis of pure fact: I, as I know myself, am a permanent feeling, which, through experience, gradually differentiates itself into a world. But the feeling which I am has another side, namely, desire. I am a desire, which desires TO BE - to be ever more and more, - that is the active, creative, free aspect of me. Now, my wellbeing, which means my ever-greater-being, depends upon the extent and harmony of my world. But that extent and that harmony depend upon the satisfaction of the desires of all those other beings, or 'substantial feelings,' which I recognize as entering into and affecting my world. I cannot attain the fullest being unless they do the same. Therefore I must love my neighbor as myself, since his well-being is my wellbeing. Thus the completest egoism and the completest altruism are identical, and rigorism is reconciled with Hedonism. But to love one's neighbor as oneself, when properly understood, is the substance of all morality. Hence morality rests upon a perfectly rational basis, if you like. Here again I might quote from Wordsworth :

If thou be one whose heart the holy forms

Of young imagination have kept pure,

Stranger! henceforth be warned; and know that pride,

Howe'er disguised in its own majesty,

Is littleness; that he who feels contempt

For any living thing, hath faculties

Which he has never used; that thought with him

Is in its infancy. 
Translated into prose, this means that we maim ourselves by shutting out anything from our sympathy and love. But is not this a completely rational ethics? I have put it into practice for many years, and can testify that it is, for me, completely effectual. I have found that Unheil üben ist eigenes Elend, as Jordan says. In wronging another I am damning myself. I could talk a long time about this; but perhaps I have said enough to start you on the right track, or rather, on what seems to me the right track. I am greatly interested in your experience with the lowest class of men and women; it will be very valuable to you in the future. But now, ask yourself, have they a large world? Can they have a large world, without altering their whole lives? The answer is not doubtful. The 'clam at high tide,' and the well-fed cow are, doubtless, happy ; but what a happiness! Would you exchange places with them? You will say 'No,' but perhaps add, 'Nor would they exchange with me.' I say they would, if you could make them realize your world. So of the low, selfish men of whom you speak. They are where they are because they cannot realize any larger world. They may live and die in this condition, and others of their sort may envy them; but death is fortunately not the end. The same principles upon which I rest my ethics furnish the grounds for a proof of immortality. Ethical life and immortality, I see plainly, are forever inseparable. It needs no faith, no 'will to believe,' to tell me that. It is a scientific fact. But we will speak of this great question later. To be taught by my good friend, Baralt, is certainly a great temptation to learning Spanish ; but yet I think Latin would be more to your purpose. When you know that, Spanish and Italian can be learned, each, in a month. There is nothing of value in Don Quixote that you cannot get in a translation. The refinements of Spanish are for Spaniards alone.

You do well to attack Kant's problem; it lies at the foundation of all modern thought. To be sure, he did not solve 
it, and that because he was afraid of the logical results of his own premises; but that does not prevent us from solving it by the application of his principles. By insisting upon the existence of the Ding an sich - which, by its very definition, lies outside of experience - he paved the way for a new agnosticism or skepticism, and a new dogmatism or faith. Hence the systems of Spencer, Balfour, James, etc. He also paved the way for such hollow schemes as those of Schelling and Hegel, which for half a century deluded the world, and to some extent delude it still. They functioned with the forms of thought, disregarding the content, without which the forms have no meaning (as Kant saw); and of course they arrived at a sort of Vedantic or neo-Platonic mysticism, which played into the hands of the clergy and obscurantists, as indeed Hegel meant it should. He called his system a Restaurationsphilosophia! It is thoroughly insincere, and time-serving. It has distinct merits, however, but they are not philosophical merits. Caird, as I found out in a conversation with him, is a reactionary; and Watson has recently shown himself to be the same. Their positions made this almost necessary. Things are not true because big men believe them.

I am glad you do not believe in the 'vanity of philosophizing.' Your last letter seemed to say you did, but we need not mind that. You never will refute Zeno's arguments against the reality of motion as usually conceived. They are perfectly valid, as Rosmini - the acutest thinker of the century - was forced to admit. (See my translation of his psychology, §§ I 208 sqq.) Had Zeno - the ancient Kant, only more acute - been followed, and his proofs taken seriously, we should have been spared twenty-three hundred years of mythical thinking. We should have seen that all our common-sense ideas of the phenomenal world are utterly selfcontradictory, and should have been forced to the conclusion that spirit, or 'substantial feeling,' is the one reality, through and for which all things are. You might try your hand at 
the puzzle of Achilles and the tortoise. Had Aristotle fully grasped that, he would have added to his logic of Being a logic of Becoming, as Hegel blunderingly tried to do, starting his treatise with the notion of Being!! What we really need is a logic recognizing that Being is Becoming, when properly understood. There can be no change in time, except for that which is above time. Rosmini has admirably demonstrated this, showing that mind ( $m y$ mind) is eternal and ubiquitous. This may throw a ray of light upon your problem of the 'I,' which is not so very difficult, after all. We make a complete mistake when we substitute the categories whereby reality is articulated, for reality itself. All reality is feeling; cate-, gories merely distinguish it. This is the reason why all abstract science fails to reach the truth of things. Knowledge is but one element of truth; feeling and desire are the others. A feeling, and the notion of a feeling, are widely different things. Action is the true expression of truth, I mean moral action. 'I had rather feel compunction than know the definition of it,' says Thomas à Kempis. I need not say that Faust's entire effort is to feel, instead of to know. You remember he substitutes for "Im Anfang war das Wort," "Im Anfang war die That"; and elsewhere he says, "Gefühl ist Alles," "Name ist Schall und Rauch," which is not true either....

Your joyful hope of one day coming to see the truth, and to discover what things in life are really great, will - I am sure - not be disappointed, if you are only true to yourself. And I believe you will be. You will battle against the tyranny of ideas, and insist that ideas must conform to reality, not reality to ideas. Before Plato men believed that reality must correspond to the divine will (superstition, religion). After him they held that it must correspond to ideas (metaphysics). We are learning to-day that it has not to correspond to anything but itself, that gods and ideas are mere abstractions from it. I should be much pleased to hear or 
see your oration, and also your talk to your club. Are they written down?

I hope you will long continue to hold your own against all teachers and all authorities, no matter how imposing. In the pressure of the world it is not easy to do this; but it can be done, and great is the reward thereof. By being loyal to truth you can be of infinite service to mankind, and at the same time prepare yourself for loftier spheres of activity.

I was much interested to hear that you had spoken to the class on dialectic philosophy. I do not know what attitude you assumed to it. There is dialectic and dialectic. Have you read Trendlenburg's criticism of Hegel's dialectic in his Logische Untersuchungen? It is well worth reading. My friend, Chiappeli of Naples, has shown the connection between the dialectic of Hegel and that of Marx.

I expect to extend the scope of my work at the Alliance next year, and to get Bakewell, Griggs, and others to help me. Perhaps you will be able to take a hand. When do you graduate?

Political economy is not a science; that is certain. It is far too abstract, and omits too many of the essential elements of human nature. It must widen itself out into a study of man as a social being. And to that you should devote yourself. For one thing is certain: all future reforms must rest upon a new conception of the social man. The old notions, due to religion and metaphysics, have had their day and are no longer available. We must come to see that man is eternal and divine in his own right, and that he is working toward the only possible and conceivable heaven, - a republic of pure, wise, loving, energetic spirits, rising to ever completer harmony and closer intimacy with each other. To aid in realizing this heaven I believe you are called. Good-night !

I am, with faith, hope, and love, ever yours, Thomas Davidson." 


\section{CHAPTER XIX}

\section{ROUSSEAU, AND EDUCATION ACCORDING TO NATURE}

In what Davidson wrote on Rousseau, and Education according to Nature there are many side lights as to his philosophical position, and his views on sociology. He gave lectures on the subject at Glenmore, as well as in New York; and they were amongst the most useful parts of his oral teaching. What he committed to writing in 1898 is here summarized in four sections; the first on "Ideas and Aspirations as to Authority, Nature, and Culture, Current in Rousseau's Time"; the second on "Rousseau's Life" ; the third on his "Social and Educational Theories"; and the fourth on his "Influence."

\section{Ideas and Aspirations as to Authority, Nature,} and Culture, Current in Rousseau's Time ${ }^{1}$

If true human greatness consists in deep insight, strong and well-distributed affection, and free, beneficent will, Rousseau was not in any sense a great man. His insight, like his knowledge, was limited and superficial; his affections were capricious and undisciplined ; and his will was ungenerous and selfish. His importance in literature and history is due to the fact that he summed up in his character, expressed in his writings, and exemplified in his experience a group of tendencies and aspirations, which had for some time been half blindly stirring in the bosom of society, and which in him attained to complete consciousness and manifestation for the first time. These tendencies and aspirations, which may be

1 Summarized from Rousseau, and Education according to Nature. Copy. right, 1898 , by Charles Scribner's Sons, Publishers. 
comprehended under the one term individualism - or, more strictly, subjective individualism - have a history; and this we must now sketch, if we are to understand the significance of Rousseau.

The ruling principle of the Middle Ages was authority. Man, created for God's glory, was only a means to that end, and had no freedom of thought, affection, or will. The task of the centuries since that time has been to shake off this yoke, and to restore men to freedom; that is, to convince them that they are ends in and through themselves.

The Germanic Reformation claimed freedom for the individual intelligence; the Italian Renaissance, freedom for the individual feelings and emotions. Neither, however, thought of aspiring to freedom of the moral will, which is the only true freedom. This is a fact of the utmost importance in enabling us to comprehend the thought and practice of the sixteenth, seventeenth, and eighteenth centuries. We look vainly in these for the conception of moral freedom ; and what its absence meant we can perhaps most clearly see when we realize that the complete and logical outcome of the Reformation was found in Voltaire; that of the Renaissance, in Rousseau. It took the clear mathematical mind of the French to carry principles to their logical conclusions in thought and practice. What Rousseau demanded was absolutely free play for the feelings and emotions. But it took a long time for any one to become clearly aware that this was the true meaning of the Renaissance.

The reformers appealed to reason, the humanists to nature. The notion of nature was an inheritance from the Greeks, but, as time went on, nature, and gradually mind or reason also, fell into disrepute; and the supreme object of interest became Plato's so-called ideal world. This tendency, along with many other things in Greek philosophy, passed over into Christianity, and reached its culmination in the Middle Age, when nature and reason were both equally 
regarded with suspicion as the origin of evil ; and the ancient place of Plato's ideal world was taken by an authoritative revelation.

In the seventeenth century churchmen, for the most part, clung to revelation and authority; other thinkers tried to make peace between reason and nature. The English mind, generally preferring nature, tried to explain reason through it; the French, setting out with reason and finding no way of arriving at nature, left the dualism unsolved. Bacon, Hobbes, and Locke form a strong contrast to Pascal, Descartes, and Malebranche. Rousseau generally followed the former, especially Hobbes, who conceived the "state of nature" to be one of universal war. He taught that in spite of differences, mental and bodily, when all is taken into account men are not only equal, but have equal rights. "The right of nature" is the liberty of each man to use his own power as well as himself for the preservation of his own nature - that is, his life - "and to do anything which he shall conceive to be the aptest means thereto." A common power must be set up to maintain covenants between men, and to direct their actions for the common benefit.

"The attaining of this sovereign power is by two ways. One is by natural force.... The other is when men agree amongst themselves to submit to some man, or assembly of men, voluntarily, on confidence to be protected by him against all others." Hobbes went on to say that the power once established can never be replaced or annulled, and is binding on all; that the sovereign, once elected, can do no injustice; and hence cannot be put to death, or be punished by his subjects. His views with regard to law are characteristic, and are as follows : "The law of nature and the civil law contain each other. For the laws of nature, which consist in equity, justice, gratitude, and other moral virtues on these depending in the condition of mere nature . . . are not properly laws, but qualities that dispose men to peace and obedience. When 
a commonwealth is once settled they are actually laws, but not before. . . . The law of nature therefore is a part of the civil law." And again, "Reciprocally, also, the civil law is a part of the dictates of nature. For justice, that is to say, performance of covenant and giving to every one his own, is a dictate of the law of nature."

In I689 Locke published two Treatises on Government. In considering how political power could rise he made the two fundamental assumptions of Hooker and Hobbes: (I) that mankind started on its career in a state of nature, in which all individuals enjoyed complete liberty and equality; (2) that the transition from this to the civic state was through a social contract ; but he sided with Hooker, against Hobbes, in maintaining that the state of nature was one of peace, governed by a natural law. He says: "The state of nature has a law of nature to govern it which obliges every one, and reason is that law. It teaches all mankind who will but consult it, that being all equal and independent no one ought to harm another in his life, health, liberty, or possessions.... All being the servants of one sovereign Master, they are made to last during his pleasure."

Locke rejected Hobbes's theory of despotic sovereignty, and believed that men, by submitting to common laws, gain freedom. He maintained that when a form of government failed to perform its functions it might be overthrown and another put into its place.

Hobbes and Locke were the chief inspirers of Rousseau's social and political theories. Among others that influenced him were Montesquieu and Morellet. By his scientific researches the former caused a reactionary effect upon Rousseau, many of whose theories may be simply considered as a protest. Morellet, though combating Rousseau's idea that human corruption is due to the arts and sciences, was at one with him in maintaining that men in a state of nature are good, and that most governments have corrupted them. He accordingly 
wished to return to the simplicity and equality of nature by the establishment of a community of goods, that is, socialism.

When Rousseau began to write, the chief questions were these: (I) Was the state of nature one of freedom and peace, or of war and slavery? (2) Are the laws of nature beneficent, or the opposite? (3) Do men gain freedom through the social contract, or lose it ? (4) Are they improved, or degraded, by social union and culture? (5) Since all men are free and equal in the state of nature, how do the social subordination of one man to another and social inequality come about, and what is their justification? (6) Are men bound to submit to social regulations against their wills? While these questions were fermenting in men's minds Rousseau came upon the scene.

\section{Rousseau's Life}

Human beings may, roughly speaking, be divided into two classes, - those who live for passive enjoyment, and those who live for active mastery. The former seek to enjoy each moment; the latter live chiefly in the future and often attain a permanent place in the world's history. Rousseau belonged to the first class, Voltaire to the second. How, then, did Rousseau become an important factor in a great historic movement? (I) Because, like other men of his type, he was thrown into circumstances which wounded his sensibility, and was thus driven to imagine others in which it would find free play; (2) because the movement in question was toward the very things which he represented, - sensibility, subjectivism, and dalliance. He had, moreover, the rare advantage of being able to express his imaginings in a style which for simplicity, clearness, effectiveness, and nearly every other excellence, looks almost in vain for an equal. Keen sensibility, uttered with confident and touching eloquence, is the receipt for making fanatics, and Rousseau made them. Meanwhile his ambitious rival, Voltaire, was making sceptics. 
Jean Jacques Rousseau was born at Geneva in $17 \mathbf{r} 2$. His father, a watchmaker by trade, was descended from an old Parisian family and inherited the French characteristics, love of pleasure, liveliness, sensibility, romanticism, and gallantry. Jean Jacques's mother died at his birth, leaving her son to the care of his aunt, who indulged him greatly. At the age of six Rousseau spent every evening, and occasionally an entire night, in reading with his father the highly colored romances that had formed his mother's library. A year or two later he was interested in such books as Plutarch's Lives, Ovid's Metamorphoses, La Sueur's History of Church and Empire, and Bossuet's Lectures on Universal History, besides certain volumes of Molière. Plutarch was his favorite author. "To these readings," he says, "and the conversations with my father to which they gave rise, I owe the free, republican spirit and the unyielding pride, impatient of every form of servitude, which have tormented me all my life... There grew in me this heart at once so haughty and so tender, this effeminate yet indomitable character, which, hovering between weakness and courage, has always placed me at odds with myself, and has caused me to miss the satisfaction of either abstinence or enjoyment, indulgence or self-control."

In 1720 when his father left Geneva Rousseau was placed in the care of a clergyman at Bossey for two years. The rule was kindly, but it was here that the lad suffered an unjust punishment to which may be traced the origin of one of Rousseau's chief doctrines - that it is discipline and the curbing of natural impulses that confuses and degrades human nature. Later he was apprenticed to an engraver, a rough and violent man. Of this experience Rousseau writes forty years afterwards: "I was driven to vices which otherwise I should have hated, such as lying, idleness, and theft... Had I fallen into the hands of a better master I should have passed, in the bosom of my religion, my country, my family, and my friends, a quiet, peaceable life, such as my nature demanded, 
amid regular work, suited to my taste, and a society suited to my heart." The whole of Rousseau is here. Of heroic, moral goodness in the midst of circumstances offending both taste and heart, he had not even a conception.

After running away from his master, home, and relatives, Rousseau lingered a short time in the neighborhood of Geneva, getting food and shelter as best he could, and rioting in the sense of animal freedom, and in romantic visions of his future career. Thence he wandered into Savoy, was converted to Catholicism, and for many months endured the varying fortunes of a vagabond's life. Nothing, perhaps, is more characteristic of Rousseau than his description of his Arcadian longings and his self-pity at this time. "I must have an orchard on the banks of Lake Geneva," was his dream. "I must have a firm friend, a sweet wife, a cow, and a little boat. Till I have all these I shall never enjoy complete happiness on earth.... I sighed and cried like a child. How often, sitting down on a big stone to weep at leisure, did I amuse myself by watching my tears fall into the water!"

Having one day entered a peasant's house and asked for dinner, offering to pay, he received nothing but skimmed milk and coarse barley bread. Later, feeling that his guest would not betray him, the man opened a trapdoor in the floor and brought out a ham, some good white bread, and a bottle of wine, on which, with an omelet, Rousseau made a royal dinner. The peasant then explained to him that in order to avoid ruin at the hands of the taxgatherer he was obliged to feign abject poverty. "All this was absolutely new to me," writes Rousseau, "and it made an impression that will never be wiped out. This was the germ of that inextinguishable hatred which grew up in my heart against the oppressors of the unhappy people."

His vagabondage, which lasted four years, did much for him. It satisfied his lust for adventure; it awoke in him a profound passion for rural simplicity ; it made him acquainted 
with the common people, and awakened a lively sympathy for them; it inspired him with a love of natural scenery such as no one before him had ever felt; and it made his language the expression of genuine passion and first-hand experience.

For nine years Rousseau spent the greater part of his time at the home of his patroness, Madame de Warens. When in 174I they wearied of each other he left her, resolving to try his fortune in Paris, and hoping, if he were successful, to save her from financial ruin. Up to this time he had been a bundle of ardent desires, undisciplined by either serious reflection or moral training. He was lying, faithless, slanderous, thievish, sensual, cruel, cowardly, selfish. Only toward the end of this period do germs of nobler things begin to appear.

Through the influence of Madame de Broglie he obtained a secretaryship at Venice, but having quarreled with the ambassador by whom he was employed, he returned to Paris and resumed his Bohemian way of living. Here he met Thérèse Le Vasseur. His loyalty to her through all changes of fortune is perhaps the noblest trait of his whole life.

The productive period of Rousseau's career is included between the years I74I and I778. It was during this time that his literary and musical work was done. In I 762 he published his famous Emile, a philosophical treatise on education that involved him in immediate difficulties. Threatened with arrest, he fled to Switzerland and thence to England. He returned to France in 1767 and lived for a time under an assumed name. The last eight years of his life were spent in Paris; some of his minor works belong to this period. A few weeks before his death he went to live at Ermenonville, about twenty miles from Paris, and there he died suddenly on July 2, I778, at the age of sixty-six.

Perhaps the most astonishing thing about Rousseau is that he went through life, not only without learning the meaning of duty, but firmly believing that the life of pure caprice which 
he led was the ideal life, and that he himself was the best of men. This indeed he openly maintained. So far was he from being ashamed of his undisciplined spontaneity that he wrote his Confessions to prove that the spontaneous man is the best of men. It is hardly an exaggeration to say that the whole aim of his literary activity was to show how men may be made happy and contented without being moral.

But what Rousseau sought to prove by eloquent words, by insidious appeals to man's natural craving for happiness on easy terms, he disproved by his own example. His obtrusive independence, due to absence of moral ties, was spongy, unmanly, and repellent. We might pity him if he did not pity himself so much; but we can in no case admire or love him. ... A sadder old age than his has not often been recorded.

\section{Rousseau's Social and Educational Theories}

In I749 Rousseau wrote an essay, which won the Dijon Academy's prize, on " Has the Progress of the Sciences contributed to corrupt or to purify Morals ?" This discourse was attacked from many quarters, but, by no means daunted, he wrote another entitled, "What is the Origin of Inequality among Men, and is it authorized by the Natural Law ?" In this he assures us that reflection is contrary to nature, and that the man who thinks is a depraved animal. He draws a picture of man in his purely animal estate, wandering in the forests, without industry, without speech, without home, but free, strong, and happy.

Rousseau next shows us how every step in advancing civilization has led to corruption. The great evil of inequality began when what had previously been common to all was claimed as private property. From this point on it is easy to follow the development of civil society, involving, as it does, the decay of freedom, virtue, and happiness, and the growth of slavery, vice, and misery. 
In a letter thanking the author for a copy of this discourse Voltaire wrote: "Never was such ability put forth in the endeavor to make us all stupid. On reading your book one longs to walk on all fours." The work is indeed in many respects absurd, yet it contains a large amount of solid truth. What Rousseau wrote of the origin of language and of ideas is better than anything that had been said before his time. The book contains not only the tinder that kindled the French Revolution, and the germ that burst into the American Declaration of Independence, but also the forces that are "toiling in the gloom" under the surface of our present social order. Lastly, there is in it an important pedagogical truth, which may be summed up in the Greek aphorism: "Education is learning to love and hate correctly."

This discourse was written in I753, not long before Rousseau's reversion to Protestantism. Nine years later he published the Social Contract, in which, recognizing that a return to the state of nature is impossible, he tries to show how man's lost freedom may be recovered in the state of culture. According to his Social Contract each individual was to give up his personal freedom, and accept in exchange social freedom, by submitting himself to the supreme direction of the general will. There is always danger, however, that in the enforcement of laws there may be some tyranny and injustice. When this happens the "social contract" is broken and the parties to it return to a state of nature, free from all authority, but free at the same time to make a fresh contract. Here we have the justification of revolution.

Rousseau's "state of nature" is a pure fiction of the imagination. Animal caprice is not freedom. The phrase "natural rights" is self-contradictory, for where there is no social order there are no rights; in so far all beings are equal. But his chief error lay in supposing that human nature could be transformed by the fiat of the legislator, and society be made to assume any arrangement which he might choose to 
give it. No good can ever be done to a people by trying to force it into any mold prepared for it from without. All that the wise reformer can do is to diffuse such knowledge and culture as shall give a deeper and wider meaning to experience and so make possible higher ideals. Any attempt to force the process, or to substitute for its slowly but freely attained results a rigid, unprogressive scheme such as Utopias are sure to be, can lead to nothing but slavery and death.

Rousseau's educational system was meant to be a preparation for that sort of life which his own nature pictured to him as the highest - a quiet, uneventful, unreflective, half animal, half childish " natural life, free from serious tasks, aims, and duties." . . . Had he been logical he would have sent children for nurture and education to a tribe of savages; but instead he propounded this problem: How can a child, born in civilized society, be so reared as to remain unaffected and uncorrupted by the vices inseparable from civilization? His solution is given in Emile, the first words of which are: "Everything is well as it comes from the hands of the Author of things ; everything degenerates in the bands of men."

In dealing with infant life Rousseau lays down many sensible but chiefly negative rules. The young child is not to be swaddled, confined, or rocked, but to be allowed the utmost freedom of limb and voice. Its cries must be attended to at once, in so far as they express real needs, but no further. Father and mother must combine all their efforts to develop the nature of the child. The directions regarding the treatment and food of the infant are in the main excellent. They may be summed up in the one precept: Let nature have her way.

Rousseau considered that habit as regards set times for food, sleep, etc., was something to be avoided. In this respect his teaching is both unnatural and unwise, for it may safely be said that all evolution is due to the acquisition of habits. Habit is economy of energy. 
To Rousseau the end of existence is happiness, and happiness is merely the sensuous enjoyment of each moment as it passes, without thought for higher things, without regard to others. Whatever interferes with present enjoyment is to be regarded as evil. It would hardly be possible to form a more pitiful conception of human life and education than this. There is not a moral or noble trait in it. Instead of Noblesse oblige, Rousseau's maxim amounts to Bonheur invite. In these days when uncontrolled individualism still has its advocates it is well fully to realize what it means. "See that children have a good time" is received as a divine oracle by millions of parents and teachers. No wonder that a good time has become America's chief god!

Rousseau's theory of education was destructive of all social institutions and all true civilization. He maintained that children should not be taught obedience. Since nature and things resist but do not command, the teacher should do the same. Human relations should be replaced by mechanical relations, if the precious individuality of the child is to be guarded. $\mathrm{He}$ is to meet the iron law of nature everywhere, the love of humanity nowhere.

Of course children as natural creatures are never to be reasoned with. "Use force with children and reason with men; such is the natural order. . . . The child may be bound, pushed, or held back with merely the chain of necessity, without his murmuring." In this way he will never learn what kindness is, and so he will not acquire the unnatural sentiment of gratitude, or indeed any sentiment of a human sort.

"Early education," says Rousseau, "should be purely negative. Exercise the child's body, his organs, his senses, his strength; but keep his mind indolent as long as possible." This is what he calls natural education, but it is a highly artificial one. Nature is made to exclude its highest manifestations, and then the child is watched, dogged, guided, and forcibly controlled at every step, and all for the sake of 
keeping him in a condition of sub-moral, sub-human innocence. The only moral lesson that he would teach children is to do harm to nobody. This "involves the injunction to have as little to do with society as possible; for in the social state the good of one is necessarily the evil of another." It is needless to say that the assertion is the exact opposite of the truth, and subversive of all civilization.

At the age of twelve Émile had learned only to play. Rousseau would now have him cultivate the "sixth sense, which is called 'common sense,' not so much because it is common to all men, as because it results from the well-regulated use of the other senses." The boy is still to be guided by immediate interests. When his curiosity is roused the natural sciences may be taught; but he is to study nothing which he does not see to be useful for his own special, sensuous ends. At the age of fifteen he is at last to learn to read, and his one book is to be Robinson Crusoe, which will make him eager to learn the natural arts. With regard to these Rousseau says: "The first and most respectable of all the arts is agriculture. I should give blacksmithing the second place, carpentry the third, and so on."

Rousseau may fairly claim the honor of being the father of manual training. While admitting that the isolated man may do as he pleases he insists that in society everybody must work. And manual labor is to be preferred to every other, as afforcing the greatest freedom. He poured contempt upon the accumulated treasures of human experience and upon all the means whereby they are made available to individual minds, - books, study, schools, colleges, universities, social intercourse. He continually speaks of science, learning, and all that depends upon them, as degradations and necessary evils.

But Rousseau had other teachings which were of a different nature. His attacks upon luxury, display, and the vain waste of wealth, and his eloquent praises of plain, simple, 
modest living, have laid humanity forever under deep obligations to him. When a century later Emerson said, "Give me health and a day, and I will make the pomp of emperors ridiculous," he had been to school to Rousseau. "Good-bye, proud world, I'm going home," might have been written by Rousseau.

Of Émile at the close of his boyhood Rousseau writes thus : "He has all the virtues that relate to himself. In order to have also the social virtues, he merely requires to have the relations which call for them, and the light which his mind is now completely ready to receive. Without disquieting any one he has lived contented and happy so far as nature has allowed." So far, rather, as Rousseau's utterly false views of nature have allowed! Emile has all the time been caged, watched, and trained in ignorance into complete artificiality. $\mathrm{He}$ is now an altogether fantastic and impossible creature, utterly unloving and unlovable.

Having hitherto represented rigid necessity, Émile's tutor must now become his intimate friend. Under his guidance Emile "must study society through men, and men through society," beginning with the study of the human heart. His surroundings must be such that "he shall think well of those who live with him, and become so well acquainted with the world as to think everything that is done in it bad. . . . Let him know," says Rousseau, "that man is naturally good, but let him see how society depraves and perverts men. . . . Direct your pupil to all good actions that are possible for him; let the interest of the poor be always his interest; let him aid them, not only with his purse but with his care; let him serve them, protect them, and devote his time to them; let him become their agent; he will never again in all his life fill so noble a place."

By what process the animal, self-centered Émile of sixteen becomes the bold philanthropist of eighteen, Rousseau says he is not bound to tell us, and we never find out; but the 
new Émile, if he could be considered a reality, is certainly an admirable creature and deserves all the encomiums of his maker.

To Rousseau, who had been both a Catholic and a Protestant, who had heard his father tell of the Moslems in Constantinople, and who had listened to Voltaire, sectarianism, with its exclusive dogmas, lost all meaning and authority. "Let everybody," he says, "think about these things as he pleases. I do not know how far they may interest other people; they do not interest me at all. But what interests me and others like me is that every one should know that there exists an Arbiter of the lot of men, whose children we all are; who orders us to be just; to love one another; to be kindly and merciful; to keep our agreements with everybody, even with our enemies and his; that the apparent happiness of this life is nothing; that after it there comes another in which this Supreme Being will be the rewarder of the good and the judge of the wicked. These are the dogmas which it is important to teach young people. . . Keep your children always within the narrow circle of those dogmas which relate to morality."

Émile's courtship is carried on under the eye of the despotic tutor, who at first arranges everything for his pupil's gratification and enjoyment. Suddenly, however, this epicurean existence is changed and the young man undergoes the severe discipline of a stoic. Man must now rise above his natural desires and take Reason for a guide. Accordingly Émile is bidden to leave his Sophie for a time, and to set his strongest inclinations at defiance. After an absence of two years, which are devoted to travel, and in which Émile learns much of social obligations and responsibilities, he returns to Sophie and with their marriage the book ends.

The worst feature of Rousseau's treatment of the parting of the lovers is that, while Émile is urged to obey the voice of reason and conscience, he is not told why this voice 
should be obeyed any more than the voice of passion and interest. So far as we are shown, both are equally subjective and blind, and there is no third faculty to be umpire between them.

In Rousseau's next work, Emile and Sophie, we find the hero in adversity. Having been captured by Corsairs and sent to the galleys, he writes: "In my present state what can I desire? Alas! to prevent me from sinking into annihilation I need to be animated with another's will in default of my own." This piece of characteristic sophistry, which would justify any form of slavery, convinces him that his change of condition is more apparent than real; "that, if liberty consisted in doing what one wishes, no man would be free; that all are weak, dependent upon things and upon stern necessity; that he who can best will all that it ordains is the most free, since he is never forced to do what he does not wish." Here we have the germs of the Schopenhauerian doctrine that true freedom consists in renouncing all will, even the "will to live," which means that to be happy is not to be at all - the last conclusion of pessimism.

Rousseau proved to his own satisfaction two things: (I) that his education according to nature will enable men and women to stand the test of the severest adversity, and (2) that the life of cities is altogether corrupt and corrupting.

\section{Rousseau's Influence}

No one can deny that the influence of Rousseau's ideas upon educational theory and practice has been, and still is, very great. His passionate rhetoric and his scorn for the conventions as contrasted with the ideal simplicity of nature roused men from their slumbers and made them reconsider what they had so long blindly accepted. So far his work was invaluable. His bitter, sneering condemnation of the fashionable life of his time, corrupt and hypocritical, with its distorting and 
almost dehumanizing views of education; his eloquent plea for a return to a life that was truly and simply human, and to an education calculated to prepare for such a life, were righteous and well timed. His purpose was thoroughly right, and he knew how to make himself heard in giving expression to it. But when he came to inform the world in detail how this purpose was to be carried out, he undertook a task for which he was not fitted either by natural endowment or by education. His passionate, dalliant nature prevented him from seeing wherein man's highest being consists, while his contemptuous ignorance of study, science, and philosophy closed his eyes to the historic process by which men have not only come to be what they now are, but by which their future course must be freely determined.

Gathering up the various defects of Rousseau's social and pedagogical theories, we can clearly see the false assumption that lay at the bottom of them all. It is a very common and widespread error, and is fatal wherever it occurs. It consists in assuming that the later and higher stages in evolution are to be explained by the laws that manifest themselves in the earlier and lower, and must be made to square with these. It throws forward the darkness of the earlier upon the later, instead of casting back the light of the later upon the earlier. Thus it continually tries to explain human nature by the laws manifested in sub-human nature. It insists that man should go back and allow himself to be governed by the necessary laws of the latter as the fatalistic Stoics said. This is the sum and substance of Rousseau's teaching in sociology, ethics, and pedagogy. It is the sum and substance of much popular teaching in all departments of theory and practice to this day. Yet nothing could be more misleading or more fatal to progress. The acorn does not explain the oak, but the oak the acorn. The meaning of the acorn is revealed in the oak, and the meaning of nature in culture. Each to-day reveals the meaning of all yesterdays and contains the free promise of all 
to-morrows. And so the problem of life is not to make man live according to nature, but to make nature live according to man; or in less ambitious phrase, to elevate the "natural" into the "spiritual" man; blind instinct into rational freedom. Rousseau's system, therefore, exactly inverts the order of nature and progress. It advocates the descent, not the ascent, of man.

In spite of this, it has been given to few men to exert by their thought an influence so deep and pervasive as that of Rousseau. It extended to all departments of human activity, - philosophy, science, religion, art, politics, ethics, economics, and pedagogy.

In philosophy Rousseau influenced Kant, and through him all German, and therefore all modern, philosophy. Even its latest development, agnosticism, can be traced back through Kant's unknowable "thing-in-itself" to the same source.

Rousseau's influence in religion was felt by many of the French Revolutionists, especially by Robespierre and St. Just, and contributed important elements to the neo-Catholic renaissance in the Latin countries and to the Protestant reaction in the Germanic, as well as to English and American Unitarianism. It was also the determining influence in the theological movements initiated by Schleiermacher and Ritschl. In art his influence has been almost paramount throughout Christendom. We may trace his footsteps in the rural cottages and picturesque parks so common in Europe and America; in the landscape paintings and genre pictures that fill our galleries; and in the nature groups, and sentimentally posed figures that delight the majority of our sculptors.

French literature, for the last hundred years, has been soaked in Rousseau's teaching ; and in Germany both Goethe and Schiller were powerfully affected by him. In England - where the poison has for the most part been rejected his influence has been mainly beneficial and can be traced in the writings of the following : Burns, Lady Nairne, Keats, 
Shelley, Byron, Southey, Coleridge, Wordsworth, Leigh Hunt, the Brownings, Carlyle and Ruskin, Clough and Tennyson, Morris and Swinburne, Dickens, Thackeray, George Eliot, and Mrs. Ward. On the other side of the Atlantic we find Longfellow and Lowell, Whittier and Emerson; and among the Italians, Leopardi, Manzoni, Carducci, and D'Annunzio. What is true here is equally true of the literature of Greece, Scandinavia, and Russia. Ibsen, for example, is Rousselian to the core.

Turning to the field of politics we find that the French Revolution was in very large degree Rousseau's work; and the formulas in which the American Declaration of Independence was couched were largely drawn from him. Upon political theory the effect of his teaching has been so great that he may be fairly called the father of modern political science. He gave wrong answers to the questions which he propounded; but these questions were just the ones that required to be answered.

Hovering between two equally immoral systems, Epicureanism and Stoicism, and having apparently no experience of free will, Rousseau developed no moral system. Nevertheless, his views were not without effect upon subsequent ethical theories.

In the sphere of economics Rousseau's influence, though great, is quite different from what he expected. Though entirely averse to socialism and anarchism, he was in large degree the parent of both. His stoicism is virtual socialism, while his epicureanism is virtual anarchism, as could easily be shown. It ought to be added that one of the noblest and most conspicuous traits in Rousseau's character was unfailing sympathy with the poor and the oppressed, involving hatred of their oppressors; and it is this sympathy and this hatred - which his example did much to make common that have, respectively, caused the socialistic and anarchistic movements of this century. 
Of his educational demands perhaps only three have been responded to: (I) that children should, from the moment of their birth, be allowed complete freedom of movement; (2) that they should be educated through direct experience, and not through mere information derived from books; (3) that they should be taught to use their hands in the production of useful articles. But certain others of his notions lingered on for a time, much to the detriment of education, and were with difficulty shaken off.

To give an account of all the educators influenced by Rousseau would be to write a history of modern pedagogy. Among the chief, however, are Pestalozzi, Herbart, Froebel, and Antonio Rosmini-Serbati ; the latter far less known, but well deserving of careful study by educators.

Rousseau's Émile has made men attempt to defend existing systems of education, and, finding that they could not, resolve and endeavor to discover better ones. There is still much to be done. We have, even now, no scientific theory of pedagogy; and the reason is that we have no scientific theory of human nature. We are still distracted and blinded to the truth, on the one hand by certain traditional conceptions that once formed part of a view of world economy long since rendered unbelievable and obsolete, and on the other, by certain modern philosophic prejudices of a dualistic sort for which Kant is in the main responsible. The former make us still inclined to believe that the soul is a created substance beyond the reach of experience, a transcendental monad, possessed of certain fixed faculties and capable of being trained only in a certain definite direction to a fore-appointed end. The latter make us believe that it is a bundle of categories, empty thought-forms, existing prior to all sensation or experience, and conditioning it. In either case we are irrationally induced to regard, and to talk about, the soul as something other than what by experience - the only source of true knowledge - we know it to be, and thus to build our educational 
theories upon a mere chimera. There is not one fact in our experience going to show that the soul is either a substance or a bundle of categories. Indeed, when subtly considered these words are absolutely without meaning. When we ask what we know the soul to be we can only answer: A sentient desire, or desiderant feeling, which through its own effort after satisfaction gradually differentiates itself into a world, or, which is the same thing, gradually learns to refer its satisfactions to a world of things in time and space. Feeling is primary; ideas, or differentiations in feeling, are secondary; - exactly the contrary of what Herbart believed. The world that we know, whether material or spiritual, is entirely made up of feeling differentiated by ideas.

The end of education, therefore, can be none other than the complete satisfaction of feeling by an ever-increasing, harmonious, that is, unitary, differentiation of it into a world of sources of satisfaction. This satisfaction will be greater in proportion as the sources are richer and more numerous. Hence, every soul will be consulting for its own satisfaction by doing its best to satisfy every other soul, and to make it as rich as possible. Thus the most perfect egoism will be found to be one with the most perfect altruism, and the law of virtue to be one with the law of blessedness, as in the end it must be, unless all existence be a mockery. On this view of the soul, and on this alone, will it be possible to erect an intelligible and coherent structure of education - intellectual, affectional, and moral. 


\section{CHAPTER XX}

\section{INTELLECTUAL PIETY}

In addition to his longer and more important works Thomas Davidson wrote many short articles on philosophical, literary, and political subjects. The majority of these are extremely suggestive, and have elements in them of perennial interest. Such were his papers on "American Democracy as a Religion," in the International Journal of Ethics (October, I 899); " Education as World Building," in the Educational Review (November, 1900); "Intellectual Piety: a Lay Sermon" (1896); "Faith, as a Faculty of the Human Mind" (a paper read by him at a philosophical convention held at Chicago); and many others contributed to the Journal of Speculative Philosophy. I select two of the above-named for partial reproduction in this book.

\section{Intellectual Piety: a Lay Sermon}

Of all a man's duties none is so essential, none so fundamental, as the duty of knowing the truth; and yet none has been so seldom enforced by religious sanctions, none is so frequently made light of and ignored. If we were asked to point out the crowning defect in all the systems of ethics hitherto promulgated, we should probably not be far wrong if we should say, Failure to impress the duty of knowing before acting. To this evil may be traced by far the majority of evils that infest the world around us.

Moral action is distinguished from all other kinds of action by this, that it is action based upon conscious choice. We refuse the attribute "moral" to all mechanical and instinctive action, for no other reason than because it is unaccompanied by choice. Even in the case of human beings we make 
moral responsibility coextensive with power to choose; and call a man who acts from uncontrollable impulse, passion, or instinct, insane.

Now choice, the basis of all moral action, depends upon intellectual appreciation. An error in intellectual appreciation is a moral error. The criminality of the greatest of crimes is wholly due to the intellectual act that preceded it, and vanishes when that act can be shown to have been pious. This is the sole justification of just warfare, and of the legal execution of criminals.

Before proceeding to show the evils that arise from intellectual impiety, and the supreme necessity of intellectual piety, let me try to make its nature clear. Nothing is more familiar to us than the fact that knowledge of the right does not insure the performance, that mere knowledge has but a limited moral force. Now intellectual appreciation differs from knowledge in this, that it is knowledge armed with moral efficiency, knowledge which commands respect and submission. We are wont to express this familiarly by saying that not only a man's head, but also his heart, must be right. Not only the thoughts of the head, but also the thoughts of the heart (to use the profound old English biblical expression), must be pure, and a man wants a new heart far more frequently than a new head. The truth is, that the element of piety in the intellect is due to what we may call the heart more than to what we may call the head. Let me make this a little clearer.

I have on other occasions explained that, by intellect as distinct from reason, I mean the primitive faculty which grasps the essential ideal unity of the universe, which makes it possible for us to transform our groups of sensations into things, and look at these as something distinct from, and independent of, ourselves - to look at them as something objective. I have also said that this faculty is the source of all freedom, a fact, indeed, which follows directly from its being the moral faculty. But observe that intellect is not by 
itself sufficient to insure freedom. Before it can do so, an element uniting the two must intervene. Mere intellectual comprehension is absolutely cold and inactive. It is possible to conceive a being gifted with perfect intelligence, and yet remaining entirely inactive from want of any motive to action. If all things were indifferent to it, that is, if one thing had no more value for it than another, it would certainly not act with reference to any of them; it would not choose one in preference to another, and, therefore, would not be free in any important sense. What turns intellect into a spring of action and freedom is not its power of distinguishing things, but its power of seeing that things have different values, that one thing is better than another, and, therefore, to be preferred to another. Better and preferred are only terms for more lovable, more deserving to be adhered to by the faculties of the spirit, more worthy to determine the attitude of the spirit. When the spirit accommodates itself to the things it beholds, in exact proportion to their ideal value, it is perfectly free; for it is determining itself in accordance with the laws of being.

In other words, piety of intellect consists not in a clear, cold distinguishing of one thing from another, but in the power to appreciate the different values of things, when so distinguished; that is to say, in loving things in exact proportion to their intrinsic worth. The moral power of intellect consists solely in its ability to distinguish worth, and this ability is, in the strictest sense, the ability to love. Since love is usually considered a matter of the heart, we may say that intellectual piety lies in the thoughts of the heart. In fact, it is only the truth which is revealed to the heart that has any moral effect. This was clearly recognized by the old Hebrew prophets. Isaiah, for example, says :

By hearing ye shall hear, and shall in no wise understand;

And seeing ye shall see, and shall in no wise perceive ;

For this people's heart is waxed gross,

And their ears are dull of hearing, 
And their eyes they have closed;

Lest haply they should perceive with their eyes, And hear with their ears,

And understand with their heart

And should turn again, and I should heal them.

The truth is, that there is no chance of a man's being healed unless he understands with his heart, that is, until he loves things in accordance with their true value. If in this connection we ask, What is morality? what is religion? we shall get a ready answer: Morality is action in strict accordance with the relative value of things. Religion is the love which prompts this action. Immorality and injustice are simply distribution of action according to a false estimate, and impiety or irreligion is the spirit of misdirected love which prompts this distribution.

If, now, we look away from theory and turn our eyes upon the seething, toiling, competing, suffering, self-flaunting world about us, and ask ourselves the cause of all that is not satisfactory there, we can see that it is the false estimate placed by men upon the things of the world, the want of intellectual piety. Men, instead of making themselves acquainted with the constitution of the world - as by calm attention and patient study they might - and distributing their interest and affection in accordance with the relative value of things, rush into life blindly and without thought, adopt conventional standards of value, and so frequently spend their days in impiety, upholding injustice, or following current fashion. One does not need to examine the lives of the mass of mankind very closely to see that not two in every hundred of them have ever, in all seriousness and without prejudice, put to themselves the question, How must I distribute my interest and affection among the objects which I find in the universe, in order that I may do justice to all, and so live a life in accordance with its laws - a true moral and religious life? 
Indeed, not only is this general question rarely put, but hardly any attempt is made to distribute interest in any just way, even among the commoner things usually deemed worthy of interest. In a large class of society, interest and affection are distributed almost in inverse ratio to the value of things. The more frivolous a thing is, the more interest does it excite. People are given up to the frivolous - to frivolous talk, frivolous reading, frivolous work, frivolous pleasure. But even in classes which claim a certain amount of seriousness, the scale of interest has nothing to do with the real value of things; there is hardly any trace of intellectual piety. In by far the majority of families in almost any city or country I know, the all-absorbing interests are wealth and comfort; higher things, art, science, and even religion, are looked upon as merely amusements, or as furnishing opportunities for the display of wealth. Only among the very few, among men generally regarded as unpractical dreamers, is there any serious attempt to distribute affection in accordance with the true value of things; to love with supreme love that which is highest, the eternal; next, that which most closely approaches the eternal ; and last of all, that which in its nature is fleeting and unreal.

The men who do this are the only men in the world who are truly happy, living the natural life of the spirit, at peace with heaven and earth, shedding goodness on all sides, because they have nothing else in them to shed. But such men hardly seem to be of the world, though they are in it ; and, indeed, if we mean by the world the complex of material phenomena, they are not in the world with the best part of them. Their intellectual piety makes them fix their affections upon things whereof material phenomena are but fleeting manifestations. If all men followed the example of these few, life would be blessed, sin and suffering would almost entirely cease, and earth would become heaven. 
But what is the effect of the opposite course, of distributing affection falsely, of neglecting and ignoring those things that are of the highest moment, and loving those of inferior merit with the heart's best love? We have only to look around us to see. Just consider what the effect of setting the heart upon wealth, position, show, or comfort is, not to speak of lower and criminal things? Is not this one result of intellectual impiety the cause of well-nigh all the evil with which philanthropists are trying to contend, which threatens to grow over our heads, to overwhelm our civilization, and conduct us back to barbarism? Suppose, on the contrary, that the whole human race suddenly became intellectually pious, and set upon each thing, spiritual and material, its proper value. How long do you think the present brutal condition of society, in which each one struggles to supplant or overreach his neighbor and make the fruit of the earth fall into his own basket, would last? Not an hour. Let wealth, ease, and comfort, position, and pride once be measured by the standard of true intellectual piety, and they will cease to seem worth struggling for, except in so far as they contribute to make the realization of higher ends for all spiritual beings possible.

A great deal might be said upon the blessed effects of intellectual piety, and the accursed effects of intellectual impiety ; but it is so easy, by a little thought, to realize both, that the above indications may suffice. Let us now ask ourselves (I) how the now prevailing intellectual impiety came about, and (2) how it may be best remedied, and the world restored to intellectual piety and its blessed results.

First, then, how did the widespread intellectual impiety, which at present confounds and mars the world, come about ? Mainly from two causes : (I) the natural, constitutional impiety of the human heart, and (2) the transition which is at present going on in the world from one kind of intellectual piety, namely submission to authority, to another, namely individual insight. Let us consider these two causes in their order. 
(I) The natural impiety of the human heart. In saying that the human heart is impious by nature, I am using the term nature in its old original sense of instinctive tendency, and not as meaning essence. The human spirit is in essence thoroughly pious; in other words, its true essence is realized only when it becomes thoroughly pious. It would be strictly correct to say that perfect piety is the ideal, and the destined end of the human soul. But the human soul is able to realize this, which is at first only implicit in it, solely through the medium of the senses, solely through stimulating and awakening influences derived from other beings, since no being can act or develop without a stimulus from without. In its lowest stages the soul is lethargic and hard to rouse. It can be stirred only by acute stimuli due to numerous external beings acting upon it at once, and even then it is roused to only the lowest and least intelligent kind of activity, namely, reflex action. Now the habits of the soul are formed by its actions, and these at first are determined solely by the nature of the external stimuli. These stimuli being violent, - necessarily so, in order to rouse the soul's latent activity, - the soul learns from the first to determine itself, and to act solely with relation to violent stimuli. The more violent the stimulus, the more certainly and strongly does the soul react.

Not only so, but when a stronger and a weaker stimulus affect it at once (other things being equal) it may very readily, in reacting against the stronger stimulus, neglect the weaker altogether. It is this inborn and necessary tendency of the spirit, in its lower phases of development, to respond to stimuli in proportion to their strength that I would term the natural impiety of the spirit. It is what the theologians mean by the term original sin, which they have tried to account for by various myths, such as the temptation of Eve, which has a curious kernel of truth at the heart of it. So long as the spirit remains in a purely animal and natural condition, this tendency to respond to the strongest stimuli is really no impiety at all. 
It is really the piety of animal nature, whose highest good is pleasure, and whose highest evil is pain. But the time comes, for certain spirits at least, when out of and over the animal nature, developed to its highest, there arises another nature, totally different in kind from the former, and tending in very large measure to counteract and govern it.

I shall not try to determine at what point, and under what circumstances, this higher nature passes from latency into activity. That, in certain beings, it does so pass, is a fact, and the fact is sufficient for my present purpose. This higher nature is the intelligent nature. As soon as this begins to manifest itself in any being, that being begins a new phase of existence. It ceases to respond to stimuli in proportion to their strength. Such response, which belongs to its merely animal nature, becomes impiety, assumes the attitude of original sin. In accordance with its new nature it gradually ceases to respond to stimuli, as such, at all, and responds to things with power proportionate to their ideal value, as intellectually, that is, freely, conceived. In a word, the being in question passes gradually out of the region of material, sensible stimuli, into a region of ideal motives, which, being inactive and unstimulating, leave the action of the spirit perfectly free. All the action of adherence or non-adherence on the part of the spirit is due to the pure inner spontaneity of the spirit, to pure spiritual love or aspiration. But the process from animality to perfect intellectuality, in other words, to piety of intellect, is very difficult and slow. The animal habit of responding to strong material stimuli fights along with the intellectual need of spiritually aspiring. Indeed, it is this fight that constitutes the entire interest in human life and human history. Slowly, as man advances, he unlearns his animal habits, or, at least, learns to subordinate them to his intellectual insights. More and more his actions become guided by ideas and less by stimuli. For a very long time ideas have to be embodied either in art, or in living human 
beings, in order to be effective; and a man's spiritual height can at any time be accurately measured by the spirituality or ideality of the art, or of the human beings, whom he loves. At bottom a man is exactly what he loves.

I say "for a very long time" but I might have said "forever"; because I believe that, in order to be truly effective, ideas must always be embodied. Unless they are so, they never appeal fully to our faculty of aspiration, but have always the chill of an imposed duty, a chill which damps the purest ardor of the soul. That is good Christian doctrine; because, while Judaism called upon men to obey God's law, Christianity called upon them to love God, as manifested in Jesus Christ. But, although we cannot fully love ideas, or ideal things, except as embodied, it does not follow that we need be led astray by the embodiment. Embodiment, as such, is simply forcible presentation. But, in the long run, all embodied ideas only serve to lead up to that pure idea which is the end of love, and the vision of which is the soul of freedom and blessedness.

From what has been said you will see that the intellectual impiety of our day, as well as of all other days, is, primarily and in large measure, due to the natural impiety of the human heart, the necessary legacy of the animal nature. It is the animal nature fighting with the intellectual nature, the "law of the flesh warring against the law of the spirit," that makes men direct their affections toward the coarse, strong stimuli of wealth, ease, gluttony, pomp, and all the other objects to which animal selfishness naturally tends, and that brings about all the sin and suffering that there is in the world.

(2) But the present prevalence of intellectual impiety in the world is partly due to another reason, namely, to the transition through which we are passing, from the intellectual piety of authority to the intellectual piety of insight. All transitions from one ideal to another are slow and difficult, but this one is especially so, because its consequences are so far- 
reaching, extending to every institution of society, and every attitude of the individual. Perhaps you will find it strange that I use such an expression as "intellectual piety of authority," as if submission to authority could consist with intellectual piety. But so it was, and, to a very large extent, so it is even now. At a certain stage in human development intellectual piety consists in reverent submission to authority. Such submission is simply what we call faith, neither more nor less. Faith at one time was intellectual piety. There is no use in hiding that fact from ourselves; but it is not so now. Nowadays, intellectual piety is submission to pure intelligence, in the sense in which I have been using that term, as comprehending spiritual insight, love, and freedom. The transition from one mental attitude to the other is what we are now passing through, and what is introducing so much confusion into our institutions, so much impiety into our lives. Let us consider the two attitudes. They mark two eras in the world's history, the one the era in which the individual is regarded as the servant and creature of institutions, the other the era in which he is looked on as the lord and creator of institutions.

In times when animal habits and sensual brutality were still fighting hand to hand with the first cold dawnings of intellectual insight, that insight was in a very disadvantageous position. Its power was slight compared with that of its foe, and though, being eternal, it could not be crushed, it could be rendered almost powerless, unless it was so embodied as to be able to utilize some of its enemies' brute force. Under these circumstances, in order to be effective at all, it was forced to ally itself with that half-animal, half-divine instinct of personal ambition. Men of clear heads, eager for power, were glad to have such an ally - an ally which has no superior. Insight results in justice, and justice is the pillar of power. Thus intelligence, in its battle with animality, found strength only by taking on the form of individual authority. 
This individual was at first a tribal patriarch, later on a chief, later still a king, and, if he abused his authority, a tyrant. When individual authority'became thus tyrannical and abusive the insight and sense of justice, ;which had now grown up, turned against it; having found an ally in the self-respect of a morally developed people, aided sometimes by what were supposed to be miraculous, divine sanctions. When tyrannies were put down, and insight and justice no longer found strength in individual ambition, they were embodied in laws and legal systems, which imposed themselves as abstract rules upon human life, and the transgression of which entailed punishment. But in both cases - whether embodied in human individuals or in legal systems and institutions - the insight which constitutes the higher nature appears to the generality of men as a restriction and a fetter. Doubtless they learned to submit gracefully to this restriction, and even to hug the fetter, but such submission was always felt to be a form of subjection. The divine, simply as such, was not loved, nor did men in submitting to its dictates - called by the name of justice - feel themselves free. Eschylus, one of the greatest of ancient seers and poets, tells us, "There is no one free but Jupiter."

I need not tell you that all the forms of government that have ever been are only so many arrangements for giving effect to the divine insight, and imposing it upon men inclined to follow their animal nature and habits. In ancient times these governments armed themselves not only with what we are wont to term the terrors of the law, but also with power derived from current beliefs in supernatural agency, which beliefs were themselves a very crude form of divine insight. While men were in this condition it is plain that intellectual piety, so far as such a thing could be said to exist at all, consisted in submission to constituted authority; for it was through such submission that the higher nature of man was in any way enabled to triumph over the lower. As the Bible expresses it, the law was a taskmaster, and, in the earlier 
stages of advancement, obedience to this taskmaster was the best thing that men could do. If we should ask what service ancient civilizations, generally speaking, performed for the cause of human progress, the answer would be, They succeeded in forcing external submission to intelligence embodied in the form of laws, with fear of punishment attached. These laws neither did nor could accomplish submission of the will or the affections, still less could they command the love of the intellect. Nevertheless, they accomplished a most necessary and a most important work. Until men have learned outward conformity in action to law, they are not capable of any higher spiritual attainment. Fear is the first attitude assumed by the animal toward the spiritual. The transition from this attitude to a higher was marked by the rise of Christianity. The great movement so called was, of course, preceded by a considerable period of preparation, especially among the Hebrews and the Greeks.

Among the former, mere submission of outward action gradually gave place to submission of the affections, and men learned to love the divine. Among the latter, outward submission tended to give place to insight, that is, to pure piety of the intellect. Had any man appeared about the beginning of our era, capable of placing himself at once at the advanced standpoint of the Hebrew and the advanced standpoint of the Greek, and had he been able to impose his doctrine upon the world, the result might have been the spread of true intellectual piety, in its wide triple sense of insight, love, and freedom. Unfortunately, Jesus, the man who did succeed in imposing himself upon the world, and who well deserved to succeed, could place himself at only one of these two standpoints - that of the Hebrew. He taught men to love the divine as manifested in his own person. In other words, he taught them to submit the affectional part of their nature to the divine, and this was a step of incalculable importance, a step which replaced fear by love. What he failed to do was 
to make men submit their pure intelligence to the divine, in the only way in which intelligence is justified in submitting itself, that is, through clear insight. As far as their affections were concerned the Christians were free; they followed the good, the divine, because they loved it in one splendid manifestation. But they were not altogether free; they were still subject to authority with a part of their nature, namely, with the pure intelligence. Nothing can free the intelligence and enable it to act with perfect liberty, except clear, unwavering insight, and this Christianity did not give, and could not give. The place of insight was taken by faith, - faith in the life and words of an individual; and this life and these words necessarily became authoritative, and had to be embodied in a law-imposing institution, namely, the Church. Just as the State had been, and was, an institution replacing insight into the divine and affection for it, in order through authority to secure outward conformity of action; so the Church was an institution replacing insight into the divine, in order to secure affection for it. The Church was, therefore, an institution higher than the State; it represented less through authority, and made possible a greater degree of freedom, namely, freedom of the affections. In the Church men acted and lived through freeing love, instead of through slavish fear. But after all, it was an authoritative institution, and, in so far, an imperfect one. In spite of this imperfection, if she had remained true to herself and her inmost principles, she ought to have been able to impose herself upon the State and to absorb it, as a higher institution ought always to absorb a lower. Indeed, in one period of her history, the Church came very near to this, and it was only her infidelity to herself that prevented her from doing so altogether. If, through the lives of her members, or even of her priests, nay, even of her head, the Pope, she could have exacted that divine love which Jesus had hoped that his representatives, imbued with his righteousness, might at all times exact, there can be no doubt that the 
kingdoms of this world would have become the kingdom of Christ. We all know how far she failed in this respect. At the very time when the kingdoms of the civilized world seemed almost within her reach, she was represented in her supreme dignity by several men, whom a woman, afterwards canonized by the Church, - and well deserving canonization, if ever woman did, - was constrained to speak of as demons incarnate, daemones incarnati.

That the divine, when so represented, should call forth man's affections and secure the submission of the State was utterly impossible ; and so Church and State, instead of being absorbed into one great institution, setting man's affectional nature free, and gradually working toward the liberation of his intellectual nature through pure insight, fell gradually back into the position of the ancient states, and, through material force (the use of which Jesus had actually forbidden), as well as by spiritual threats conceived in the spirit of exclusiveness, hatred, and tyranny, flung men back into the condition of slaves, living and acting in fear. However much we may blame the Church - and she deserves great blame for relapsing into this pagan condition - we must never forget that her errors were in a certain sense due to her very constitution, and the imperfection of the doctrine of Jesus upon which she was originally founded. Jesus and his immediate followers had called for faith, instead of for insight, and faith had, of absolute necessity, to result in a dogmatic system; for articles of faith must be expressed as dogmas, if expressed at all. What is more important, however, is, that dogmas, from their very nature, could not defend themselves rationally, inasmuch as they were not based upon intellectual insight, but upon authority. If they defended themselves at all, they had to do so by material force.

It is true that on more than one occasion the Church attempted to base her dogmas upon intellectual insight, first in the second, third, fourth and fifth centuries, through the 
ponderous writings of the so-called fathers of the Church, of whom the most important and able was St. Augustine; again in the twelfth and following centuries through the efforts of the schoolmen so-called. The former, the Church Fathers, employed for their purposes the philosophy of Plato mostly; the latter, the schoolmen, the philosophy of Aristotle. But on each occasion the attempt failed, and failed signally, for the very good and very inspiring reason that the dogmas were false, and nothing that is false can ever be based upon intellectual insight. Fortunately it is not in the nature of things that any institution existing to exercise authority can be eternal ; for, in the long run, man must attain his true nature, which is absolute freedom, intellectual as well as other.

The long struggle which the Church carried on against the State, in so far as it was in any degree representative, was a struggle of love and duty against fear and law. In this struggle, the Church, as an institution, may be said to have succumbed, and, indeed at the Protestant Reformation, the Church was expressly made subject to the temporal ruler; but, after all, the Church did impart a great deal of her spirit to civil institutions, so that in our day a very large number of men and women, who care nothing whatever for the Church, live and act from love and cheerfully accepted duty, and in no degree from fear.

The Church, as I have said, was, from the very defect in the nature of her fundamental principle, necessarily an authoritative institution, as far as the intellect was concerned. She put faith and dogma in the place of insight and clear conviction, and, when she began to degenerate, actually set her face against the latter, and discouraged free inquiry and free thought, as hostile to piety and religion. They were, indeed, hostile to piety, as she conceived it, and this the event has proved. As she conceived it, piety - and piety, in the last result, always means intellectual piety - meant the unquestioning submission of the intellect to the authority of dogma. There can be no question that there was a time when this 
was real piety, the very best thing that men could do. There was a time when the dogmas of the church were higher than the loftiest insights of even the best of living men, and when this is the case, and men can in any way be convinced that it is the case, then submission becomes intellectual piety. Very few people, comparatively speaking, have ever worked out the proof that the earth moves round the sun; nevertheless, we should at the present day regard it as intellectual impiety and arrogance for any one who had not examined the proof, to question the fact.

But the reign of faith is of necessity the reign of authority. Faith is authoritative, or it is nothing. That this is true, any one who thinks clearly, by simple reasoning, can easily see. But it has also been demonstrated by experience. The Church has lost power as an institution, exactly in proportion as she has ceased to be authoritative. Let us now ask ourselves, What is the effect of authority in matters of intellect, and especially in the loftiest matters with which the intellect can deal? Simply this, to paralyze the intellect and render men indifferent to its dictates. This, of course, would not be felt, and, indeed, would not be prejudicial, so long as the dogmas of faith were nearer the truth than the insights of intellect; but, as soon as the intellect arrives at higher insights than the dogmas contain, then any attempt to confine the intellect within the limits of dogma can result in only one of two things, - paralysis of the intellect, or rebellion on the part of the intellect and an open hostility to dogma and the entire institution based upon it.

Now both of these results have been actualized in the last three hundred years, and exist in a very pronounced state at the present moment. On the one hand, we have a very large number of people who, utterly incapable of profound thought, and unaided even by dogma, nevertheless, in a blind and imbecile way, cling to dogma, and lead superficial, conventional, and altogether pitiable lives. This is the case 
with by far the majority of formal churchgoers, many of whom are sunk so deep in intellectual impiety and death, that it seems as if even the last trumpet would not rouse them. On. the other hand, we have at the present day a large number of persons, who, rebelling openly against dogma, and the Church based thereon, reject even the good that there is in the Church, and fall back into an unsettled, hopeless condition, in which they vainly grope about for a clear principle of action. They have rejected authority, but have not attained insight; and so they either wander about in a sort of grim uncertainty, which they call agnosticism; or else adopt, as a principle of action, some abstract formula borrowed from the old religion without acknowledgment, and declared to have been found among the inmost instincts of the heart. When authority and intellect fail, the heart is always made to do duty, and, in consequence, invested with a kind of mysterious sanctity, as if its blind dictates were necessarily infallible oracles. Among these men too we find great impiety of intellect.

Before taking up our second question - How may the prevailing impiety of intellect be remedied - let me recapitulate, in a few words, the answer to the first. The now prevalent impiety of intellect is due to two main causes: ( $\mathrm{I}$ ) the natural impiety of the human heart, its primitive animality, which, when it resists intelligence, becomes original $\sin$; (2) to the transition now going on from faith or authority in matters intellectual to clear insight and perfect freedom. The former of these causes is potent in almost every individual, producing selfishness and blindness; the latter is potent in all our social institutions, causing confusion of the most threatening kind, ranging class against class, and bidding fair, in the form of nihilism and anarchism, to annihilate the civilizing efforts of many centuries.

Now it is a strange fact, and one which every man who is not a mere play actor, unable to discern the signs of the time, sought to weigh carefully, that the first effects of the 
birth of a new truth in the world often take the form of gigantic courses of heartless and hideous crime. Nihilism and anarchism are cases in point. The hideous crimes perpetrated by their votaries are really performed in obedience to a true principle; but the principle is by these votaries so imperfectly and incorrectly grasped, that it becomes a curse, instead of a blessing, and rouses prejudices most prejudicial to itself. What nihilists and anarchists are sinning for is freedom, and freedom, when properly comprehended, is the highest possible of blessings ; but to these men it is a mere word, or at best a synonym for utter impiety. Thus, without in the smallest degree palliating the acts of these men, or failing on every possible occasion to express our righteous horror of them, we need not fail to recognize that the end which they so foolishly and criminally seek to attain is the true end of all noble human endeavor. For just as Christianity rose above ancient paganism and overthrew its institutions, in order that men's lives might be freed from the authority of fear and be guided by love, so at the present day pure intelligence, combining in itself insight, aspiring love, and freedom, is slowly rising above Christianity even, and seeking to free men's souls from the authority of faith and dogma, so lifting them into absolute freedom. The world's battle of progress is now fought in the name of perfect intellectual piety, which alone can make men free and blessed.

In the struggle, no doubt, many of our existing institutions must go down ; indeed, in the end, they must all go down, in so far as they are in any way authoritative; for among men intellectually pious authority has no place or power. We ought always to remember that the amount of authority requiring to be exercised among a people is always in exact inverse ratio to its spiritual advancement, its intellectual piety. Among the intellectually pious all authority resolves itself into insight - insight into the ultimate laws of absolute being, or, as theologians awkwardly say, into the will of God. 
We are now ready to answer our second question, How can intellectual piety be realized on the earth, and intellectual impiety be made to cease?

We may answer this question in a preliminary sort of way by saying, By teaching men to disregard the blind promptings and blinding habits of their animal nature, and to see things as they are objectively in themselves, estimating each according to its true value, which will be at once absolute and relative. We may express this otherwise, thus, By cultivating in every man pure intelligence and pure divine love, and so strengthening these that they shall without difficulty subject and rule animality and selfishness. We may express it in a third and very brief way, thus, By turning every man and woman into a philosopher, and a hero or heroine.

You will doubtless say to me: It will be a long time before we succeed in doing that! Your notion is Utopian, visionary, wild in the last degree! I am only too well aware that it will take a long time to make men profound thinkers and heroes, and if I thought otherwise, I should most certainly deserve all the epithets you might be inclined to heap upon me. In saying what I have said, I have only sought to point out the ultimate weal toward which we must certainly move, if we are to progress at all, - the goal of human perfection, which is perfect insight, perfect love, perfect freedom. The failure to see that this is man's goal leads to very many evils, evils of the most crying kind, of which most people are but little aware. Let me name two of the saddest and most hurtful of these.

The first relates to the theory of education and takes this form, that in educating a child we should do everything in our power to let it follow its natural inclinations. This is almost an axiom in American education - at least I know it is so in several parts of the country where it has been my lot to teach. This idea I believe to be in the highest degree false and dangerous. One easily understands how it arose - from 
a reaction against the brutal, bullying systems of education which were formerly prevalent here, and are so still in England and several other countries. One consequently can excuse it to some extent. Nevertheless, this does not alter its character, which is in the highest degree pernicious. If by the natural inclinations or nature of the child we mean the animal nature with which it comes into the world, nothing can be more untrue than that we ought to indulge and cultivate this nature. Indeed, the very opposite is true. This nature ought to be completely subjected and subordinated to that higher nature which is only latent in the child at its birth and for a long time afterwards, the intelligent and moral nature.

It is true that a child's natural instincts and tendencies ought to be regarded to this extent, - that they ought to be carefully studied, in order that it may be taught to subordinate them, and rise above them into the region of pure intelligence and complete freedom. The course of education for every child ought to be, as far as is possible, a copy of the education which the race has undergone, and is undergoing, just as each child is a copy and epitome of the whole development of the race in all other respects. First of all, the child ought to be taught in its outward acts to respect authority blindly, and, if need be - mark you, I say, if need be - even through fear. Then it ought to be taught to act from loving confidence and to this end a model worthy of love and confidence ought to be continually kept before it, as parent, nurse, or teacher, while at the same time it is made to live in a world of art, - not merely of graphic and plastic art, but of art in the broadest sense, - in a world of the lovable. Last of all, at the proper time, the child, now grown a young man or a young woman, must be taught to act from simple insight, to shape its actions in accordance with the recognized worth of things, without any regard to what its own animal inclinations, its own personal desires and ambitions, may be. 
But in order to be able to act in this way, it must labor and study to know the true worth and meaning of things, to see them in their true relations, to be, in one word, a lover of wisdom, a philosopher.

Now, the second of the evils which arise from the failure to recognize man's true destiny is just this, - a contemptuous denial that every man and woman ought to be a philosopher. So much does the old habit of authority and convention in matters of intelligence and morals still prevail, so much are men still the slaves of these, that philosophy, which alone can make men free, is still looked upon with suspicion, and illconcealed contempt. One continually hears : "But you can't expect every man to be a philosopher! It takes a long time to learn philosophy, and people generally have other things to attend to. They must sow and reap, buy and sell, eat and drink, and they must have a good time. Philosophy is dull, solemn business." The implication, of course, is, that sowing and reaping, buying and selling, and so on, are more important things than philosophy, and this, indeed, is what the world of our time practically believes.

The general belief is that the end of life is to acquire material wealth and have a "good time," which means to satisfy the natural inclinations, which our education accordingly fosters and pampers. I say this is the result of a failure to recognize that the aim of man's life is man's perfection, and that perfection consists in perfect insight, perfect love, and perfect freedom. As soon as men see this clearly they will no longer look down upon philosophy, which is but another name for loving insight, one of the essential elements in human perfection. To despise philosophy is to despise spiritual perfection, for clear knowledge is one of the elements of that perfection.

There is no duty more incumbent upon any human being than to know; unless it be the duty of loving with divine love everything known, in proportion to its worth, and sternly 
refusing to be guided by personal feelings and inclinations. A man or a woman who is not a profound thinker, seeing the things of the world in their true ideal proportions and acting accordingly, is a mere dependent, half-enslaved creature, whatever amount of so-called culture, refinement, and kindliness he or she may have. Such a person is still a slave to authority and convention, a mere play actor in life, bound to play a traditional, unreal part, without any of the glorious liberty of the children of God, of them who see the Divine face to face, and, in the light thereof, all things in their true worth.

The only reason why it is necessary to sow and reap, to buy and sell, and, indeed, to live at all in this world, is that the spirit may be enabled to rise to the heights of conscious insight, love, and freedom. If this end is missed all is in vain. A mere blameless, legally correct life will save no man. There is no unjust God, who will pick us up out of our cowardly, ignorant, narrow, prejudiced, slavish condition, and all at once pour upon us an ocean of insight, love, and freedom, without any effort on our part. The true God of philosophy, the God of the religion of the future, the just God, gives to each man precisely what with his own efforts he has righteously won, neither more nor less. The man who asks for more is a miserable dependant, sycophant, and beggar; the man who is content with less is a fool.

The upshot of the whole matter is, that knowledge and clear insight, of the intellectual, worth-estimating kind, is essential to all true well-being in this world. It is the want of intellectual insight into the true worth and meaning of life and its institutions that is the cause of well-nigh all the misery, sin, and confusion that are now cursing the world. The mass of men live on blindly, not knowing the meaning of the things that are most close to them, and thoughtlessly giving countenance to institutions and practices that crush out the life of the spirit. Not one in every fifty ever asks 
himself whether our political and social institutions, our state, our industry, our education, are founded on truth and right, or upon lies and convention-supported wrong.

And yet this is one of the first duties of every man. How much human energy and spiritual force are being thrown away and wasted in doing things that ought never to be done at all, the result of which clogs and binds in slavery the spirit! How much industry, ministering to pomp and pride and self-indulgence, is worse than useless! How much charity is worse than wasted, making human beings puling dependents, instead of beings rejoicing in divine liberty! How much education is absolutely pernicious, pampering the animal instincts and inclinations, and helping to sink the soul in matter, to enthrall it, and to hide from it the vision of God! How much precious time is wasted in frivolous reading of a sickly, sense-pampering kind, - time that might well be employed in obtaining intellectual insight, and in learning to love the things of the universe as they deserve! Amongst the greatest curses of our time, the greatest barriers to spiritual insight and human happiness, are misdirected education, and frivolous reading, and devotion to frivolous and meaningless art. Before we can hope to advance in righteousness and happiness we must reform our education from the foundation up, in accordance with insight into the true, eternal nature of the spirit ; we must make it a means for spiritual perfection, and not a means for acquiring material wealth with which to glut the senses.

At the same time those of us who have already reached manhood and womanhood must seek to undo the effects of our vicious early education, and strive with all our might, by labor and study incessant, to rise to divine insight, love, and freedom. We must learn to know the universe we live in, in order that we may be able to live in accordance with its nature and being. We must give up all frivolous reading, all devotion to frivolous art, and consecrate our time to the study of 
the great thinkers in all departments of human knowledge, physical and spiritual, and of the great artists, - those who have embodied in their works the truths of the eternal. What shall we say of people who devote their time to reading novels written by miserable, ignorant scribblers - many of them young, uneducated, and inexperienced - and who have hardly read a line of Homer or Sophocles or Dante, or Shakespeare or Goethe, or even of Wordsworth and Tennyson, who would laugh at the notion of reading and studying Plato or Aristotle, or Thomas Aquinas, or Bruno, or Kant, or Rosmini ? Are they not worse than the merest idiots, feeding prodigallike upon swinish garbage, when they might be in their father's house, enjoying their portion of humanity's spiritual birthright? I know of few things more utterly sickening and contemptible than the self-satisfied smile of Philistine superiority with which many persons tell me, "I am "not a philosopher." It means simply this, I am a stupid, low, grovelling fool, and I am proud of it!

But it is of no use to rail at the ill. Let us rather, all of us, from this day forward, resolve to be intellectually pious, to bend all our energies to the comprehension of that world, physical and spiritual, which is our larger selves, through Science, Philosophy, Art; and to exercise our souls in the correct loving of all things in proportion to their intrinsic worth. And inasmuch as art and science and philosophy are long, and the world-self which we have to comprehend is infinite, let us, like immortal spirits, combine to give each the benefit of the labor of all. 


\section{CHAPTER XXI}

\section{FAITH AS A FACULTY OF THE HUMAN MIND ${ }^{1}$}

To the question, How does the human mind attain to the knowledge of God? two main answers have been given: (I) through the natural faculties of the mind, (2) through a supernatural revelation. Catholic Christianity, as reflected for example in the pages of Thomas Aquinas, united these two answers, and maintained that, while the human faculties are capable of discovering that God is, a revelation is needed to know what God is, and how he is related to human beings. It held, moreover, that natural knowledge is a condition of supernatural knowledge, and that the latter is the material of faith.

Since the days of Kant, all this has been changed. That philosopher thought he had proved - and the world, on the whole, has agreed with him - that man's knowledge of actuality extends only to sense experience, since the forms of his mind have reference and applicability only to these. When he attempts to apply them in any other region, they find themselves without any contact, and when that is the case, they help him to no truth. Now, since, according to Kant, God is not an object of sense experience, man's faculties do not enable him to say there is any such being, or, indeed, anything supernatural at all. In truth, Kant believed himself to have conclusively demonstrated that man can attain to no knowledge of any metaphysical reality. His reason, indeed, has to postulate God in order to make the world appear rational; but whether any reality corresponds to this postulate, it is impossible to say.

1 A paper read by Mr. Davidson at a Philosophical Convention held at Chicago. 
If Kant be right in maintaining that the categories of the mind are mere forms which are utterly useless without a content derived from experience, - and this seems to be really the case, - it follows directly that, if we are to know God at all, it must be through some sort of experience. This experience may be either direct or indirect, that is, either inwardly cognized, or outwardly revealed. In the former case it will produce science and conviction; in the latter, at best, belief and persuasion. Furthermore, an external revelation of God can have no meaning for any one who has no experience corresponding to the terms in which that revelation is couched. Hence it follows, in the last resort, that we can have no knowledge of God without experience, and that of personal sort. The question, then, whether we know God, resolves itself into the question whether we have any direct experience of God.

But here we must be careful not to fall into confusion. In saying that, if we are to know God, we must have some personal experience of him, I do not mean that the whole content and system of this knowledge must be of an individual sort. If it were, it would be mere mysticism of the bad kind, a series of individual impressions, indistinguishable from hallucinations, and utterly irreducible to true knowledge. True knowledge is the result of universal human experience, built up out of combined human experience by many successive generations. This is eminently true of our knowledge of the outward material world. If each individual had to derive his knowledge of that from his own experience, his world would be of the meagerest sort, and it is otherwise only because he adds to his own experience that of the race, as organized in language, science, art, and philosophy. Granting, then, that man has an experience of God, and that out of this experience he can frame and systematize a knowledge of God, we shall expect to find that this knowledge is universal, and that each individual, if he is to arrive at a knowledge of God, must 
supplement his own experience by that of the race. But the God experience of the race is organized in religious institutions, religious creeds, and sacred books. Hence it is to these that the individual must go in order to supplement his own narrow experience. Only by these can he test its validity and assign its place. Without the experience of the race, his own could have little value; without the latter, that of the race would have no value at all; for we may fairly and justly say that that of the race is valuable to him only in so far as it enables him to interpret his own. Mysticism detached from scholasticism is mere dreaming; scholasticism detached from mysticism is empty dialectics, a mere playing with hollow concepts.

If, then, a knowledge of God involves an experience of God, it is clear that we must have a faculty corresponding to and mediating this experience. And I think that this faculty has long been recognized and named, being none other than faith. I am quite aware that the term "faith" is often used to mean a belief in certain historic facts, whose reality cannot be proved by the ordinary methods of history; and a famous scholar has maintained that there are no fewer than six meanings of "faith" in the New Testament alone. But even in that work the most common and vital meaning of "faith" makes it the faculty of the mind which grasps the substance and order of that invisible world in which lie the grounds of all our hope. And in this sense exclusively I shall use it in this paper. I will treat it as a faculty of the human soul, and ask what it reveals and what it commands.

But here at the very outset I am arrested by the prior question, Is there any such faculty? Kant, as we have seen, assumes that there is not, and all the conclusions of his philosophy, as well as of most other philosophy since his time, are deeply influenced by this assumption. Nevertheless it is one that stands at direct variance with the convictions of the race, into whose consciousness there enters the thought of an invisible world. In refusing to acknowledge the faculty of 
faith, therefore, we are setting aside, as unreal, one half of the content of the human race - consciousness - as a mere illusion to which nothing in reality can be shown to correspond. We say, in effect, that it is a mere delusive play of the transforming and recombining imagination, or else that it is due to a misuse of the empty forms of thought, the latter being Kant's notion. The question in the last resort is one of simple fact, and its answer must depend on an appeal, first to the individual consciousness, and then, for confirmation, to the general consciousness. Have we then, let us each ask ourselves, any direct experience of an invisible world? Before attempting to answer this question, let us be sure that we clearly understand what it means, and not rashly say No, because we have no experience of an invisible world at all like our experience of the visible world. We must, indeed, beware lest we take the question to mean, Have we any visible experience of the invisible world? This, of course, we have not, though many persons have claimed such experience and many more look for such experience as the only thing that would make certain the existence of an invisible world.

We must bear in mind that our ordinary experience of the material world consists of two elements which are readily enough distinguishable, though not, in reality, separable, an element made up of sensations, and an element by which these sensations are combined and converted into an objective, tangible world of things. If either of these elements were different, our material world would be different from what it is ; and if the latter element were entirely different, we should no longer have what we call an external world at all, - a world of sensible things existing in time and space. Now, if we are to have any experience of the invisible world, we must, indeed, have in it two elements analagous to these; but there is no reason why they should be similar to these or go to make up a similar result. Our sensations need not be those of color, sound, taste, smell, touch ; and the things we form 
out of them need not be bodies visible and tangible in time and space. When, therefore, we ask whether we have any experience of an invisible world we must look for a world very different from the visible one.

That we have a whole range of feelings entirely different from those that are connected with our senses, there can be no manner of doubt. They are what we call the moral feelings, - feelings aroused in us by actions and not by things. Such feelings are those of justice, injustice, right, wrong, remorse, reverence, duty, etc. It is likewise beyond doubt that we have a series of mental forms by which we combine these and the like into an invisible world of spiritual personalities. Kant has been at great pains to show us just what the forms are which enter into the composition of our material world, namely, the forms of sense and understanding. No one, so far as I know, has undertaken to draw out a scheme of the forms which enter into the composition of the spiritual world. And yet the task does not seem extremely difficult. I do not, indeed, flatter myself that I can give such a scheme in all its details; but I think I can point out the way in which it may be reached.

It is a familiar fact in all ethical experience, that when we do certain acts we are filled with a peculiar, elevating, inspiring joy; when we do others we are filled with a strange, degrading, paralyzing pain, or remorse. I am not at present concerned in determining how these feelings come to be distributed as they are at any particular time. It is enough for the present purpose to know that they always exist. Further, I am not concerned in showing how these feelings were developed and what lower stages they have passed through before showing their real nature. It is sufficient to know that nature. Now these feelings of joy and remorse are as clearly facts of experience as the sensations of color or sound and belong as clearly to a real world. The question is, Have we any means of constructing for ourselves the world to which they belong? 
In order to make the meaning of this question clearer, let us once more call to mind that the material world which we know is constructed by the forms of sense and understanding out of certain subjective sensations. Can we, then, out of those moral sensations, by any forms of our spiritual being, construct for ourselves a moral world? That such a world has actually been constructed, we know. In that world is one supreme spiritual being, all powerful, all loving, all holy, - a being who is the author of all spiritual beings, whose activity is directed toward the realization in themselves of his perfections. Is this world, then, a real world? And if it is not, can we construct a real moral world, or, which is obviously the same thing, a real metaphysical world?

That such a world has been constructed and has taken outward form in religious institutions, which fill the larger half of human life, affords at least a presumption of the reality of this world and, at the same time, a test for the validity of any world which the individual may construct. The difficulty with regard to the moral or metaphysical world is due, in large measure, to the fact that there does not seem to be the same concensus in regard to it that there is in regard to the material world. There is a general belief that all men have a common material world, that earth, sky, sun, moon, stars, mountains, plants, animals, etc., are the same for everybody; whereas it seems clear that the moral world is different for different people, and some seem to have no moral world at all. The conclusion is drawn that because the moral world is not the same for everybody, there cannot be any real moral world at all.

Now I think there is a double mistake in all this : (I) the material world is not so much the same for everybody as it is generally believed to be, and (2) the moral world is more the same for everybody than it is believed to be. But while insisting upon this, we may readily admit that the material world is more the same for everybody than the moral world 
is, and the ground of this is not difficult to discover. The material world is to a large extent constructed for us by the spontaneous action of our powers, free will hereby entering into it ; and these powers, just because they are spontaneous, are much, though by no means altogether, the same for all persons. The moral world, on the contrary, being a world of acts, freely and consciously performed - for nothing is moral that is not free and conscious - largely depends upon the free will of each individual for its character and content. A person who performs no moral acts - and acts here include thoughts - has no moral world. In spite of all this, however, there is a fundamental similarity between all moral worlds. Deduct what is due to differences of culture, language, and conceptions, and there remains a residue which is much the same in all cases. This is daily becoming clearer and clearer through the comparative study of religions.

I have said that certain acts bring to every man satisfaction, and certain other acts remorse. By acts I mean here not merely the changes that a man makes in the world, but I include also all the motives and interests involved in the acts. Now these feelings of satisfaction and remorse are a content, and a very real one, and it cannot be said that mental forms when applied to them are empty. It may be true that the forms of sense and understanding cannot be applied to them, and indeed it is true; but it still remains to be seen whether the mind has not other forms in which to apply to them, and which when so applied give us a moral or a metaphysical world of reality. In the feelings of remorse and satisfaction, when we come to examine them closely, there is involved the consciousness of authority, which we cannot help recognizing as rightful. This is, if we may so speak, the form of these feelings, - the form of the moral sense, - just as space and time are forms of the "outer" and "inner" senses. We can no more get rid of the authority which these feelings involve than we can get rid of space and time in our 
consciousness of the material world. But feelings which involve authority are found to involve much more. And here it is that the faculty of faith with its forms comes in. By means of these it explicates what is contained in these faculties or states of consciousness. And what are these forms? They are none other than what Kant calls the postulates of the pure reason, - God, freedom, and immortality. In other words, Faith constructs for us a world of free immortal beings, living and moving and having their being in God, just as Understanding constructs for us a world of transient, necessitated things, determined by the categories of quantity, quality, relation, and modality. And there is no reason to doubt the validity of the one more than of the other. To Kant, indeed, God, freedom, and immortality are mere postulates, revealing and shaping no reality; but this is because he does not recognize that we have any moral sense giving us experience for these terms to determine. As soon as we recognize that we have a moral sense, and that this sense gives us the content of moral experience, we at once see how those forms, which with Kant remained empty postulates, may determine the content and result in a real moral world.

It is curious and interesting in this connection to see how Kant, from his failure to see that the moral sense has a content of which God, freedom, and immortality are the forms, has been obliged to let his philosophy fall asunder into two disconnected parts, both of which are imperfect and which do not supplement each other. In his Critique of Pure Reason Kant gives us a theory of experience of the world as known, without doing anything to prove to us that it is not a subjective delusion entirely dependent for its character upon the nature of our consciousness. In his Critique of the Practical Reason again he finds the grounds of Morality in a mere "categorical imperative," which hangs in the air, and is not supported by any metaphysical order of being. He sees, indeed, that this imperative, in order to be rational, demands 
three postulates, - God, freedom, and immortality, - but whether these postulates correspond to any reality he is unable to say. He does not recognize that the moral sense and the forms of faith supply that very world of things in themselves which is needed to complete the phenomenal world and at the same time to supply the laws of ethical life. Accordingly he does not see that things in themselves are and must be free, moral, and eternal beings, and that the phenomenal world is the result of their activity. Hence his world, like his philosophy, breaks up into two disconnected parts, the world of theory having no connection with the world of practice, and both being left without any eternal foundation. The effect of this upon the philosophy of the last hundred years has been in many ways most unfortunate. It has broken up the world of man's consciousness; it has induced a despair of ever understanding the world; it has discredited philosophy and brought about a decay of interest in it ; it has led to a low materialism in science, to the divorce of ethics from any theory of the world, and to the decay of religion and the religious consciousness which rests upon the conviction that the world at its foundation - that is, in its essential being - is free, divine, and moral.

It is a very common reproach cast against philosophy that its history is a history of ruined systems; that instead of advancing in an orderly way, like the experimental sciences, it has had in every epoch to begin afresh. One reason for this is very obvious: the world to be explained is different at different epochs, and so is the form of the explanation demanded; but this is not the only reason. A far deeper and more potent one is this, - that all the philosophies hitherto have failed to take due account of one most important element in the nature and theory of the world, namely the content of faith ; they have left that to religion, which has nearly always stood aside of, and in opposition to, philosophy. It may be said that there is one very marked and important exception 
to this rule, namely the scholastic philosophy of the Middle Age. This, it may be said, took account of the content of faith. While this is in one sense true, it is so only when faith is used in a peculiar sense, one largely different from that in which it is used in this paper. In scholasticism " faith " means, not a faculty of the human soul, but an acceptance by the reason of certain facts and dogmas held to have been communicated by a special revelation from God. As a consequence of this, philosophy was not extended so as to include religion and the data of faith ; rather were religion and theology placed in opposition to philosophy and the latter made merely a handmaid of the former. I think, then, we may say that philosophy has never taken account of faith as an integral faculty of the mind, or correlated its data as such, with those of the other faculties. The world of philosophy, therefore, has always been an imperfect world. It is true, indeed, that numerous attempts have been made to arrive at the forms of faith without taking account of the faculty of faith. Such are the so-called proofs of the existence of God, which have played so important a part in philosophy, but whose insufficiency Kant so clearly showed in the Critique of Pure Reason. Since this was done, the existence of God, and therewith of freedom and immortality, have become, to say the least, problematic. Those who still believe in them do so either from old habit and association or because they believe that these things are a matter of direct divine revelation. For nearly all others they are either implicitly or explicitly obsolete notions; and since these are the notions that give meaning to life, life is suffering from the want of them.

If I am told that these practical needs should not be allowed to have any weight in a matter of pure philosophy, I can only reply that no advance in philosophy or anything else has been made, save in answer to a practical need. At the present time it has become evident that there is no true way of reaching any certainty with regard to God, freedom, and 
immortality, unless we can show that they are involved in actual experience, that we have a faculty whereby they are directly cognized. Neither revelation nor inference will help us, since they are both meaningless without the experience referred to.

Now I think I have shown that in the data of the moral sense, as determined by the forms of faith, we have the existence of a moral and metaphysical world - the two terms mean the same thing - assured to us. It is no longer either a matter of hearsay or a postulate; it is a reality and the truest of all realities. I am, indeed, very far from supposing that I have worked out this great truth in all its details or given it a completely scientific form; but I think I have shown its presuppositions and bearings, and likewise its necessity in order to give unity and completeness to our view of the world, and meaning to our lives. Having now shown what faith, as a faculty of the human soul, reveals to us, let us next try to see what it commands us to do. The word "command," I must admit, is here not a happy one, if it be taken in its literal sense; for faith gives no commands of any kind: it simply reveals to us a world of reality, with which, for good or for evil, we are inseparably bound up and leaves us to draw our own conclusions as to what conduct is best with reference to that world. Only in this sense does it command us. What we have now to consider is, what the moral world, being such as it is, revealed to us by faith, suggests in the way of conduct.

The moral world, then, is a world of eternal beings, having their root and origin in one Eternal Being of infinite perfection, which includes boundless freedom. All these beings are so connected with the Perfect Being that he is at once their deepest form and necessarily, therefore, their goal. Here we must adopt a line of thought with which the philosophy of Aristotle has made us familiar. That thinker tells us that the state is prior in nature to the individual, which is only a 
particular case of a universal law, namely that the end is prior in nature to the beginning, for any individual. Just as it is the political characteristic in man that makes possible at once the civil institution and civilized man, so it is the divine characteristic or form in him that makes possible the Kingdom of Heaven and the divine man. Indeed, it is the divine form immanent in the world, that, in working itself out, is gradually reducing it to the image of God.

Man, then, is man, because he has in him that divine form. In this he differs from all the rest of the creation known to us. Having this form, he is free. But he possesses this form only in an undeveloped form, and his freedom, therefore, is potential, rather than actual. Man is not free but he has the power to become free by actualizing the divine form in himself. This is the strange condition in which man finds himself, - a condition which gives rise to all the endless discussions in regard to the freedom of the will. It is entirely possible to maintain that a man is free and also that he is not free, the facts being that he is not actually free until he frees himself. It is difficult to express this in intelligible language. He cannot choose until he does choose : it is in the very act of choosing that he becomes free to choose. Perhaps we may make this somewhat clearer by a parallel case which 'occurs in perception. When I perceive that this paper is white I make a judgment to that effect ; the judgment and the perception are one and the same thing. I do not perceive and then, having perceived, judge. I can neither perceive till I have judged, nor judge till I have perceived. In the judgment the subject is not subject nor predicate predicate until the judgment is pronounced. It is in the judgment that I become first aware of them and of their relation. In the same way, before I choose I am incapable of choosing : my will is absolutely determined one way or the other by what we call motives, generally assignable. When, on the other hand, I do choose, my choice is entirely free. Indeed, I have no method of telling which is 
the stronger motive center. I have made my choice. The stronger motive is the one I choose to follow. It is strong because I follow it, and I follow it because it is strong. In one and the same act I impart to a motive all the strength it has, and follow it because it is strong. I can never say, This I recognize to be the stronger motive, and therefore I must, or shall, follow it. In recognizing it as the stronger, I have made it the stronger. This is the paradox of the will, which has a perfect parallel in the paradox of the intellect. The fact is that our spiritual powers, those that express the divine form, are not conditioned by before and after; if they were, freedom would be utterly impossible. It may be said, Does the will then act without motives, spontaneously and blindly? Are acts of will purely arbitrary acts? Here we must make a distinction. What are usually called motives, and regarded as determining the will, do not determine it at all and, in so far, it may be said to act without motives. But there is another motive which is forever present, namely freedom, and from this it cannot possibly escape. But what is freedom? It is simply the activity of the will itself. In saying, therefore, that freedom is the motive of the will, we are simply saying that the will is its own motive. It moves because it moves; it is determined because it determines itself. It is moved by motives because it makes the motives. It wills itself, its own actuality, and that alone. In so far as it does, or seems to do, aught beyond this, it is not in reality willing at all ; in so far as actions are determined by natural laws without the interference of the will, there is, in fact, dreaming, - a mere hypnotic state-consciousness, - - without will.

Man's will, the form of freedom in him, is his essential self. This will is a form, which being infinite cannot be realized in any assignable time. The process is therefore an everlasting one, tending forever toward a goal that can never be reached. That goal is God, who is the Perfect Will, Freedom completely actualized. Seeing, then, that faith shows us 
to be sons of God, whose form is divine freedom, or the complete realization of the will, and seeing that the complete realization of the form of a thing is the truth of the thing, we may state the whole duty of man in a word, namely, $B e$ your true self, or $B e$ a will, or $B e$ free, or Be perfect as the Father which is in Heaven is perfect. These imperatives all mean the same thing, and that thing is at once the essence of all religions and of all true ethical systems. It is not my purpose here to enter into the details of the manner in which the imperatives may be obeyed, or to lay down a code of ethical rules or precepts of perfection. I merely wish to say that faith reveals to us a world in which all life is eternal life, and since we are in that world, we are in duty bound to live for eternity. This is the point which this whole paper is intended to emphasize. At the present day, having set aside and ignored the data of faith, because the nature of faith has been misunderstood, we are trying to construct formulæ and ideals of life without God, freedom, and immortality. We are saying, "The present phase of existence is all; let us see how we can make the most of it," and are, in consequence, tending to a low prudential utilitarianism. It is true that we are still so far influenced by old habits and thoughts, forms derived from a view of the world which included the data of faith, that we neither see the end we are making for nor hasten toward it as rapidly as we should otherwise do; but these habits and thought forms, if unsupported by the total views to which they belong, will inevitably sooner or later die out, and then the race to the new goal will proceed with headlong speed. I see no other way to prevent the result than by restoring to human consciousness the content of faith, by showing that God, freedom, and immortality are not motives derived from a special external revelation, but that they are integral parts of the human consciousness, as such. I do not, of course, mean to say that every human being is born with these conceptions clearly defined in his mind - 
very far from it ; I only mean that they are there in the same condition in which all other conceptions originally are, a condition of potentiality or latency. They can be brought out into clearness only as the forms of the understanding are brought out by actual experience. As the forms of the understanding are evolved through contact with the world of sense, so the forms of faith are evolved by contact with morality and religion, and particularly of the latter. What we need above all things at the present day, is a comprehension of the religious world, - not merely an intellectual comprehension of it, but a comprehension of it with the whole being. We must be able to enter into the consciousness of Isaiah, of Jesus, of the Buddha, of St. Francis, St. Bernard, and of all those to whom the moral world has been a clear reality. And not only so, but we must enter into the whole religious consciousness, that which underlies and includes the consciousness of all such men as these, the religious consciousness of the world. It is in this and through this that our conceptions of the data of faith will find definiteness and fullness, and that the moral world will gain reality for us. And another great and far-reaching result will accrue from the true view of faith as a faculty of the human soul, namely the insight that all religion is one religion, that all revelations are portions of the one continuous revelation which is being made to and through humanity; that they are aspects of the spiritual world, in which are all reality, and ultimately all truth. The world at the present day is still divided up into a number of religious sects which oppose and paralyze each other, and in doing so prevent the realization of the Kingdom of Heaven. Each sect chains a special revelation, and standing upon that, condemns or ignores all other revelations. Thus the spiritual force of the world is wasted in vain controversies about external matters, instead of being turned to realize the inner and eternal world and to make the content of it the norm and guide of life. Thus philosophy and religion, State and 
Church, are divorced, and the harmony and the unity of life broken up. Here in America we frequently, and with entire justice, congratulate ourselves that we have completely separated State and Church, and forbidden the one to interfere in the affairs of the other. But we ought to be fully aware that this is but a temporary condition of things, rendered necessary because the Church has placed itself in a false position, by claiming to stand upon something which does not correspond to any human faculty, - upon merely external revelation. As soon as there is a church which men feel and recognize to be the embodiment and organ of something revealed to themselves, this opposition will of necessity cease and Church and State will stand to each other in an organic relation. Then there will no longer be any conflict between the two as to which should undertake the work of education; then there will be no attempt to find a means of teaching morality apart from religion, no effort to render unto Cæsar the things that are Cæsar's, without rendering unto God the things that are God's.

Ladies and gentlemen, the World's Fair, which has furnished the occasion for bringing us together, is a marvellous exhibition of what the genius of men can make of the material world to satisfy the demands of his own nature to furnish the conditions under which he may realize the divine form or image in himself. But what if, when the conditions are given, the end for which they exist be not realized, what if we stop short with the conditions, satisfied with them, and never use them to raise ourselves toward our true end? What if we never at all become conscious of that high world in which our end lies? What if God, freedom, and immortality be entirely forgotten in all our doings, or remain matters of mere hearsay? What, then, would the World's Fair be worth?

You probably all know that the last Paris exhibition furnished the starting point for a great idealistic reformatory movement in France, a movement which bids fair to renovate 
her whole moral life. Is it too much to hope that the Chicago World's Fair may, through its Auxiliary, accomplish something of the same sort for the United States, that a movement may now be started which, by claiming faith as an integral part of human nature, and proving that it makes us certain of God, freedom, and immortality, shall give unity, consistency, and impregnability to religion, and make it the fortress of ethical life? 


\section{APPENDIX A}

The following prospectus of one of Mr. Davidson's courses of lectures in New York is printed as an illustration of the kind of material he deemed it advisable to bring before the Breadwinners, and of the range of his own studies. It is printed in the belief that it may be of use, not only to students of the subject outside the Universities and Churches, but also to those within them who wish to become familiar with the vast range of the literature of the subject.

\section{THE ORIGINS OF MODERN THOUGHT}

\section{A SERIES OF TWENTY LECTURES WITH A LIST OF BOOKS FOR COLLATERAL READING}

BY THOMAS DAVIDSON

\section{THE ORIGINS OF MODERN THOUGHT AND BELIEF}

The aim of this course of lectures is to investigate the nature and validity of modern thought by tracing it to its origin in the past. This is now, for the first time, rendered possible through the results achieved in the last half century by archæological and historical research and literary criticism, - results which have done much to set the past in its true light and deliver us from the weight of its authority. The course consists of twenty lectures, ten on ancient, and ten on mediæval and modern thought, closing with an attempt to outline the tendencies of future thought.

\section{I - ANCIENT THOUGHT}

\section{LECTURE I - INTRODUCTORY}

In what sense should, and must, past thought influence us? True and false conservatism. Need for a thorough and unsparing criticism of tradition in thought and practice, especially at present. "New occasions teach new duties" and creeds. The evil of over-conservatism and 
over-radicalism. All advance either by evolution or revolution: the difference. The relation of the United States, as a nation, to past and present thought. The sources of modern thought and practice : Hebrew prophetism, Greek philosophy, Roman statesmanship, Muslim scholasticism, Jewish and Christian scholasticism, Germanic paganism.

\section{LeCture II - Hebrew Prophecy}

Its origin, affinities, and nature as shown by the higher criticism. The central trinity of Hebrew concepts : monotheism, Messianism, holiness. I ts gradual evolution under social influences. Authentic Hebrew history begins with Samuel; so does prophecy. Tendencious reconstruction of previous history out of myths and legends derived from various sources. Character of Hebrew historical records. The worship of Yahweh. The central conflict of Hebrew history: church and state; authority and freedom.

\section{LeCtuRe III - Hebrew Prophecy}

Hebrews and Canaanites under David and Solomon. The religious influence of these men. Priests, prophets, and wise men: their origin and functions. Wisdom literature. Division of Hebrew kingdom. Israel and Judah and their relations. The civic and prophetic parties. Nomadism of the latter. Elijah and Elisha. Gradual growth of monolatry, then of monotheism. Song of Solomon. Amos and Hosea, and the state of Israelitish thought at the time of the Captivity.

\section{LeCtuRe IV - HebreW Prophecy}

The ideas of Messianism and holiness. Isaiah and his influence. The Law. The Book of Deuteronomy and Josiah's reformation. Its failure and the result of it. Prophecy and monotheism triumphant. Yahweh becomes the universal God, and the Jews his chosen people. The creed of Judah at the Captivity. Why different from that of Israel. Jeremiah" and the breach with ritual. The fate of the ten tribes. They were not "lost." The return, and the "second Isaiah." Ezekiel and the rise of apocalypticism. The end of true prophecy.

\section{Lecture V - Hebrew Prophecy}

Replaced by scribism and a written law. The post-exilic theocracy: its origin. The Law, introduced by Ezra. The Hexateuch and its composition. Origin of the Old Testament canon: its divisions and their order-Prophets, Law, Hagiographa. The wisdom literature: Job, 
Proverbs, Qoheleth, etc. The Psalms : their date and use. Post-exilic Messianic notions. The Messiah unknown to the Old Testament. Judea under the Persians and under the Greeks.

\section{Lecture Vi - Hebrew Prophecy}

In conflict with foreign ideas. The Dispersion and its doctrines. Knows no personal, temporal Messiah. Replaced by Logos and Sophia. The Maccabean Rising and the Chasidim. The Book of Daniel. Sadducees and Pharisees. Babylonian and Persian influences and notions: angels, personal immortality, heavenly Messiah, Messianic age, final judgment, eternal hell, with devils. Apocryphal works in Hebrew and Greek: their importance for the understanding of Christianity. Great value of the Book of Enoch. Infiltration of Greek thought. Roman conquest of Judea, and its effect on Messianism. Condition of Hebrew thought in the century before Christ; Jesus and the Kingdom of Heaven. The purpose of Jesus. The two elements in his teaching, - righteousness and Messianism. Their relation and conflict. The causes of his immediate failure and ultimate success. Jewish and pagan Christians. Paul's influence. The New Testament: its origin and purpose.

\section{Lecture VII - Greek Philosophy}

Judaism and Hellenism; revelation and reason; miraculism and nature. Epochs in Greek thought: mythology, theology, philosophy. Origin of the last: its problem and purpose. Fate and the gods. Necessity and convention. Evolution of thought from naïve objectivism to pure subjectivism. Thales and Anaxagoras. Realism and idealism. Being and Becoming: their origin and relation. The One and the Many, and the puzzle they offer. Zeno's paradoxes and what they prove. Monism and atomism; both equally lead to subjectivism.

\section{Lecture ViII - Greek Philosophy}

The Sophists and the triumph of subjectivism. Ancient Kantianism. Decay of mythology and theology and of the institutions founded upon them. Naturalism and spiritualism an insoluble dualism for the Greeks : the reason of this. The Greek "up-clearing," and its effects. "Man the measure of all things." The force of moral authority transferred to the inner world. Socrates, the archsophist, inventor of science and of moral freedom. The nature and conditions of these. The Socratic method and its results. 


\section{Lecture IX - Greek Philosophy}

The true Socrates, freed from Platonic additions. His contributions to humanity. The irony of Socrates.

\section{Lecture $X$ - Greek Philosophy}

Plato, and his distortion of Socrates's thought. By his poetic ideas, replacing the old gods, he bequeaths to the world a hopeless and unnecessary dualism, leading to metaphysics, asceticism, mysticism, obscurantism, spiritual aristocracy and authority, unfreedom, romanticism, etc. His doctrine of universals. Champions Being as against Becoming. His Republic: its meaning and effects on subsequent thought and practice. Aristotle, the champion of Becoming. His explanation of change. Form and matter; energy and potence. His God: how arrived at ; utterly empty and useless, except to lead to mysticism and Nirvana. Aristotle's world scheme, and its effect upon thought and science. He is the last great Greek thinker. After him Hellenism passes into cosmopolitanism. Stoicism and epicureanism: religions rather than philosophies. The character of post-Aristotelian thought: its mysticism, paving the way for mediævalism.

\section{II - MEDIÆVAL AND MODERN THOUGHT}

\section{Lecture XI - Union of Hebrew Prophecy and Greek Philosophy}

This is the source of medirval thought, which starts definitely with the Nicene Creed (A.D. 325). Greeks and Jews in Alexandria and other cities. The Synagogue and the School (I Corinthians i, 22). The Logos doctrine and its double origin. Philo, the Jew, and his attempts to reconcile Moses and Plato-Jewish theism and Greek idealism - by allegory. The effect of this. The importance of Hellenic Judaism.

Primitive Christianity an ethical law and a Messianic hope. Based on what were believed to be facts. Innocent of metaphysics, theology, or dogma. Paul and rabbinical Christianity: its extension to the pagan world. Johannine Christianity and the intrusion of Greek (mystical) thought, necessitating dogma. Nature of dogma. Primitive Christianity and the Apostles' Creed, which contains no sign of Greek thought. 


\section{Lecture XII - Union of Hebrew Prophecy and GREeK PhILOSOPHY}

Eastern (Greek) and Western (Jewish) Christianity: pantheism and theism. The former formulated by Origen, who acknowledges two Christianities, an historical and a spiritual (Matthew xiii, 2). Origen's influence. Personal and non-personal Messianism. The latter takes form in neo-Platonism. The relation of this to Christianity : dogmatism and mysticism. The Christian and neo-Platonic trinities. The neoPlatonic world scheme and its gradual intrusion into Christianity, causing asceticism, mysticism, monasticism, and decay of science. Mithra worship, and its effect on Christianity. Gnosticism: takes final form in Manichæism (Mani, A.D. 215-276). Nature, spread, and lasting effects of this. Gradual decay of primitive Christianity under Greek and gnostic influences. Faith vs. Metaphysics. Heresy. The New Testament canon: its use to prevent heresy.

\section{LeCture XIII - Roman Statesmanship}

The legal element in Christianity. Origin and character of the Roman State. The Empire and its need for a universal religion. Religion and State in the ancient world. Vain attempts to find an imperial religion, and their sad results. The causes of the success of Christianity. Its union with the Empire, giving definiteness and force of law to Hebrew beliefs clothed in Greek abstraction. The dogmas of Christianity thus claim both divine and human authority. Gradual formulation of the fundamental dogmas of Catholic Christianity, - trinity and incarnation. Reason abdicates in favor of faith, and the Middle Age begins.

\section{LECTURE XIV - Roman StatesmanshiP}

Augustine lays the basis of Latin Christianity by incorporating into it elements from Roman legalism, neo-Platonic (Plotinian) mysticism and Manichæism. His notions of atonement, redemption, and evil. The secularization of the Church leads to a reaction in the form of monasticism. The nature and meaning of this: triumph of (Platonic) supernaturalism. Growth of mysticism. Its connection with the works of (Pseudo-) Dionysius Areopagita. Their character, origin, and effects upon the Church. Contradictory elements in the Church's creed : world renunciation and world rule. The Eastern and Western Empire and Church. The inroads of the barbarians. St. Benedict and Western monasticism: contempt for the world. 
(Digression) What is it in human nature that makes it possible for the supernatural and mystical to triumph over the natural and rational?

\section{LECTURE XV - MUSLIM Scholasticism}

Origin, nature, and spread of Islam. It is mainly Judaism carried to its extreme logical results. The Christian (Ebionite and Nestorian), Mazdean (Sabian and Manichæan) and Arabic pagan elements in it. It denies the two fundamental Catholic dogmas (Koran, Sura cxii). The Koran: its origin and character. Arab philosophy: its origin and character. A compound of Aristotelianism and neo-Platonism. Eastern and Western schools, and the great names in both. All the problems of later Christian scholasticism discussed in the Arab schools. Arab additions to thought. The ultimate triumph of blind orthodoxy in both schools. The dogmatic Sunnites and the mystic Shi'ites. The Sufis. Islam the true Unitarianism.

\section{Lecture XVI - Jewish and Christian Scholasticism}

Effect of Islam upon Jewish thought. Ibn Gabirol (Avicebron) and Maimonides (forerunners of Spinoza). The Fons Vita and Moreh Nebukhim. Effect of Islam on Christianity compels it to give systematic formulation to its dogmas. The result,-scholasticism. The relation of this to patristicism and mysticism. Irish and Anglo-Saxon learning. Charlemagne, Alcuin, and the revival of learning. The ideals of Charlemagne. Gregory VII and his supernatural programme. St. Anselm, St. Bernard, and the reaction of Roscellinus and Abelard. Joachim of Floris and St. Francis. Europe sinking into supernaturalism when roused by Islam. Islam the bearer of civilization for nearly five hundred years.

\section{LeCTURE XVII - Christian Scholasticism}

Paved the way for rationalism. The epochs of scholasticism and their respective characteristics. Philosophy the handmaid of theology. Scotus Erigena, and the introduction of mysticism into the West. The struggle between theism and pantheism. The Platonic doctrine of universals and the Christian Trinity. Realism and nominalism. Joachim's Eternal Gospel, and the introduction of Aristotle into Western thought. The far-reaching effects of both. Thomas Aquinas, Bonaventura, Dante. 


\section{Lecture XVIII - Germanic Paganism}

Nurse of individualism. Latin and German; Authority and Freedom. Effect of Arian and Catholic Christianity upon the Germans. The Holy Roman Empire. German mysticism: its nature and importance. Germanic reaction against Latin mysticism. The Reformation (revolt of reason) and the Renaissance (revolt of nature). Their effects. The growing demand for individual liberty in thought, affection, and act. Conditions of this. Savonarola and Bruno, Servetus. Rise of modern thought. Shakespeare, Bacon, Hobbes, Locke, and Descartes. Spinoza and Berkeley. Hume and the complete breach with past thought constructions. The response in English, Scotch, and German philosophies. The reconstructive rationalism of Kant. Philosophy in earnest. Voltaire and Rousseau. Catholic and Protestant reaction after the French Revolution. Neo-Catholicism and Hegelianism. Rosmini. Return to mysticism and despotism. Herbert Spencer, Darwin, Huxley, and the doctrine of evolution. Agnosticism and philopistism.

\section{LeCture XIX - The Conflict Between ANCIENT AND MODERN THOUGHT}

The characteristics of the two. Supernaturalism and naturalism. The gradual decay of the former and growth of the latter. The effects of physical science, historical research, and higher criticism. The "up-clearing." The contents of the deposit of ancient thought, and its present influence. What of it must pass away, and what be retained. The spiritual results of past experience, thought, and belief will remain, but they will assume new forms to suit present thought, and give birth to new, free institutions. Influx of Hindu thought.

\section{LeCture $X X$ - The New Thought}

Its relation to the old. Old thought theocentric; new thought anthropocentric. "Man is man, and master of his fate." The effect of this view upon thought and institutions ; upon the individual consciousness ; upon science, ethics, religion, sociology, education. The division between Church and State healed. Labor in the future. What we may learn from the Orient. The spiritual promises of the past more than fulfilled in the present. The Heaven of the future the republic of free, pure spirits, ever growing through mutual intimacy and help. 


\section{COLLATERAL READING}

\section{Collateral Reading}

Those who wish to make a study of the subject of these lectures will find help in the following works, which have been selected chiefly on account of their accessibility :

\section{For LECTURE I}

I. Condorcet, J. A. N. Esquisse d'un Tableau Historique du Progrès de l'Esprit Humain.

2. Comte, A. Système de Politique Positive.

3. Lecky, W. E. H. History of the Rise and Influence of the Spirit of Rationalism in Europe.

4. White, A. D. A History of the Warfare of Science with Theology.

\section{FOR LECTURE II-VI}

5. Driver, S. R. Introduction to the Literature of the Old Testament.

6. Driver, S. R. A Critical and Exegetical Commentary on Deuteronomy.

7. Driver, S. R. Isaiah, His Life and Times.

8. Smith, W. R. The Religion of the Semites.

9. Smith, W. R. The Prophets of Israel.

I0. Smith, W. R. The Old Testament in the Jewish Church.

I r. Wellhausen, J. Die Composition des Hexateuchs.

I2. Wellhausen, J. Prolegomena zur Geschichte Israels.

13. Wellhausen, J. Israelitische und Jüdische Geschichte.

14. Cornill, H. Der Israelitische Prophetismus.

15. Holzinger, H. Einleitung in den Hexateuch.

16. Haupt, P. The Polychrome Bible.

17. Renan, E. L'Histoire du Peuple d'Israel.

18. Renan, E. Le Cantique des Cantiques.

19. Renan, E. Les Origines du Christianisme.

20. Ewald, H. Commentary on the Prophets of the Old Testament.

21. Somerwell, R. Parallel History of the Jewish Monarchy.

22. Oort and Hooykaas. The Bible for Learners.

23. Schrader, E. The Cuneiform Inscriptions and the Old Testament.

24. Cheyne, T. K. Jeremiah, His Life and Times.

25. Cheyne, T. K. The Origin and Religious Contents of the Psalter.

26. Cheyne, T. K. Introduction to the Book of Isaiah.

27. Cheyne, T. K. Job and Solomon (Wisdom Literature).

28. Kuenen, A. The Religion of Israel to the Fall of the Jewish State.

29. Ryle, H. E. The Canon of the Old Testament.

30. Wildeboer, G. The Origin of the Canon of the Old Testament. 
31. Schürer, E. A History of the Jewish people in the Time of Jesus Christ.

32. Charles, R. H. The Book of Enoch.

33. Keim, T. The History of Jesus of Nazara.

34. Westcott, B. F. Introduction to the Study of the Gospels.

35. Strauss, D. F. The Life of Jesus.

36. Harnack, A. History of Dogma.

37. Harnack, A. Das Neue Testament ums Jahr 200.

38. Harnack, A. Chronologie der altchristlichen Litteratur.

39. Weizsäcker, C. Das Apostolische Zeitalter.

40. McGiffert, A. C. The Apostolic Age.

41. Pfleiderer, O. Paulinism.

42. Jülicher, A. Einleitung in das Neue Testament.

43. Brandt, W. Die Evangelische Geschichte und der Ursprung des Christentums.

\section{For Lectures VII-X}

44. Zeller, E. Die Philosophie der Griechen.

45. Ueberweg-Heinze. Grundriss der Geschichte der Philosophie. 2 vols.

46. Byk, S. Vorsokratische Philosophie.

47. Marshall, J. A Short History of Greek Philosophy.

48. Gomperz, T. Griechische Denker.

49. Davidson, T. The Education of the Greek People.

50. Dickinson, G. L. The Greek View of Life.

51. Grote, G. A History of Greece, Chapter LXVII.

52. Xenophon. Memorabilia of Socrates.

53. Fouillée, A. La Philosophie de Socrate.

54. Pfleiderer, O. Sokrates und Plato dargestellt.

55. Plato. Dialogues (translated by B. Jowett).

56. Bussell, F. W. The School of Plato.

57. Grote, G. Aristotle.

58. Grant, A. Aristotle.

59. Rosmini-Serbati, A. Aristotele Esposto e Esaminato.

\section{For Lectures XI-XIV}

6o. Drummond, J. Philo Judæus, or the Jewish Alexandrian Philosophy.

61. Heinze, M. Die Lehre vom Logos in der griechischen Philosophie.

62. The Ante-Nicene Fathers (Translated).

63. Bigg, C. The Christian Platonists of Alexandria.

64. Hatch, E. The Influence of Greek Ideas and Usages upon the Christian Church (Hibbert Lectures, 1888).

65. Schaff, Ph. History of the Christian Church.

66. Müller, K. Kirchengeschichte.

67. Richter, A. Neu-Platonische Studien.

68. Flügel, G. Mani, seine Lehre und seine Schriften.

69. Kessler, K. Mani. Forschungen über die Manichäische Religion. 
70. Harnack, A. Monasticism, its Ideals and its History.

71. Montalambert, C. F. The Monks of the West.

72. Gibbon, E. The Decline and Fall of the Roman Empire.

73. Grandgeorge, L. St. Augustin et le Néo-Platonisme.

74. Frothingham, A. L. Stephen Bar Sudaili, the Syrian Mystic, and the Book of Hierotheos.

\section{FOR LECTURE XV}

75. Muir, W. The Life of Mahomet and History of Islâm.

76. Sprenger, A. The Life and Teaching of Mohammed.

77. The Koran. Translations by Sale, Palmer, Rodwell, Lane-Poole.

78. Nöldeke, T. Geschichte des Qorâns.

79. Müller, A. Der Islâm im Morgen- und Abendlande.

80. Schmölders, A. Essai sur les Écoles Philosophiques chez les Arabes.

8r. Renan, E. Averroès et l'Averroisme.

82. Dieterici, F. Die Philosophie der Araber im X. Jahrhundert n. Chr.

83. Steiner, H. Die Mu'taziliten, oder die Freidenker im Islâm.

84. Syed Ameer Ali. Life and Teachings of Mohammed.

85. Gobineau, Cte. de. Les Religions et les Philosophies dans l'Asie Centrale.

86. Wellhausen, J. Reste arabischen Heidentumes.

\section{For LECTURES XVI-XVII}

87. Stöckl, A. Geschichte der Philosophie des Mittelalters.

88. Hauréau, B. Histoire de la Philosophie Scolastique.

89. Von Eicken, H. Geschichte und System der Mittelalterlichen Weltanschauung.

90. Jourdain, A. Recherches Critiques sur l'Age et l'Origine des Traductions Latines d'Aristote.

91. Steinschneider, M. Die Hebräischen Uebersetzungen des Mittelalters.

92. Bäumker, C. Avencebrolis (Ibn Gabirol) Fons Vitæ.

93. Guttmann, J. Die Philosophie des Salomon ibn Gabirol.

94. Munk S. Guide des Égarés, Traité de Théologie et de Philosophie par Moise ben Maïmoun, dit Maimonide.

95. West, A. F. Alcuin and the Rise of the Christian Schools.

96. Bryce, J. The Holy Roman Empire.

97. Gfrörer, A. F. Pabst Gregorius VII und sein Zeitalter.

98. Scheffel, J. V. Ekkehard, eine Geschichte aus dem Zehnten Jahrhundert.

99. Sabatier, A. Vie de S. François d'Assise.

100. Picavet, F. Roscelin, Philosophe et Théologien.

ror. Rémusat, C. de. Abélard.

102. Deutsch, S. M. Peter Abälard, ein kritischer Theologe des zwölften Jahrhunderts. 
103. Cousin V. Fragments de Philosophie du Moyen Age.

104. Reuter, H. Geschichte der religiösen Aufklärung im Mittelalter.

105. Talamo, S. L'Aristotelismo della Scolastica.

106. Prantl, C. Geschichte der Logik im Abendlande.

107. Tocco, F. L'Eresia nel Medio Evo.

108. Vaughan, R. W. B. The Life and Labors of St. Thomas of Aquin.

109. Dante. New Life, Banquet, and Divine Comedy.

r 10. Görres, F. Die Christliche Mystik.

II I. Vaughan, R. A. Hours with the Mystics.

112. Preger, W. Geschichte der Deutschen Mystik im Mittelalter.

113. Deniflé, P. H. Die Universitäten des Mittelalters bis 1400 .

I14. Krumbacher, K. Geschichte der Byzantinischen Litteratur (A.D. 5271453).

I 5. Davidson, T. The Philosophical System of Antonio Rosmini-Serbati.

I16. Denzinger, H. Enchiridion Symbolorum et Definitionum.

\section{For LeCtures XVIII-XIX}

I17. Anderson, R. B. Norse Mythology.

I18. Zeuss, K. Die Deutschen und die Nachbarstämme.

1 19. Ueberweg-Heinze. Grundriss der Geschichte der Philosophie, Part III.

120. Villari, P. La Civiltà Latina e la Civiltà Germanica, in Saggi di Storia, di Critica e di Politica (pp. 37-93).

121. Fisher, G. P. The Reformation.

122. Symonds, J. A. The Renaissance in Italy.

123. Villari, P. Life and Times of Girolamo Savonarola.

124. Frith, J. Life of Giordano Bruno.

125. Fischer, K. Geschichte der neuern Philosophie.

126. Bacon, F. Novum Organum Scientiarum.

1 27. Hobbes, T. Leviathan; or, The Matter, Form, and Authority of Government.

128. Descartes, R. Discourse on Method and Metaphysical Meditations.

129. Spinoza, B. Ethics and Theologico-Political Treatise.

I30. Locke, J. An Essay Concerning the Human Understanding.

131. Hume, D. Treatise on Human Nature.

132. Morley, J. Voltaire and Rousseau.

133. Davidson, T. Rousseau, and Education according to Nature.

134. Kant, I. Critique of Pure Reason and Critique of Practical Reason.

135. Hegel, G. W. F. Phenomenology of Mind and Logic.

136. Schopenhauer, A. The World as Will and Idea (Vorstellung).

137. Darwin, C. The Origin of Species and The Descent of Man.

138. Comte, A. Cours de Philosophie Positive.

139. Spencer, H. First Principles and Principles of Biology.

140. Von Hartmann, E. Die Philosophie des Unbewussten and Die Selbstzersetzung des Christentums. 


\section{For LeCtuRE XX}

I4I. Goethe, J. W. Faust and Wilhelm Meister.

142. Michel, H. L'Idée de l'État.

143. Drummond, H. The Ascent of Man.

144. Huxley, T. H. Lay Sermons, Addresses, and Reviews.

145. Hodgson, S. H. The Metaphysic of Experience.

146. Marx, K. Capital.

147. Wundt, W. System der Philosophie and Grundriss der Psychologie.

148. Drews, A. Die Deutsche Speculation seit Kant.

149. Nietzsche, F. Thus spake Zarathustra and Beyond Good and Evil.

I 50. Royce, J. The Spirit of Modern Philosophy and The Conception of God. 


\section{APPENDIX B}

\section{LECTURES AND INTERPRETATIONS BY THOMAS DAVIDSON}

\section{Courses of Lectures}

I. Athens, Ancient and Modern (stereopticon)

2. History of Greek Sculpture (stereopticon)

3. Modern Greece

4. Greek Moralists

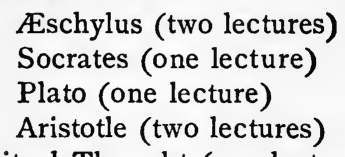

5. Spiritual Thought (one lecture) and its Heroes (ten lectures)

Aristotle

Philo Judæus

Plotinus and his School

Dionysius Areopagita

Thomas Aquinas

Bonaventura

Thomas à Kempis

Dante

Savonarola

Giordano Bruno

6. Goethe's Faust

7. Rosmini's Philosophy

8. Greek Education

9. Jesuit Education

\section{Single Lectures}

A. On Greek Subjects

I. Are the Homeric Legends Greek?

2. The Home of Clytemnestra

3. The Growth of Art Ideas among the Greeks

4. Sappho

5. The Irony of Plato

6. Aristotle's Debt to Plato

7. Greek Education up to Aristotle

8. Aristotle on Education 
9. The Greek Theory of the Drama

I0. The Fragments of Heraclitus

II. The Niobe Group

\section{B. On Mediaval Subjects}

I. The Revival of Thought in the Thirteenth Century

2. The Teachers of Dante

3. The Convivio (Banquet) of Dante

4. Dante's Guides in the Spirit World

5. The Nibelungen Lied

I. Ontology

\section{On Modern Subjects}

2. Intellectual Piety

3. Idols of the Theater

4. Animal and Man

5. Religion and Science

6. The Ultimate Creed

7. Divine Love

8. The Functions of a Church

9. Acceptance

Io. Detachment

1 I. Practical Duties following from a Spiritual View of Life

12. Inner Moral Life

13. Sin

14. Retribution (text, The Laocoön Group)

15. The Immortality of the Human Soul

16. The Meaning of Death

17. Sentimentality

18. The Methods of Progress

19. Practical Reforms

20. Some False Assumptions of Present Reformers

21. The Missing Social Link

22. Coöperation vs. Socialism and Anarchism

23. Meum et Teum

24. "Life, Liberty, and the Pursuit of Happiness"

25. The Relation of Property to Liberty

26. The Limits of the State's Competence

27. Education

28. Life Education

29. The Education of Girls

30. School Exhibitions 
31. Reading with a View to Culture

32. New Life

33. The Fellowship of the New Life

34. The Significance of Art

35. The Nature and Causes of our Social Difficulties

36. Social Remedies in the Light of History

III. Detailed Interpretation of Works in Philosophy AND LITERATURE

A. Philosophy

I. Plato's Republic

2. Plato's Timæus

3. Plato's Phædo

4. Aristotle's Metaphysics

5. Aristotle's Physics

6. Aristotle's Psychology (De Anima)

7. Aristotle's Ethics

8. Aristotle's Politics

9. Aristotle's Poetics

Io. Plotinus's Works (Enneads)

I I. Porphyry's Sentences

12. Proclus's Theological Instruction

13. St. Bonaventura's Soul's Progress in God

14. Rosmini's Philosophical System

15. Rosmini's Origin of Ideas

16. Rosmini's Logic

17. Rosmini's Dialectic

18. Rosmini's Psychology

19. Rosmini's Anthropology

20. Rosmini's Ethics and Politics

2I. Rosmini's Theosophy

22. T. H. Green's Prolegomena to Ethics

\section{B. Literature}

I. Æschylus's Oresteia

2. Eschylus's Prometheus

3. Sophocles's Edipus Tyrannus

4. Sophocles's Antigone

5. Dante's Divine Comedy

6. Goethe's Faust

7. Tennyson's In Memoriam 


\section{APPENDIX C}

Among Mr. Davidson's published books there are two which have unusual interest for the general reader. They are his Prolegomena to Tennyson's "In Memoriam," and The Parthenon Frieze.

Davidson considered In Memoriam to be not only the greatest English poem of the nineteenth century, but "one of the great world poems, worthy to be placed in the same list with the Oresteia, the Divina Commedia, and Faust." He wished to show that In Memoriam lay "in the chief current of the world's thought"; that it was "the record of the shattering and the rebuilding of the moral world in a man's soul."

The Prolegomena, which was published in Boston in 1889 , is considered by some readers to be Davidson's best book. It is certainly a noteworthy one, and a better introduction to the world's greatest elegy than anything else that has been written upon it. In his opinion the philosophical meaning of the poem is summed up in the prologue, and he gives us his interpretation with scholarly skill and sympathetic appreciation. The fundamental thought of the great lyric is this, - that "man's true happiness consists in the perfect conformity of his will to the divine will; and this conformity is attained through love, first of man and then of God."

The Parthenon Frieze, published with other essays in London in 1882 , and brought out in Boston and New York in 1886 , was written to combat the prevailing opinions regarding the meaning of this monumental work. The essay is a compact ?and closely built argument in which the author gives his reasons for regarding the existing explanations as worthless. Modern archæologists hold the subject to be the Panathenaic procession, or some ceremony connected with it. Davidson asserts that it may properly be called the Dream of Pericles, - a vision of social union and harmony, never realized, but having in it a great, genial, humane purpose, which, had it been fulfilled, might have changed the whole history of the world, and hastened the march of civilization by two thousand years. 


\section{APPENDIX D}

After writing his book on Rosmini Davidson remained at Domodossola for a year, and during this time he contributed several short, characteristic articles to the Pall Mall Gazette and other papers. One of these sketches, descriptive of the little town in which he made his home, is reprinted here as having more than a literary interest.

\section{A SOLITUDE IN THE ITALIAN ALPS ${ }^{1}$}

The stage that runs between the brooding loveliness of Lago Maggiore and the soaring ruggedness of the Simplon Pass stops about halfway at Domodossola, whose very situation between more renowned scenes has caused it to be treated with undeserved neglect. It is hardly noticed in the guidebooks, and though many travellers pass the night at it, they are usually so eager to reach what lies beyond that they pay no heed to the little town or its surroundings, and go away with only a vague consciousness of ever having been there. Nevertheless, the lover of nature, whose sense of beauty is not subject to the authority of guidebooks, will not grudge having spent a week or even a month among these surroundings.

Domodossola, a neat town of about three thousand inhabitants, stands on the Toce, in the bottom of a little valley completely surrounded by mountains, which are snow-capped the greater part of the year. It occupies, so to speak, the point of divergence of seven other valleys that branch off in different directions from the valley of Ossola - Val Anzasca, leading to Monte Rosa; Val Antrona; Valle di Bagnanco, with its mineral springs; Val Divedro, through which the Simplon road passes; Val Antigorio, continued in Val Formazza, in which is the Frua, one of the finest waterfalls in Europe; Valle dell' Inferno, not unworthy of its name; and Val Vigezzo, with its handsome churches and residences. Though all the surroundings of Domodossola offer that combination of Alpine sublimity and Italian beauty which at once suggests and imparts energy and rest, the mountains on the west side are especially

1 From the Pall Mall Gazette of May 26, 1882. 
calculated to attract and hold the lover of nature. These mountains rise to the height of four or five thousand feet, and are covered with vegetation to the very summit. Their steep sides are furrowed by innumerable ravines threaded by limpid torrents, whose courses form each a series of little pictures enough to fill a large gallery. Here nature and art seem to have combined to do their best. While the ravines still rejoice in their natural bosky savageness, every available spot of ground between them, to the height of two thousand feet, is under cultivation, while every little platform is occupied either by a picturesque village or an equally picturesque farmhouse. Above the line of cultivation are pine woods, whose still, somber hue, broken here and there by gayer tints, forms an imposing contrast to the bright green of the meadows below.

For the artist, to whom Nature is the all-fruitful, all-beautiful Venus, hominum divumque voluptas, or for the student, who finds that the voice of intelligence sounds clearest through the harmony of the emotions, these mountains are almost an earthly paradise. One such student has fixed his summer abode among them in a cottage situated about five hundred feet above the town, on a steep incline just below the little plateau occupied by the chief "fraction" of the village of Vagna. The cottage, whose windows look east and south, stands in the middle of an artificial terrace some sixty yards long by fifteen broad. This terrace is completely surrounded by a wall, high enough on the upper side to exclude intruders, and low enough on the downward side to leave unimpeded the view of the whole valley. At either end of the house is a little garden with vine-shaded walks, and arbors covered with creepers and fitted up with seats and tables of stone. The house is three stories high exclusive of the cellars, which are under the terrace. The first floor opens upon the terrace, which is here completely covered by a single vine, rivalling in extent the famous one at Hampton Court. All the eastern windows on the second floor are doors, and open upon a long veranda, while those on the third floor open upon small balconies.

When the student (or, as the natives call him, the hermit) wakes in the morning he is greeted by the sun rising over the snow-clad peaks of the eastward mountains. When he throws open his blinds and walks out upon the veranda the whole valley, with its mountains, 
meadows, and streams, its town, and its innumerable white villages lies stretched out before him; and he can even see the whole length of the high valley of Vigezzo, close by the Gridone, which stands out like a huge pyramid against the sky. While his eye is occupied with these things, his ear is greeted by the rushing of streams near and distant, and by the songs of birds already busy with their love making. Venus seems to be the one divinity of all the feathered bipeds, and especially of the ringdoves, whose whole life seems one act of worship. Here the ringdoves are plentiful, and so tame that it is difficult to keep them from perching upon one's head and shoulders. Their cooing seems the voice of Peace herself.

Having dressed and breakfasted, the hermit starts for his morning walk. But first he takes a look at his garden, saluting the newborn flowers with a welcome, to which they respond with dewy perfume. As he passes the church he finds that mass has already begun. All the peasantry of the village are at their morning prayers; not one is to be met outside. He stops for a moment to consider which way he shall turn, for the mountain paths are so numerous and all so beautiful that the choice is difficult. Having decided he begins to ascend, looking back every few minutes to enjoy a new view of the valley below. His way leads him now under vine trellises, now along terrace walls covered with moss, ferns, and ivy; now past waterfalls, tumbling into deep, sandy pools, whose rocky sides are tapestried with dripping ferns; now over rustic bridges of wood or stone spanning rapid torrents; now along deep ravines whose sides seem to stretch to heaven, now under groves of chestnut, now by the side of overhanging rocks, and now past chalets so quiet and picturesque that he feels no desire to go farther. Here he rests on a stone seat under the kindly shade of vine or chestnut and enjoys the full prospect of the now waking valley. Yonder on the extreme left is the Simplon diligence emerging with its load of foreign tourists from Val Divedro; in front is a group of workmen entering Val Vigezzo, whose villages and churches now stand out clear and white; the paths of the valley are threaded by men and cattle that look no larger than ants; while on the left the Rosminian novitiate, with its white walls and open courts, its ancient donjon keep and gloomy battlements half hidden in garden trees, carries his thoughts back to other days, made significant by other ideals. Having rested, the 
hermit continues his walk. He is now beyond the line of cultivation, and his path leads him through thickets and across natural meadows that with their white cottages and shrines spring suddenly up before him like a vision of fairyland. As he approaches these cottages, rustic voices of men, women, and children salute him with hearty Buon di! and he is invited to a glass of fresh milk and a piece of brown bread. As he partakes of these he talks with these simple people about their cattle and their labor, the pleasures of Alpine life, and the freshness of Alpine air. Before he leaves he is invited to come and spend a week at the cottages and share their mountain hospitality. He has now gone far enough; so bidding the cattletenders good-bye, with a promise to come again, he begins his descent by a different path from that by which he ascended. As he dives into the first wooded ravine he hears the wild, free song of the mountaineers flung to the broad sky from lungs that seem as inexhaustible as those of nightingales. He descends rapidly, but before returning to begin his studies for the day he refreshes himself with a shower bath, under a cascade that hides itself in a rocky labyrinth never trodden by profane footsteps. After thus paying his devotions to Nature and partaking of her sacrament he feels himself in that happy frame of mind that makes all mental labor easy. His day is passed at his study table, in view of the ever-changing beauties of valley and mountain. His only companions are the ringdoves, that use his study as freely as he does, and the beautiful cardellini, which seem never to weary of motion or song. When the sun is disappearing over the western mountains, and the Ave Maria is sounding from the bells of villages near and far, he takes his evening walk, enjoying for another hour the most intimate communion with Nature, a communion which satisfies every aspiration after the divine. He returns to a simple meal, after which he continues his studies for an hour or two, interrupting them from time to time in order to go out on the veranda and enjoy the sight of the mountains and valley steeped in meditative gloom or bathed with dreamy moonshine. So passes his day in the very bosom of Nature. 


\section{APPENDIX E}

\section{BIBLIOGRAPHY OF THOMAS DAVIDSON'S WORKS}

\section{Books}

A History of Education. I 2mo, 292 pages. New York, 1900. (Revised in The Dial [September 16, 1900], XXIX, I8I ; and in The Educational Review, XX, 522.)

Aristotle and Ancient Educational Ideals (Great Educators' Series). I $2 \mathrm{mo}, 250$ pages. New York, I 892.

Education of the Greek People, and its Influence on Civilization (International Educational Series). I 2mo, 229 pages. New York, I 894.

The Parthenon Frieze and Other Essays. London, I882; Boston and New York, 1886.

Prolegomena to Tennyson's In Memoriam, with Index to the Poem. Boston, I889.

Rosmini's Anthropology (translation).

Rosmini's Psychology (translation).

Rousseau, and Education according to Nature (Great Educators' Series, Charles Scribner's Sons). 259 pages. New York, 1898.

Scartazzini's Handbook to Dante, with Notes and Additions. Boston, 1887.

The Philosophical System of Antonio Rosmini-Serbati, with a Sketch of Rosmini's Life, Bibliography, Introduction, and Notes. London, I 882

\section{Articles in the Journal of Speculative Philosophy}

Schelling's Introduction to Idealism (translation) I, 159.

Schelling's Introduction to the Philosophy of Nature (translation) I.

Rosenkranz on Difference of Reader from Hegel (translation), II, 55. Leibnitz on the Nature of the Soul (translation), II, 62.

Rosenkranz on Goethe's Social Romances (translation), II, I 20, 215.

Winckelmann's Remarks on the Torso of Hercules (translation), II, 187.

Sentences of Porphyry the Philosopher (translation), III, 46.

Leibnitz on Platonic Enthusiasm (translation), III, 68.

Fragments of Parmenides, IV, $\mathbf{I}$. 
Rosenkranz on Goethe's Wilhelm Meister (translation), IV, 145.

Introduction to Hegel's Encyclopædia by Rosenkranz (translation), $\mathrm{V}, 234$.

Trendelenburg on Hegel's System (translation), V, 349.

Notice of Morris's translation of Überweg, VI, 95.

Trendelenburg on Hegel's System (translation), VI, 82, 163, 360.

Conditions of Immortality according to Aristotle, VIII, 143.

Letter about A. Vera's Review of Strauss's Ancient and New Faith, VIII, 28I.

Grammar of Dionysius Thrax (translation), VIII, 326.

Address of Professor Tyndall, VIII, 36I.

Translation of Rosenkranz's Summary of Logic, IX, 98.

The Niobe Group, IX, 142.

Reply to A. Vera's Stricture's on his Critique, IX, 434.

Notice of Anderson's Norse Mythology, X, 216.

Letter on the Philosophy of Thomas Aquinas, XIV, 87.

Bonaventura's The Soul's Progress in God (translation) (July, 1887), XXI.

Aristotle's Metaphysics. A translation of the eleventh book. XXII, No. 3, 225-253.

Dionysius Areopagita, Mystic Theology (translation) (December), XXII, 395.

\section{ARTICLES IN THE WeStern}

Lincoln Monument at Springfield (1875), I, 223.

Funeral Hymn (April, 1872), p. 41.

Greek Literature (May, 1872), p. 6I.

\section{Articles in Western Educational Review}

Self-Government in the Schoolroom (February, 1870), I, 53. Religious Instruction in Public Schools (March, 1870), I, 81.

Rimini (translation from Heine) (May, I870), I, 127.

Rimini (continuation) (September, 1870), I, 203.

(I) The Minstrel's Curse (translation from Uhland) (November, 1870), I, 252.

(2) The Origin of Language (November, I870), I, 256.

Epitaph from a Roman Tombstone (translation) (October, 1870), I, 240.

Lyric Poetry (May, I871), II, 159.

Pedagogical Bibliography (October, I87I), II, 139.

The Tragic (November, 1871), II, 321. 


\section{Miscellaneous}

American Democracy. International Journal of Ethics, October, 1899. The Brothers of Sincerity. International Journal of Ethics, July, 1898. The Ethics of an Eternal Being. International Journal of Ethics, April, 1893.

Conditions, Divisions, and Methods of Complete Education (a lecture). $16 \mathrm{mo}$. Orange, N.J., 1887.

Education as World Building. Educational Review (November, 1900), $\mathrm{XX}$, 325-345.

Education: Greek at Harvard College. Atlantic Monthly, XXXIX, 1 23-1 28, 386-388.

Aristocracy and Humanity. The Forum (October, 1887), IV, No. 2.

Review of Koch's Hist. Gram. Englisch. Round Table (New York newspaper), November 21, 1868, Sect. 200.

Ideal Training of the American Girl. The Forum (June, 1898), XXV, $471-480$.

Manual Training in Public Schools. The Forum (April, 1887), III, III-I 2 I.

On the Origin of Language (translation).

Pedagogical Bibliography: Its Possessions and Wants.

National Educational Association (1871), pp. 51-66.

Place of Art in Education. Journal of Social Science (September, 1886), No. 21, 159-187.

Giordano Bruno, Philosopher and Martyr (written in collaboration with D. G. Brinton). Philadelphia, 1890.

The Kingdom of Heaven. Christian Union (January 15, I891), XLIII, No. 3 .

Dante's Place in History. The Parthenon (April 28, 1892), I, No. 24. The Paradise of Dante. Lecture before Chicago Dante School, April 20, 1892. (Reprinted from The Parthenon.)

The Origins of Modern Thought (synopsis of twenty lectures).

Contemporary Philosophy in Italy. The Nation (August .5, 1880), No. 788.

"Ad Tres Familiares" (Latin translation of Longfellow's poem, "Three Friends of Mine"), 1876.

Intellectual Piety. New York, Fowler \& Wells Company, I896.

The Present Condition of Greece. International Review (June, 1879), VI, No. 6.

Giordano Bruno (compiled from the Freethinker's Magazine for September (E.H.), p. 289. 
When the Higher Criticism has done its Work. International Journal of Ethics (July, I897), VII, No. 4.

The Democratization of England. The Forum (June, I896), XXI, No. 4.

Victorian Greater Britain and its Future. The Forum (July, 1897), XXIII, No. 5.

The Supremacy of Russia. The Forum (September, I897), XXIV, No. I.

Evolution of Sculpture. New York, I89I.

Henry Wadsworth Longfellow. Boston, I882.

Ideal Training of an American Boy. The Forum (July, I894), XVII, 571.

Review of Kolb's History of Human Civilization. Round Table (December 19, I 868), Sect. 204.

Review of Max Müller's "Chips." Round Table (May 8, I869), Sect. 224.

Discussions with Richard Grant White. Round Table (March I3, 1889), Sect. 216; (February 27, 1869), Sect. 214; (April I7, I869), Sect. 247.

\section{CATALOGUE OF MANUSCRIPTS LEFT BY THOMAS DAVIDSON}

I. The Revival of Thought in Europe in the Thirteenth Century : Aristotle in the Schools.

2. Bonaventura.

3. Introduction (to a set of lectures on great schoolmen).

4. Thomas Aquinas.

5. Aristotle's Debt to Plato.

6. Dionysius Areopagita.

7. Philo Judæus.

8. Plotinus, Porphyry, Proclus, Neo-Platonism.

9. Dante.

I0. Dante's Ideology and Logic.

II. Dante (fragment).

12. The Convivio.

13. Greek Education up to Aristotle.

14. The Growth of Art Ideas among the Greeks.

15. Ontology.

16. Consciousness of the Divine Presence.

17. Savonarola.

I8. Is the Homeric Cycle of Legends Greek? 


\section{APPENDIX E}

19. The Present State of Thought.

20. Spiritual Thought.

21. Una Religione per l'Italia.

22. In Memoriam.

23-27. Themistocles in Exile: A Modern Tragedy, Acts I-V.

28-36. The Bearing of Ancient Thought upon Modern Social Problems (ten lectures).

37-43. Seven Lectures (on the history of Hebrew prophetism and Greek philosophy).

44. The Affiliation of the Sciences.

45. School Exhibitions.

46. The Education of Girls.

47. Life Education.

48. Education of the Young: Use of Music.

49. Self-Reliance.

50. Practical Reform.

51. Greek Democracies.

52. Hegel and Rosmini.

53. Meum and Tuum.

54. Are there Synthetic Judgments a priori?

55. Aristotle's Problem.

56. Individuality.

57. The Ultimate Creed.

58. Sentimentality.

59. Acceptance.

6o. Detachment.

61. The Missing Social Link.

62. Heraclitus (translation of the fragments).

63. Green's Theory of Cognition, and its Place in the History of Thought.

64. Dante's Convivio (translation with notes).

65. Letters to Class on East Side (summer, 1899).

66. The Brothers of Sincerity.

67. Social Remedies in the Light of History.

68. The Nature and Cause of our Social Difficulties.

69. Idols of the Theater.

70. Some False Assumptions of Present Reformers.

71. The Future of Classical Study.

72. "Ad Tres Familiares."

73. Protection and Free Trade.

74. Words, Thoughts, and Things.

75. The Methods of Progress. 
76. Art and Fact (off-print from the Western).

77. The Philosophy of Words (review of Garlanda).

78. Animal and Man.

79. Social and Economic Equality.

80-83. Athens, Ancient and Modern (four lectures).

84-89. Modern Greece (six lectures).

90. Greek Sculpture (notes for six stereopticon lectures).

9I-97. Philology (seven lectures).

98-10I. The History and Grammar of the English Language (four lectures).

102. Ontology.

I03. Olympia.

I04. Shakespeare's World and its Limitations.

105. Divine Love.

I06. The Immortality of the Human Soul.

107. Education.

108. Free Education.

109. Transfiguration.

I 10. The Practical Duties following upon the Spiritual View of Life.

II I. Reading with a View to Culture and Insight.

112. On the Nibelungenlied (first page missing).

113. The Educational Problem.

I14. The Educational Problems which the Nineteenth Century hands over to the Twentieth.

115-116. The Problems set by the Nineteenth Century to the Twentieth.

(I) The Philosophic and Religious Problems.

(2) The Economic Question.

I17. Religion and Science.

118. The Significance of Art.

119. New Life.

120. The Life of the Spirit.

121. Inner Moral Life.

I22. The Function of a Church.

123. Faith as a Faculty of the Human Mind.

124-128. Five Lectures on great Greek Moralists :

(I) Antecedents of Greek Ethics.

(2) Socrates and Intuitional Ethics.

(3) Plato and Ideal Ethics

(4) Aristotle and Institutional Ethics.

(5) Comparison and Conclusion. 
129. The Irony of Plato.

130-131. Two Lectures on Faust (old series).

132. Aristotle on Tragedy.

133. Aristotle's Poetics.

134. Prometheus.

135. The Oresteia: Agamemnon.

136. Choëphori and the Two Electras.

137. Retribution (the Laocoön group).

138. The Other World in Homer.

139. Art in Homer.

140. Women in Greece.

141. Rosmini's Philosophy.

142. Savonarola.

143. Dante's Place in History.

144. Love as God's Method of Action (according to the Divine Comedy).

145. Virgil and Beatrice as Guides.

146. Ibn Gebirol and the Cabbalah.

147. What is Death?

148. The Fellowship of the New Life.

149. The New Life and the Old.

150. Life.

I5 I. Liberty.

152. The Pursuit of Happiness.

153. The Educational Ideal : A Criticism of Modern Institutions of Learning.

154. "Sacred Diseases."

155. Scotch Ballads (badly mutilated).

156-161. Goethe's Faust (latest series; Lecture III, Sect. 159, not found).

162. Four Great Religious Poems.

163. Mediæval Philosophy: Introduction; notes and fragments.

164. Letters to East-Side Class.

165. Diaries, and loose leaves from diaries, kept by Mr. Davidson, $186 \mathrm{I}$, etc. 

APP 781703

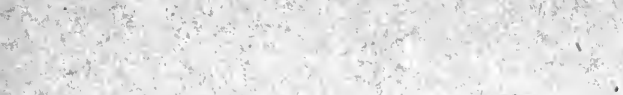

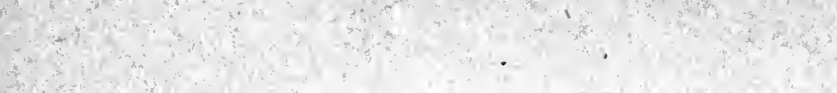

a y 4 B

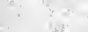
a 


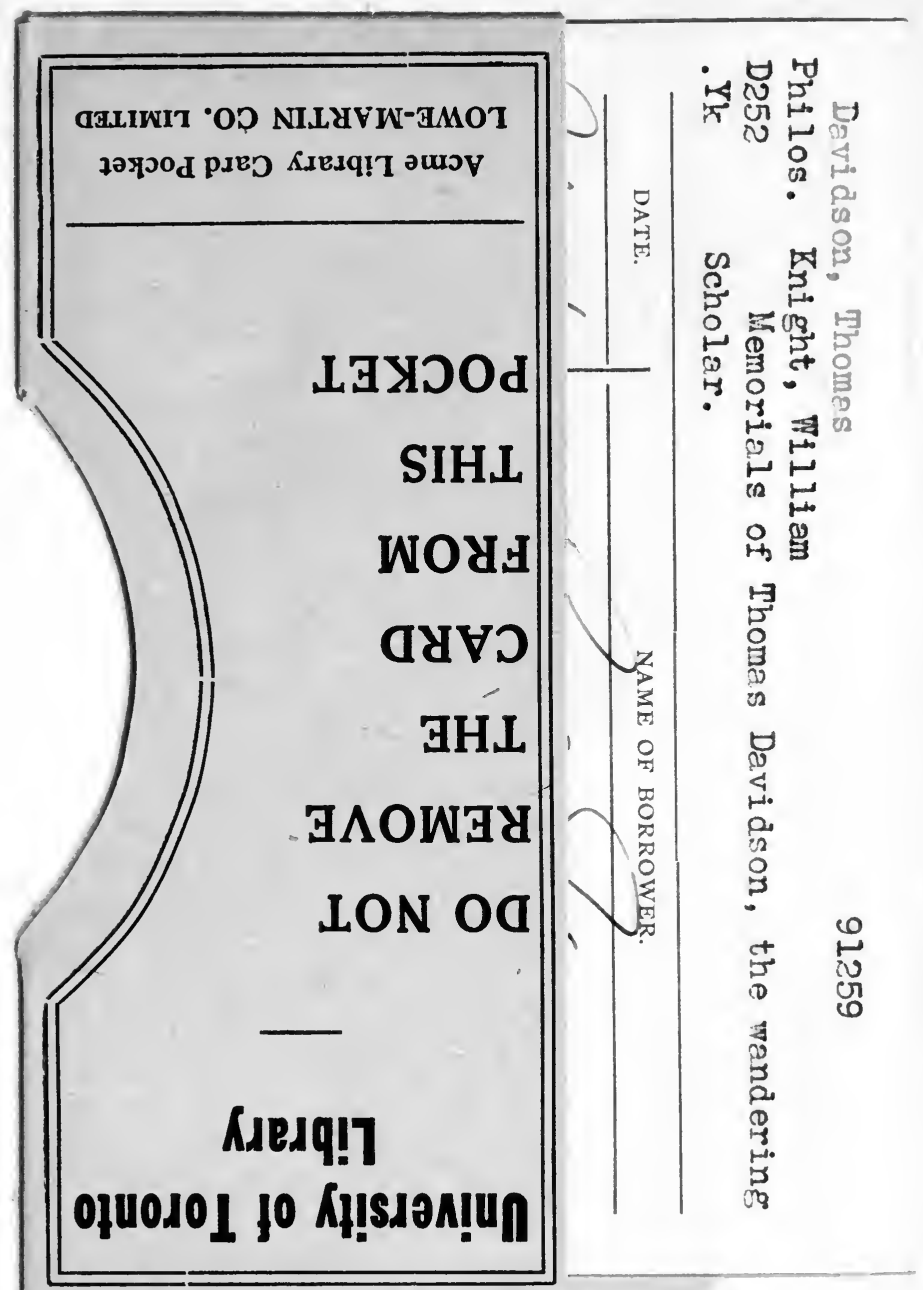



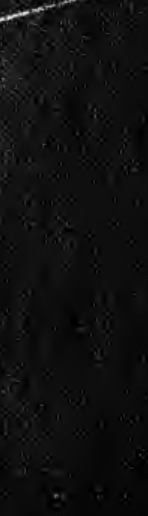